\title{
BNWL-37I PTI
}

\section{CROSS-FLOW MIXING BETWEEN PARALLEL FLOW CHANNELS DURING BOILING PART I \\ COBRA - COMPUTER PROGRAM FOR COOLANT BOILING IN ROD ARRAYS} REPORT

\author{
D. S. ROWE
}

MARCH 1967
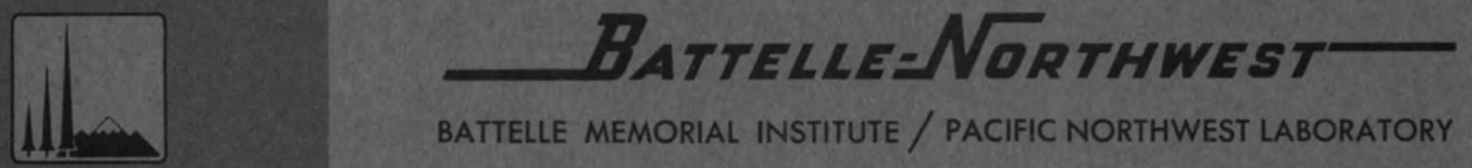

BATTELLE MEMORIAL INSTITUTE / PACIFIC NORTHWEST LABORATORY 


\section{LEGAL NOTICE}

This report was prepared as an account of Government sponsored work. Neither the United States, nor the Commission, nor any person acting on behalf of the Commission:

A. Makes any warranty or representation, expressed or implied, with respect to the accuracy, completeness, or usefulness of the information contained in this report, or that the use of any information, apparatus, methcd, or process disclosed in this report may not infringe privately owned rights; or

B. Assumes any liabilities with respect to the use of, or for damages resulting from the use of any information, apparatus, method, or process disclosed in this report.

As used in the above, "person acting on behalf of the Commission" includes any employee or contractor of the Commission, or employee of such contractor, to the extent that such employee or contractor of the Commission, or employee of such contractor prepares, disseminates, or provides access to, any information pursuant to his employment or contract with the Commission, or his employment with such contractor.

\section{PACIFIC NORTHWEST LABORATORY}

RICHLAND, WASHINGTON

operated by

BATTELLE MEMORIAL INSTITUTE

for the

UNITED STATES ATOMIC ENERGY COMMISSION UNDER CONTRACT AT(45-1)-1830 


\author{
BNWL-371 PT 1 \\ UC-80, Reactor Technology
}

\author{
CROSS-FLOW MIXING BETWEEN PARALLEL \\ FLOW CHANNELS DURING BOILING \\ PART I \\ COBRA - COMPUTER PROGRAM \\ FOR COOLANT BOILING IN ROD ARRAYS
}

By

D. S. Rowe

Reactor Engineering Section

Engineering Development Department

March 1967

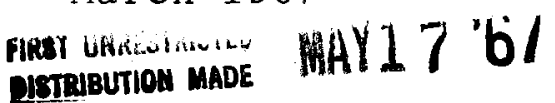

\author{
PACIFIC NORTHWEST LABORATORY \\ RICHLAND, WASHINGTON
}

This document is furnished pursuant to the Memorandum of Understanding of June 7, 1960, between U.S. and Canadian Governments, establishing a cooperative program on the development of heavy water moderated power reactors. 
Printed in the United States of America Available from

Clearinghouse for Federal Scientific and Technical Information National Bureau of Standards, U.S. Department of Commerce Springfield, Virginia 22151

Price: Printed Copy $\$ 3.00$; Microfiche $\$ 0.65$ 


\author{
CROSS-FLOW MIXING BETWEEN PARALLEL FLOW CHANNELS DURING BOILING \\ PART I \\ COBRA - COMPUTER PROGRAM FOR COOLANT BOILING IN ROD ARRAYS \\ D. S. Rowe
}

\begin{abstract}
This report presents a mathematical model and digital computer program for computing coolant flow and enthalpy in the subchannels of rod bundle fuel elements. One dimensional, two-phase, siip flow in the subchannels provides the basis for the mathematical model. The model also includes the effect of mixing that occurs through the gap between adjacent subchannels by using a turbulent (fluctuating) cross-flow and a diversion cross-flow that results from flow redistribution.

The digital computer program COBRA solves the mathematical equations by using numerical procedures similar to the modified Euler method, but with an additional feature to control diversion cross-flow and insure a stable solution. COBRA considers both single and two-phase flow in rod bundles of arbitrary geometry and can consider up to 36 subchannels and 25 fuel rods. Arbitrary heat flux distributions are specified by the axial flux distribution, relative rod power and fraction of rod power to each adjacent subchannel.
\end{abstract}


- 1

4

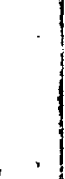

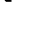




\section{TABLE OF CONTENTS}

ABSTRACT .

LIST OF FIGURES.

INTRODUCTION .

SUMMARY AND CONCLUSIONS

DESCRIPTION OF ANALYTICAL MODEL

DEVELOPMENT OF EQUATIONS.

Continuity

Energy.

Axial Momentum

Transverse Momentum

Turbulent Cross Flow.

ANALOGY TO TURBULENT FLOW ANALYSIS • • • • • • • $\quad 11$

PARAMETRIC STUDY • • • • • • • • • • • • • • 13

Effect of Interfacial Turbulent Shear . . . . . 13

Effect of Frow Diversion Momentum. • • . • . . 18

Effect of Transverse Cross-Flow Resistance. . . . 19

Effect of Turbulent Mixing Parameter. • • . • . 19

DIGITAL COMPUTER PROGRAM DEVELOPMENT • • • • • • • • 21

GENERAL FEATURES AND OPERATION. • • • • • • • • 21

DIGITAL COMPUTER PROGRAM COMPARISONS • • • • • • 25

NUMERICAL METHODS USED TO DEVELOP COBRA. • • • • 28

Modified Euler Method. . . 。 . . . . . . 28

Runge-Kutta Method. • . • . . • . . . . . 29

Iterative Solution. . . . . . . . . . . . 30

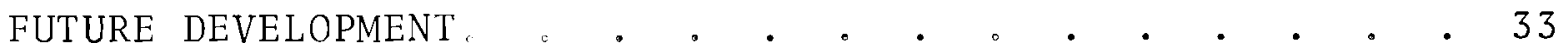

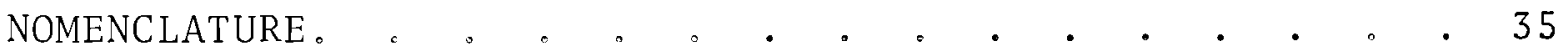

REFERENCES

APPENDIX A

APPENDIX B

APPENDIX C

APPENDIX D

APPENDIX E 


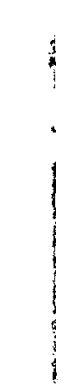

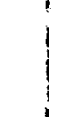

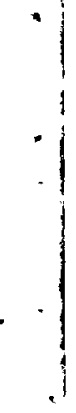

. 


\section{LIST OF FIGURES}

1 Subchanne1 Cross-F1ow Representation for Mathematical Model

2 Two-Subchanne1 Representation of Sample Problem

3 Two-Channel Representation of 19-Rod Bundle Subchannel Enthalpy and Mass Velocity for Nominal Case

4 19-Rod Bundle Subchanne1 Enthalpy and Mass Velocity for Nominal Case

5 Effect of Interfacial Shear on Enthalpy and Mass Velocity

6 Effect of Mixing Parameter ( $\beta$ ) on Subchannel Enthalpy Rise

7 Simplified Flow Diagram for COBRA

8 Illustration of Method Used to Solve for Diversion Crossflow 


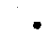

.

- 
CROSS-FLOW MIXING BETWEEN PARALLEL FLOW CHANNELS DURING BOILING PART I COBRA - COMPUTER PROGRAM FOR COOLANT BOILING IN ROD ARRAYS

D. S. Rowe

\section{INTRODUCTION}

This report presents COBRA, a digital computer program that computes flow and enthalpy in the subchannels of rod bundle nuclear fuel elements during boiling. The development of the analytical methods used in COBRA represent the first portion of a two-part study of two-phase flow and mixing in rod bundle fuel elements under the sponsorship of a cooperative program between the United States and Canada for the development of heavy water moderated power reactors. The second part of the study, to be published later, consists of laboratory experiments to verify the analytical work and supply key information that can only be obtained from experiments. The results of the total study will be a significant step toward a more accurate method for predicting the coolant conditions leading to the occurrance of boiling burnout in rod bundle nuclear fuel elements.

Accurate prediction of boiling burnout in rod bundle elements has not been possible except by using the results of laboratory tests that closely simulate the bundle geometry, power distribution, and flow conditions. One of the primary reasons for this is the difficulty in calculating the local coolant flow and enthalpy throughout the bundle. Calculating these local coolant conditions is a problem in rod bundle fuel elements for two reasons:

- First, the different sized flow channels, formed by the arrangement of fuel rods in most rod bundel designs, are such that the ratio of heat transfer surface area to flow 
area is not equal for all channels; thus, causing the coolant enthalpy rise in some flow channels to be much greater than in others. This imbalance in coolant enthalpy affects the channel flow distribution, especially during boiling conditions where the pressure drop for two-phase mixtures is much greater than for liquid flow. Since the pressure drop is nearly the same in each flow channel of the rod bunde, there is an interchange of flow between channels when the gain in coolant enthalpy is not equal. This same effect can also result from nonuniform power distribution in the bundle.

- Second, local flow and enthalpy is affected by the random travel of the coolant through the gap between adjacent flow channels. This mixing effect is caused by the natural turbulent fluctuations of the coolant flow plus those fluctuations induced by mechanical devices such as rod spacers and reduces the enthalpy difference between adjacent flow channels.

The influence of the mixing phenomena is an important factor affecting flow and enthalpy in rod bundles. Knudsen (1) illustrated this by applying the effect of mixing to much of the world's boiling burnout data. His simplified analysis showed that the apparent differences between much of the data could be reduced significantly by including the effect of mixing to get a better estimate of the coolant enthalpy at the burnout location.

No analyses are now available to accurately predict local flow and enthalpy in rod bundle subchannels during boiling. Numerous analytical $(2-8)$ and experimental ${ }^{(9-12)}$ studies of flow and heat transfer in rod bundles have been done, but they are only concerned with single-phase flow. Several computer programs $(13-17)$ for multidimensional two-phase flow 
have been developed and they have occasionally been applied to rod bundles; ${ }^{(18-19)}$ however, they have only been partly successful because they do not include sufficient detail to fully analyze the problem. The primary shortcomings of these computer programs, when applied to rod bundles, are that they do not allow turbulent, thermal mixing between adjacent subchannels or do not properly identify the enthalpy transport that occurs during bulk flow redistribution, or both. The latter point also restricts these analyses to certain types of problems.

\section{SUMMARY AND CONCLUSIONS}

COBRA, a digital computer program, uses an improved mathematical model to compute coolant flow and enthalpy in the subchannels of rod bundle fuel elements during boiling. The most significant feature of the model, developed for COBRA, is its ability to include mixing from two types of cross flow. The first type is diversion cross flow caused by flow redistribution when pressures try to equalize as the coolant flows through the bundle. The second is turbulent cross flow caused by the random travel of the coolant between adjacent subchannels. A complete description of the energy and momentum transported by these cross flows is extremely difficult for two-phase flow; therefore, as an approximation, several assumptions are made to develop the model:

- Steady, one-dimensional, two-phase slip flow exists in each subchannel during boiling.

- Turbulent cross flow exists between adjacent subchannels.

- The turbulent cross flow may be superimposed upon the diversion cross flow.

- The two-phase flow structure is fine enough to allow specification of local void fraction as a function of enthalpy and pressure. 
The conservation equations derived from these basic assumptions are coupled to each other by the cross flows in several ways. Turbulent cross flow transports thermal energy and momentum between adjacent subchannels, and are analogous to thermal diffusion and turbulent shear stress, respectively. Presently, no way exists to calculate the turbulent cross flow that occurs during boiling. As an approximation, the turbulent cross flow per unit length is assumed to be proportional to the rod spacing times the average mass velocity of the adjacent channels.

The diversion cross flow transports thermal energy from one subchannel to another and affects pressure drop because of changes in the axial and transverse components of momentum. A transverse momentum equation is used to relate pressure drop between adjacent subchannels to the square of the diversion cross flow.

This mathematical model and its numerical solution provide the basis for the digital computer program COBRA. Although this computer program is written principally for rod bundles, it is also general enough for the solution of many multidimensional two-phase flow problems if the model's assumptions are reasonably satisfied. For problems where the validity of the assumptions is questionable, solutions may still provide considerable insight to the problem.

The significant features of COBRA are:

- It has the ability to consider both single- and two-phase flow.

- It accounts for thermal mixing between interconnected parallel flow channels which results from both the transport of energy by turbulent cross flow and diversion cross flow. 
- It considers the momentum interchanges between adjacent subchannels which result from both turbulent and diversion cross flow.

- It includes the effect of transverse resistance to diversion cross flow.

- It considers an arbitrary layout of fuel rods and flow subchannels and thus allows analysis of most any rod bundle configuration. Up to 36 subchannels, 25 fuel rods, and 60 subchannel connections may be considered.

- It includes arbitrary heat flux distribution by specifying the axial flux distribution, relative rod power, and the fraction of rod power to each of the six adjacent subchannels.

A parametric study, using COBRA to evaluate the importance of several terms in the model, shows that turbulent shear stress, transverse component of axial momentum, and frictional resistance to diversion cross flow are weak parameters for most multirod designs. The turbulent thermal mixing is the most significant parameter. Mixing from diversion cross flow is only significant if the diversion cross flow is of the same magnitude as the turbulent cross flow.

\section{DESCRIPTION OF ANALYTICAL MODEL}

\section{DEVELOPMENT OF EQUATIONS}

The analytical model developed for COBRA is based upon a nodal representation of the flow cross section. In a multirod bundle, this representation is very convenient because the arrangement of fuel rods forms discrete flow subchannels defined by the subchannel walls and the narrow gap between rods. Figure 1 illustrates the subchannels of a 19 rod bundle and also shows (in the segment removed from the bundle) the representation 

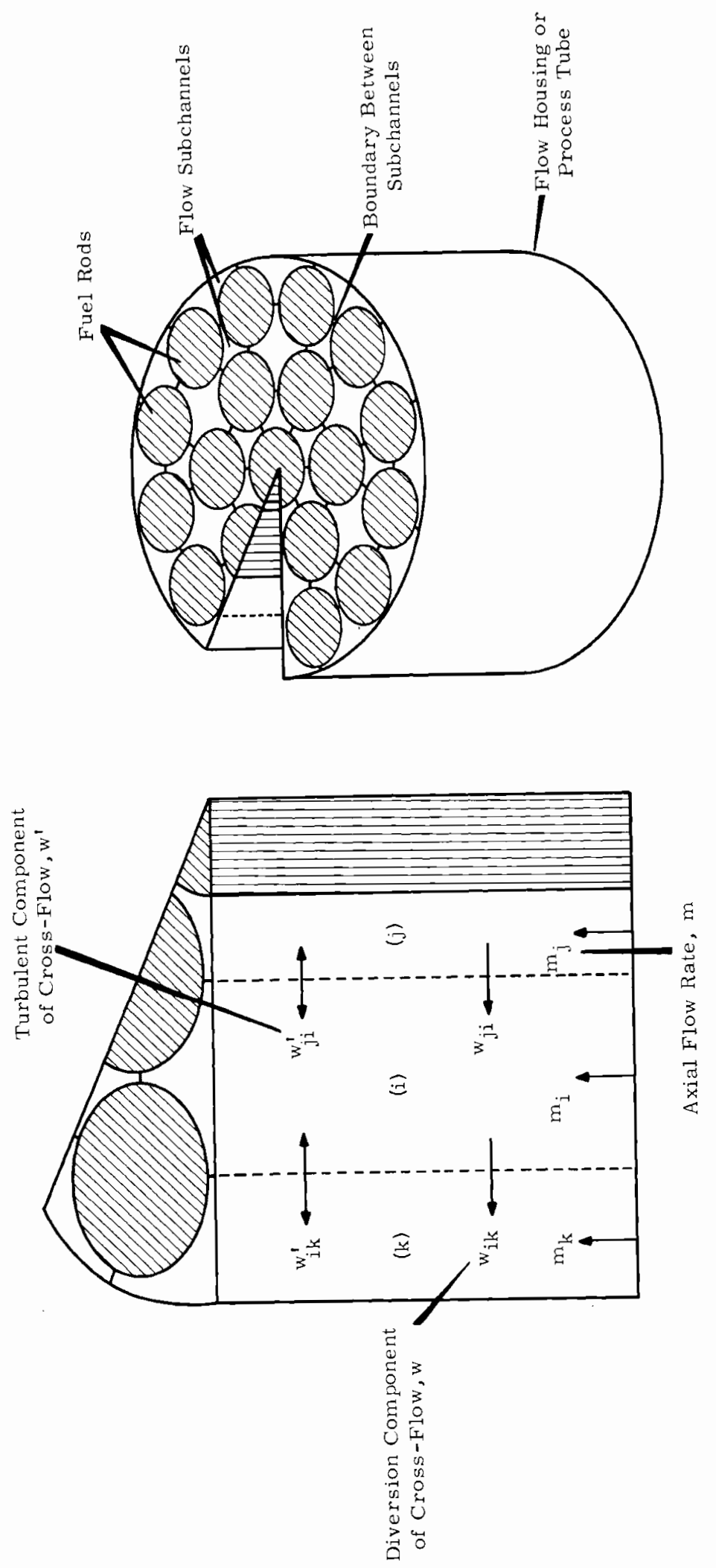

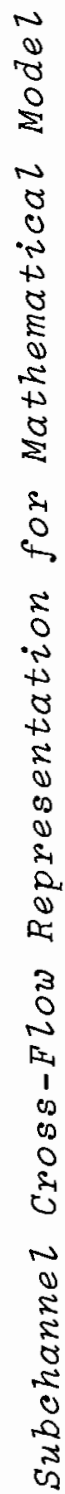

-1
$5-2$
0
0
0
-1
01 
of the assumed turbulent cross flow and net transverse diversion cross-flow between three adjacent subchannels.

The diversion cross flow is caused by actual flow redistribution resulting from pressures trying to equalize as the coolant passes through the bundle. Such flow redistribution can also be caused by "forced"* diversion from mechanical devices such as wire wraps. The turbulent cross flow is the random travel of the coolant across the gap between adjacent subchannels. Therefore, it causes no net flow diversion when averaged over a short period of time. Because both types of cross flow couple adjacent subchannels through the transfer of mass, energy, and momentum, a description of coolant conditions in a particular subchannel must include the transport effects between all adjacent subchanne1s.

Phase and velocity distribution makes complete description of these transport processes for two-phase flow conditions extremely difficult. Not knowing how much of the vapor and liquid phases is transported between adjacent subchannels and at what velocities is the largest problem. As an approximation to the actual conditions, several assumptions were made to allow a reasonable description of interchannel mixing:

- Steady, one-dimensional, two-phase slip flow exists in each subchanne1 during boiling.

- A turbulent (fluctuating) cross flow exists between adjacent subchanne1s.

- The turbulent cross flow may be superimposed upon any net diversion cross flow that may be occurring.

- The two-phase flow structure is fine enough to allow specification of local void fraction as a function of enthalpy and pressure.

* The present writing of COBRA does not include the effects of forced diversion; only natural diversion from pressure differences is considered. 
While these assumptions appear to be very restrictive, they permit development of equations that retain the features of actual mixing processes. By use of basic assumptions, the equations of continuity, energy, and momentum are derived in Appendix A:

\section{Continuity}

$$
\frac{d m_{i}}{d x}=-\sum_{j=1}^{N} w_{i j} \quad i=1,2, \cdots N
$$

$\underline{\text { Energy }}$

$$
\begin{aligned}
m_{i} \frac{d h_{i}}{d x}= & q^{\prime}{ }_{i}+\sum_{j=1}^{N} w_{i j}^{\prime}\left(h_{j}-h_{i}\right) \\
& -\sum_{j=1}^{N}\left[\begin{array}{ccc}
0 & ; \text { if } w_{i j}=0 \\
w_{i j}\left(h_{j}-h_{i}\right) & ; \text { if } w_{i j}<0
\end{array}\right] i=1,2 \cdots N
\end{aligned}
$$

Axial Momentum

$$
\begin{aligned}
& -\left[1+\frac{1}{g_{c}}\left(\frac{m_{i}}{A_{i}}\right)^{2} \frac{\partial v^{\prime} i}{\partial p}\right] \frac{d p_{i}}{d x}=\frac{1}{g_{c}}\left(\frac{m_{i}}{A_{i}}\right)^{2}\left(\frac{f_{i} \phi_{i}}{2 \rho_{f} D_{i}}+\frac{\partial v^{\prime}}{\partial h} \frac{d h_{j}}{d x}\right) \\
& +\rho_{i} \cos \theta+\frac{1}{g_{C} A_{i}} \sum_{j=1}^{N} f_{T^{\prime}{ }^{\prime}}{ }_{i j}\left(u_{i}-u_{j}\right) \\
& +\frac{1}{g_{C} A_{i}} \sum_{j=1}^{N}\left[w_{i j} w_{i j}\left(f_{D} u_{j}-2 f_{i}\right) ; \text { if } w_{i j}<0\right] i=1,2, \cdots N
\end{aligned}
$$


Transverse Momentum

$$
p_{i}-p_{j}=C_{i j} w_{i j}\left|w_{i j}\right|
$$

Turbulent Cross Flow

$$
w_{i j}^{\prime}=\frac{1}{2} \beta s_{i j}\left(\frac{m_{i}}{A_{i}}+\frac{m_{j}}{A_{j}}\right)
$$

The above equations are written for a Subchannel (i) which is one of $N$ (total) subchannels. A Subchannel (i) is only coupled to another Subchannel (j) if either turbulent or diversion cross-flow exists between them.

The statement of Equation (1) is simply that the rate of flow change in the subchannel is equal to the net diversion* to and from the subchannel. The turbulent cross-flow term does not appear in Equation ( 1 ) because, on a time average, it does not cause a net flow change $\left(w^{\prime}{ }_{i j}=w^{\prime}{ }_{j i}\right)$.

In the energy Equation (2), each of the terms on the right illustrate the mechanism of thermal mixing or energy transport in a bundle fuel element. The first term is the contribution of heat input to the subchannel and gives the rate of enthalpy change if no interchannel mixing occurs. The second term includes the effects of turbulent enthalpy transport between al1 interconnected subchannels, and the third accounts for energy transported into a Subchannel (i) from flow diversion. A term for energy diverted out of the subchannel is absent because the enthalpy change in a Subchannel (i) is dependent upon where the cross-Elow has been, rather than where it is going.

* The diversion cross-flow $w_{i j}$ is taken to be a positive value if flow is from subchannel i to $j$. 
The terms in the momentum Equation (3) also show some interesting effects. The first two terms, in the brackets on the right side (Equation 3) represent the friction and acceleration pressure drop, respectively. The third term represents the elevation component of the pressure drop; the fourth term is the contribution of turbulent cross-flow, if uniform velocity is assumed in each subchannel. This is analogous to Reynolds'stresses in turbulent flow fields. Since the subchannel velocity distributions are not uniform in a real multirod bundle, the turbulent cross-flow effect is actually less than shown in Equation (3). Modification of this term, based on experimental data, will probably be required, but, presently, the quantity* $f_{T}$ is being used to specify the importance of this term. The fifth term accounts for the effect of flow being diverted out of or into a particular channel. Some modification may also be required for this term because of the nonuniform velocity distribution in the subchannels. The quantity* $f_{\text {n }}$ is presently being used to specify the importance of the transverse component of axial momentum included in this term.

Equation (4) is a statement of pressure loss between two adjacent channels resulting from diversion cross-flow. Other transverse momentum effects exist but are difficult to include because the direction of the momentum must also be included. The overall effect of this transverse momentum is considered small because of the rather low cross-flow velocities at the center of a subchannel. These effects can also be approximated by appropriate choice of $\mathrm{C}_{i j}$ because the transverse momentum is proportional to the square of the cross-flow.

\footnotetext{
* A value of $f_{T}$ or $f_{D}=1.0$ implies an importance of these terms as derived from the one-dimensional assumption for subchannel conditions.
} 
Equation (5) assumes that the turbulent cross flow per unit length is proportional to the rod spacing times the average flow rate per unit area of the two adjacent channels. The proportionality factor $\beta$ is, presently, assumed constant and must be obtained experimentally.

\section{ANALOGY TO TURBULENT FLOW ANALYSIS}

The analytical model, based upon the transport processes between adjacent subchannels, is somewhat different from a diffusion model used for many single-phase turbulent flow and mixing studies. However, the differences are small and with proper definition of quantities, analogous relationships can be derived.

The heat flow in a turbulent flow field is often written as

$$
q_{t}=-\varepsilon_{q} \rho C_{p} \frac{d t}{d y}
$$

where $\varepsilon_{q}$ is the eddy diffusivity. In difference notation,

$$
q_{t}=-\varepsilon_{q} \rho C_{p}\left(\frac{t_{i}-t_{j}}{\ell}\right) \text {. }
$$

If the specific heat is combined with the temperature, we can write

$$
q_{t}=-\varepsilon_{q}^{\rho}\left(\frac{h_{i}-h_{j}}{\ell}\right) \text {. }
$$

In Equation (8), we used enthalpy instead of temperature as the transported quantity. For single-phase flow, Equations (7) and (8) are equivalent; for two-phase flow, only Equation (8) can apply because no temperature gradients for heat flow exist in a two-phase flow stream, although energy exchange can only occur if there is a transport of enthalpy. * Comparison of Equation (8) with the second term of the energy Equation

* This is more correctzy a mass transport of either, or both, phases and implies an enthalpy exchange. 
reveals a similarity - they are both proportional to a difference in enthalpy. The turbulent cross-flow of Equation (5) can also be related to the eddy diffusivity; therefore, by proper choice of the proportionality factor $\beta$, the analogy between the transport and diffusion models can be realized.

Since specific values of the proportionality factor $(\beta)$ for the turbulent cross flow used in this analysis are not presently available, only approximations can be made at this time. For the present analysis, we assume a value for $\beta$ will have to await the results of experiments to determine the amount of turbulent cross-flow. The turbulent cross flow will probably be significantly affected by subchannel velocity and phase distributions, and mechanical devices such as rod spacers.

For single-phase turbulent flow, the momentum exchange within the flow field is described by using a turbulent shear stress (Reynolds stress) given as

$$
\tau_{t}=\frac{\rho \varepsilon}{g c} m \frac{\partial u}{\partial y} \text {. }
$$

If the partial derivative term is approxinated by difference notation, we get

$$
{ }^{t} t=\frac{\rho \varepsilon}{g_{c}} m\left(\frac{u_{i}-u_{j}}{\ell}\right)
$$

where $u_{i}$ and $u_{j}$ are two velocities at some $\ell$ distance apart. The term $\varepsilon_{m}$ is the turbulent diffusivity for momentum and is usually a function of the axial flow rate. Equation (10) is interpreted as the apparent stress created by a fluctuating transverse flow traveling between two velocities at some distance apart. This equation may be directly related to the momentum equation's fourth term which is the pressure drop contribution of the interfacial shear stress between adjacent subchannels. The one-dimensional treatment used for this 
analysis may not rigorously account for the interfacial shear stress, but the form should be satisfactory; i.e., the interfacial shear stress between adjacent channels is proportional to the difference of the average subchannel velocities.

It is questionable whether the turbulent cross flows used for energy transport can also be used for momentum transport. For momentum, a reduced value can be expected since most momentum exchange occurs very near the gap where the velocity difference between the adjacent subchannels is reduced. The factor $f_{T}$ accounts for the importance of the turbulent momentum exchange in this analysis.

\section{PARAMETRIC STUDY}

Values of the four parameters $\left(\beta, f_{T}, f_{D}\right.$, and $\left.f \ell\right)$ included in the mathematical model have different influences on the solution of the equations. To determine the importance of each parameter, a comparison is made with a nominal case. The nominal case is a two-subchannel approximation (Figure 2) of Subchannels 1 and 2 of the 19 rod bundle sample problem given in Appendix $D$. Comparison of Figures 3 and 4 shows that the two subchannels reasonably approximate the corresponding two subchannels of the 19 rod bundle.

\section{Effect of Interfacial Turbulent Shear}

The influence of interfacial shear can be determined by varying the parameter $f_{T}$. Figure 5 compares the effects of $\mathrm{f}_{\mathrm{T}}=0$ and $\mathrm{f}_{\mathrm{T}}=1.0$ for the nominal operating conditions, and, obviously, the overall influence of $f_{\mathrm{T}}$ is small. This small effect during boiling is caused by the frictional and acceleration components of the pressure drop becoming 


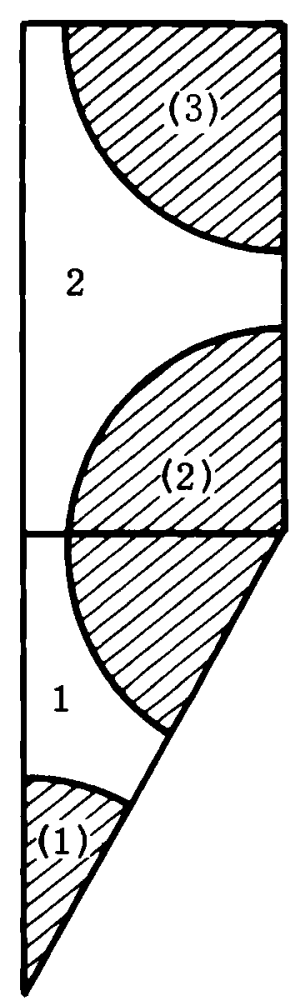

Two-Subchannel Representation

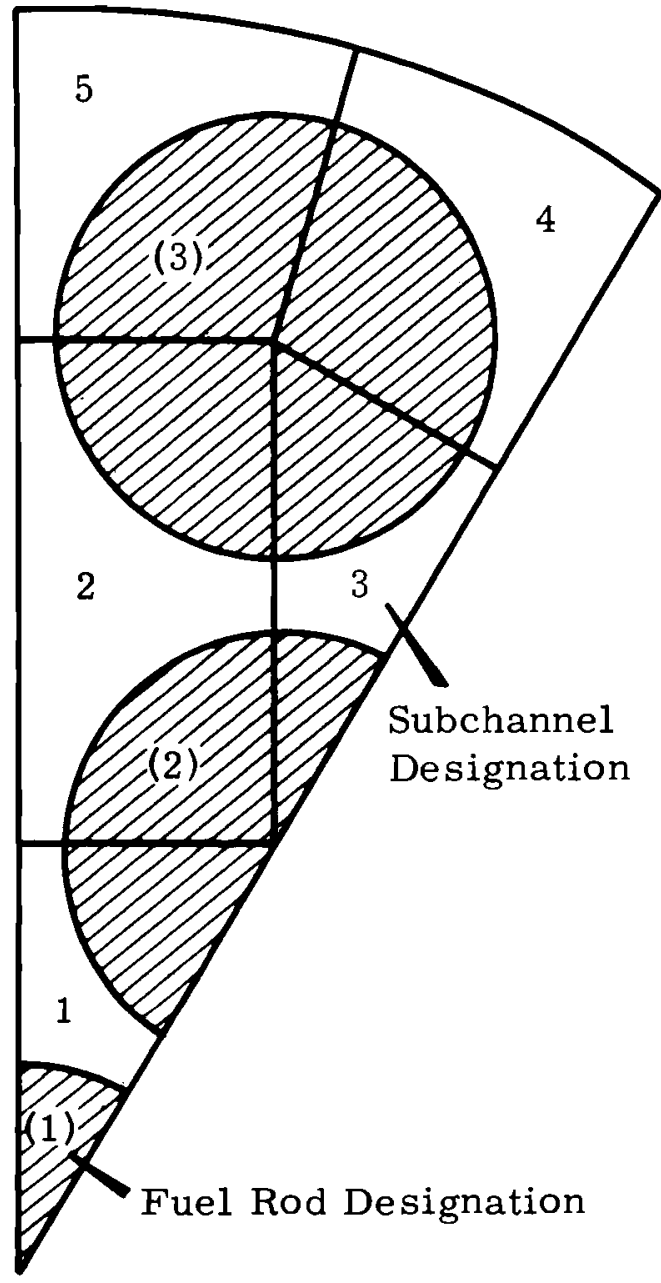

$1 \neq 12$ Section of Symmetry From 19-Rod Bundle used for Sample Problem 

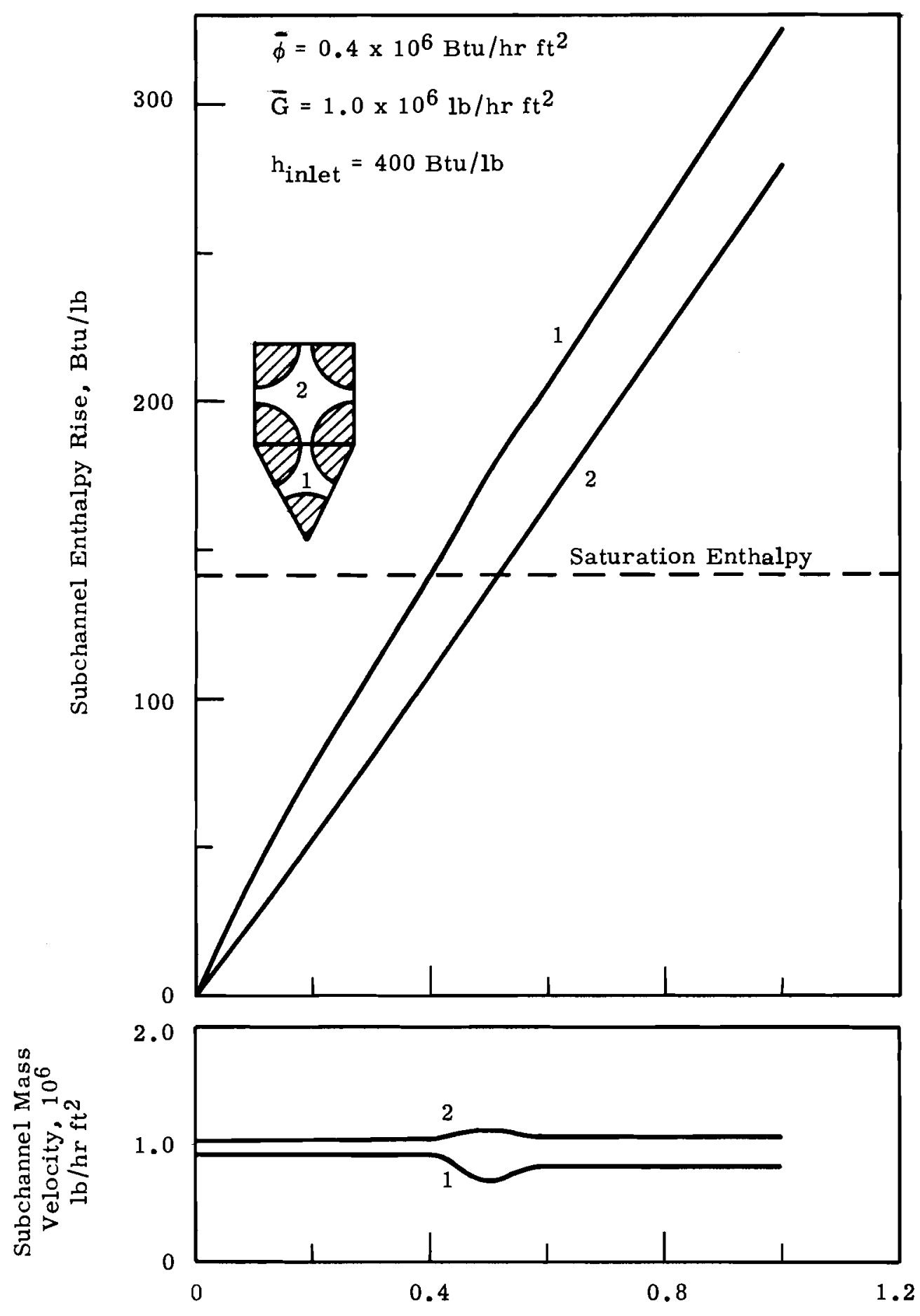

Relative Distance Along Channe1, $\mathrm{x} / \mathrm{L}$ 

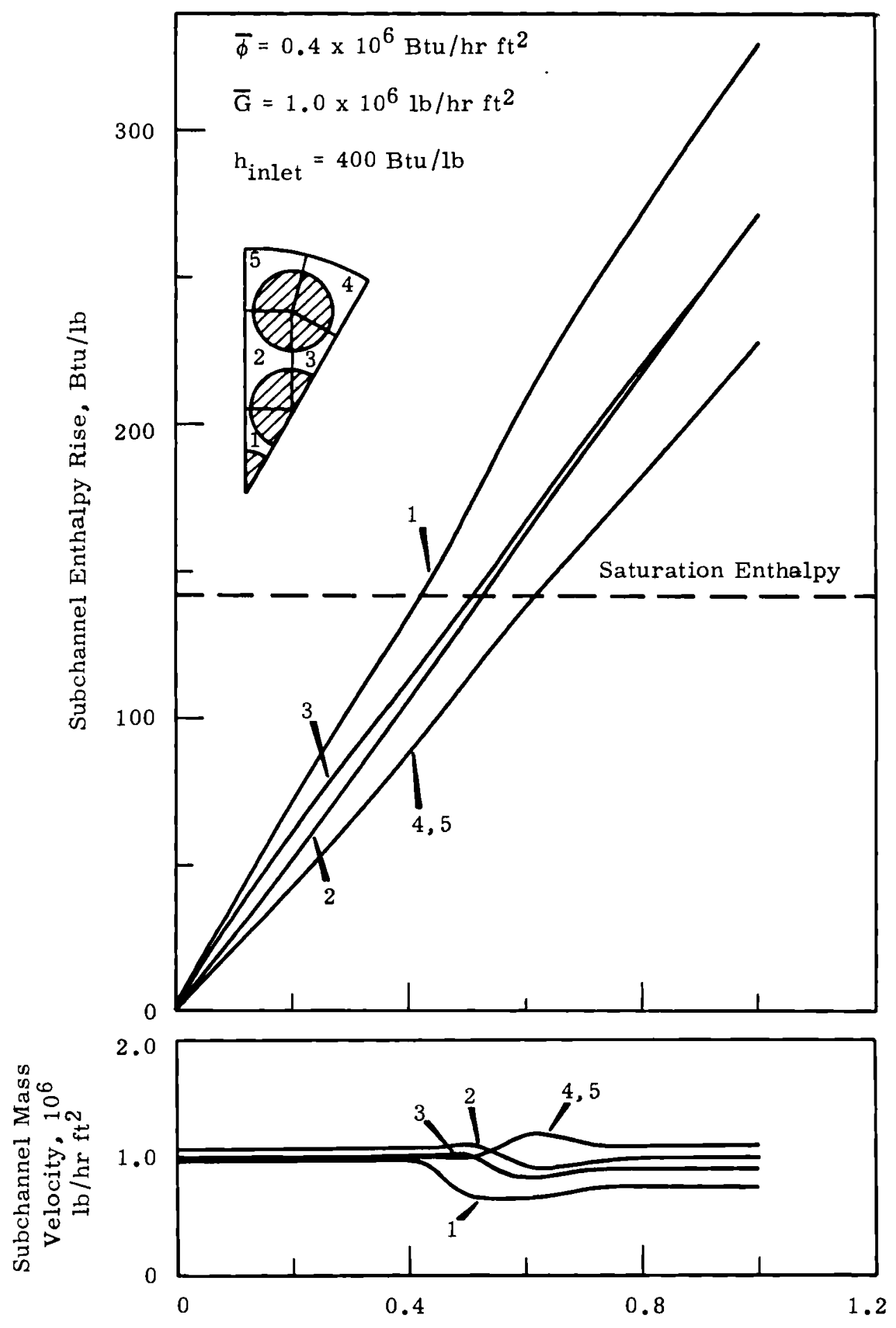

Relative Distance Along Channel, x/L

FIGURE 4. 19-Rod Bundle Subchannel Enthalpy and Mass Velocity for Nominal Case 


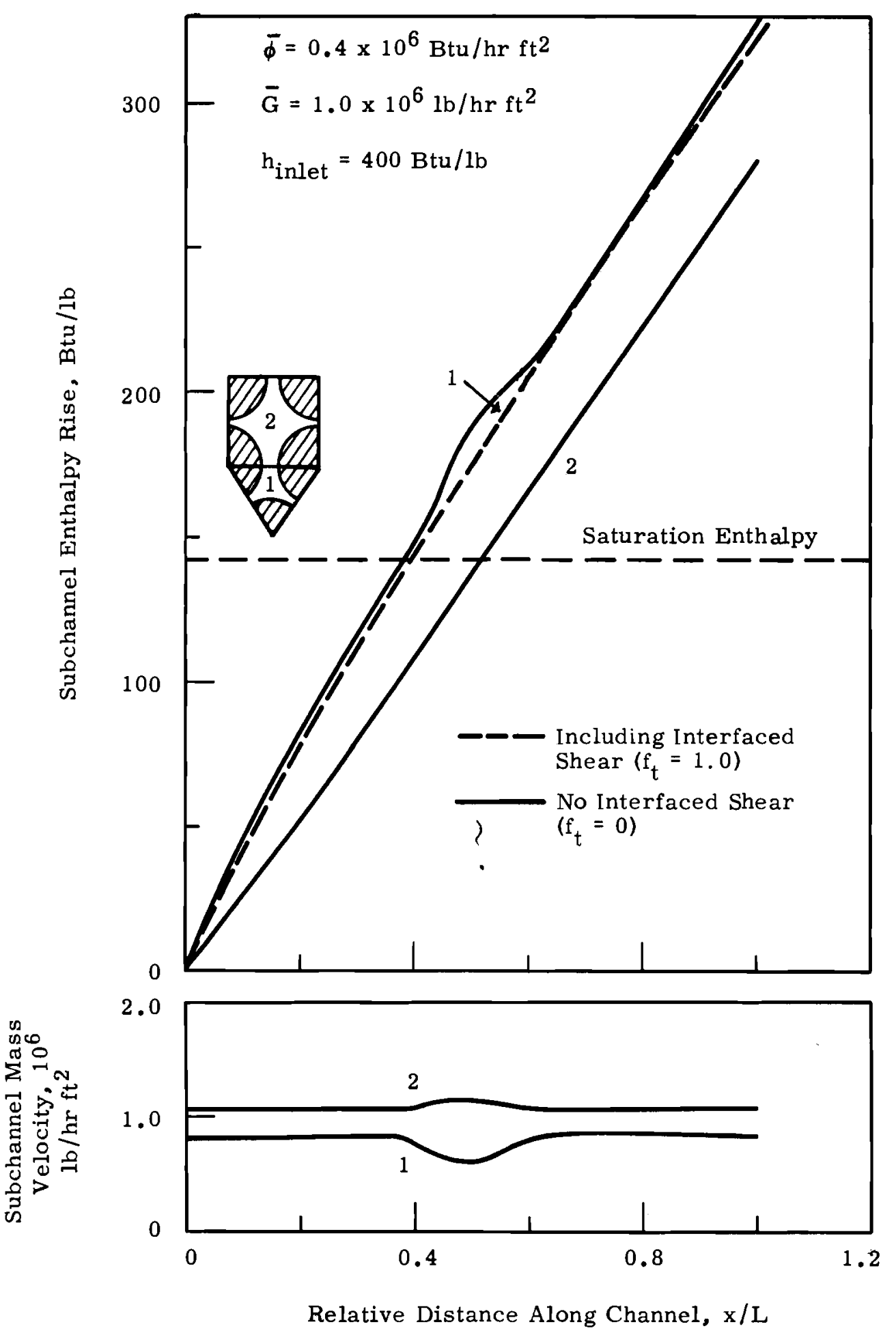

FIGURE 5. Effect of Interfacial Shear on Enthalpy and Mass Velocity 
dominant when boiling starts. Therefore, the influence of interfacial turbulent shear is small, especially during boiling conditions.

\section{Effect of Flow Diversion Momentum}

Diversion cross-flow momentum effects can be investigated by varying the parameter $f_{D}$, which gives the importance of the momentum being transported out of, or into, a subchannel from diversion cross-flow. Calculations for $f_{D}=0$ and $f_{D}=1.0$ give very little difference in the subchannel enthalpy. Some small variations in the subchannel mass velocity are noted near the point of maximum flow diversion as shown in Table I. This calculation shows that the transverse momentum term is not a strong parameter affecting the subchannel conditions.

TABIE I. Effect of the Parameter $f_{D}$ on the Subchannel Mass
Velocity

Distance Along Channe1,

0.00

0.10

0.20

0.30

0.40

0.45

0.50

0.5 .5

0.60

0.65

0.70

0.80

0.90

1.00
Subchannel 1

$\frac{\left(10^{6} \quad \mathrm{~b} / \mathrm{hr}-\mathrm{ft}^{2}\right)}{\mathrm{f}_{\mathrm{I})} \frac{\mathrm{l}}{0.906}} \quad \frac{\mathrm{f}_{\mathrm{D}}=0}{0.906}$

0.906

0.908

0.911

0.913

0.760

0.655

0.757

0). 804

0.818

0.822

0.811

0.807

0.809
0.906

0.907

0.909

0.911

0.826

0.751 .

0.775

0.796

0.806

0.811

0.808

0.806

0.808
Subchanne 12

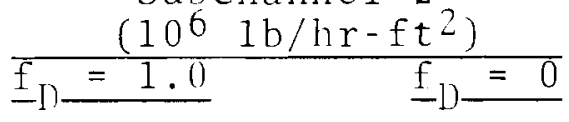

1.031

1.031

1.031

1.030

1.030

1.029

1.057

1.081

1.073

1.066

1.063

1.062

1.062

1.063

1.063 
Effect of Transverse Cross-Flow Resistance

Transverse cross-flow resistance can be varied by changing the friction constant $(f \ell)$. Calculations for $f \ell$, ranging from 0.0 to 0.01 , give nearly identical results when compared to the nominal case. Although, the transverse cross-flow resistance appears to be a weak parameter, it could become more significant for very closely spaced rods.

The fact that $f l$ is a weak parameter affecting the solution does not justify the ignoring of the transverse momentum equation or the setting of $f l$ equal to zero for all computations. For some problems, such as in square rod arrays, transverse flow resistance is required for stable computer solutions (Appendix B). Effect of Turbulent Mixing Parameter

The effects of a single, uniform turbulent mixing parameter $(\beta)$ (Figure 6) can cause very significant changes in the subchannel enthalpy rises. This parameter $(\beta)$ ranges from about 0.02 to 0.06 in multirod fuel bundles for single-phase flow conditions and with a variety of rod spacing devices. No experimental data have been reported for two-phase conditions; however, if a range as indicated above exists, determination of $\beta$ would be very important.

The subchannel mass velocity is significantly influenced by $\beta$ as seen in Table II. The lower mass velocities in subchannel 1 for $\beta=0$ can be attributed to larger acceleration pressure drop caused by larger enthalpy rises in Subchannel 1. The effect of interfacial shear on the mass velocity would only be significant prior to boiling (Figure 5). 


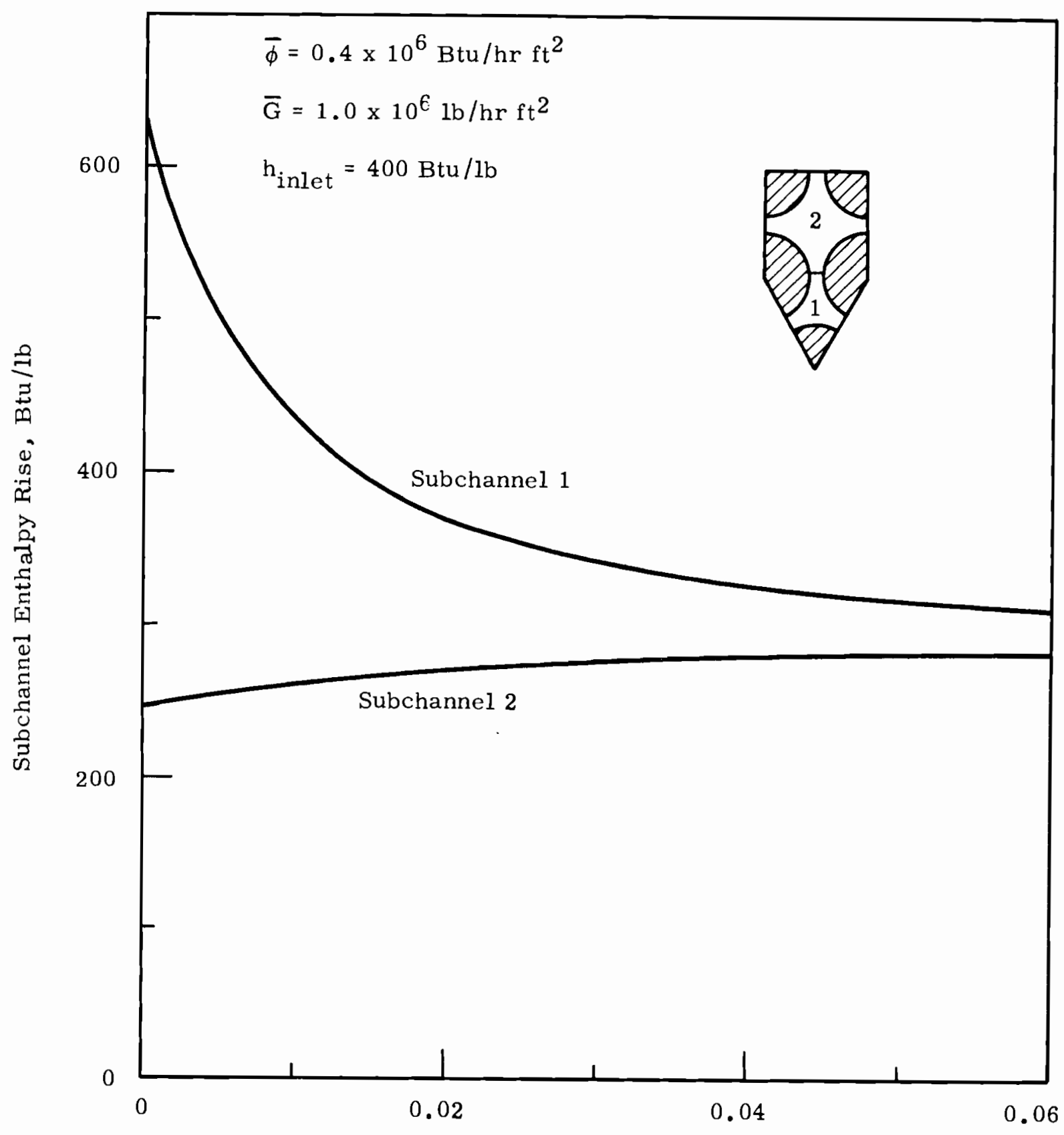

Turbulent Mixing Parameter, $\beta$

FIGURE 6. Effect of Mixing Parameter (B) on Subchannel Enthalpy Rise 
TABLE II. $\begin{aligned} & \text { Effect of the Parameter } \beta \text { on the Subchannel Mass } \\ & \text { Velocity }\end{aligned}$

Distance Along

Channe1,

$\frac{\mathrm{X} / \mathrm{L}}{\mathrm{O}}$

0.10

0.20

0.30

0.35

0.40

0.45

0.50

0.55

0.60

0.65

0.70

0.80

0.90

1.00

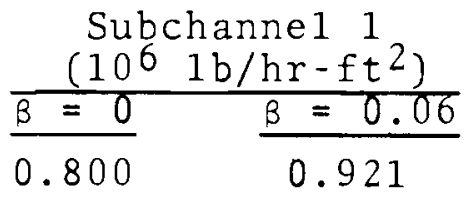

0.803

0.815

0.785

0.606

0.536

0.495

0.455

0.414

0.502

0.533

0.528

0.499

0.468

0.466
0.926

0.925

0.927

0.927

0.928

0.828

0.699

0.794

0.836

0.852

0.858

0.854

0.853

0.856
Subchannel 2 $\left(10^{6} 1 \mathrm{~b} / \mathrm{hr}-\mathrm{ft}{ }^{2}\right)$

$\frac{\beta=0}{1.065} \quad \frac{\beta=0.06}{1.026}$

1.064

1.025

1.060

1.024

1.070

1.024

1.128

1.024

1.151

1.023

1.164

1.056

1.177

1.098

1.191

1.067

1.162

1.053

1.152

1.048

1.153

1.046

1.16 .3

1.048

1.173

1.048

1.174

\section{DIGITAL COMPUTER PROGRAM DEVELOPMENT}

GENERAL FEATURES AND OPERATION

The digital computer program, COBRA is written to carry out the numerical solution of the mixing equations. If the assumptions of the model are reasonably satisfied, two-phase flow in multirod fuel elements as well as other heat transfer and fluid flow problems can be analyzed. Other problems could include geometric systems, such as rectangular channels or eccentric annuli.

The significant features of COBRA are:

- It has the ability to consider both single- and twophase flow. 
- It accounts for thermal mixing between interconnected parallel flow channels which results from both the transport of energy by turbulent cross-flow and diversion cross-flow when flow redistribution occurs.

- It considers the momentum interchanges between adjacent subchannels which results from both turbulent and diversion cross flow. (Parameters are included that allow the importance of these quantities to be specified.)

- It includes the effect of transverse resistance to diversion cross-flow.

- It considers an arbitrary layout of fuel rods and flow subchannels to allow analysis of most any rod bundle configuration up to 36 subchanne1s, 25 fuel rods, and 60 subchannel connections. A single subchannel may interact with up to four adjacent subchannels, and a fuel rod may transfer heat to a maximum of six adjacent subchannels.

- It includes arbitrary heat flux distribution by specifying the axial flux distribution, relative rod power, and the fraction of rod power to each of the six adjacent subchannels. (The latter feature allows and includes the variations in circumferential rod heat flux.)

General operation* of COBRA is explained by a flow diagram (Figure 7). The program is started by reading in a fluid property table and friction correlation constants that will be used for all succeeding cases. A control card is then read specifying what input is to be read in for the case under consideration. For the first case, all data are read; for all succeeding cases, quantities not read in are the same as the previous case. Once data are read in, the geometry information is generated and stored for future use. Most of the initial conditions are specified by the input data. If individual subchannel flow rates

* Specific details are given in the program listing and sample problem in Appendices $D$ and $E$. 


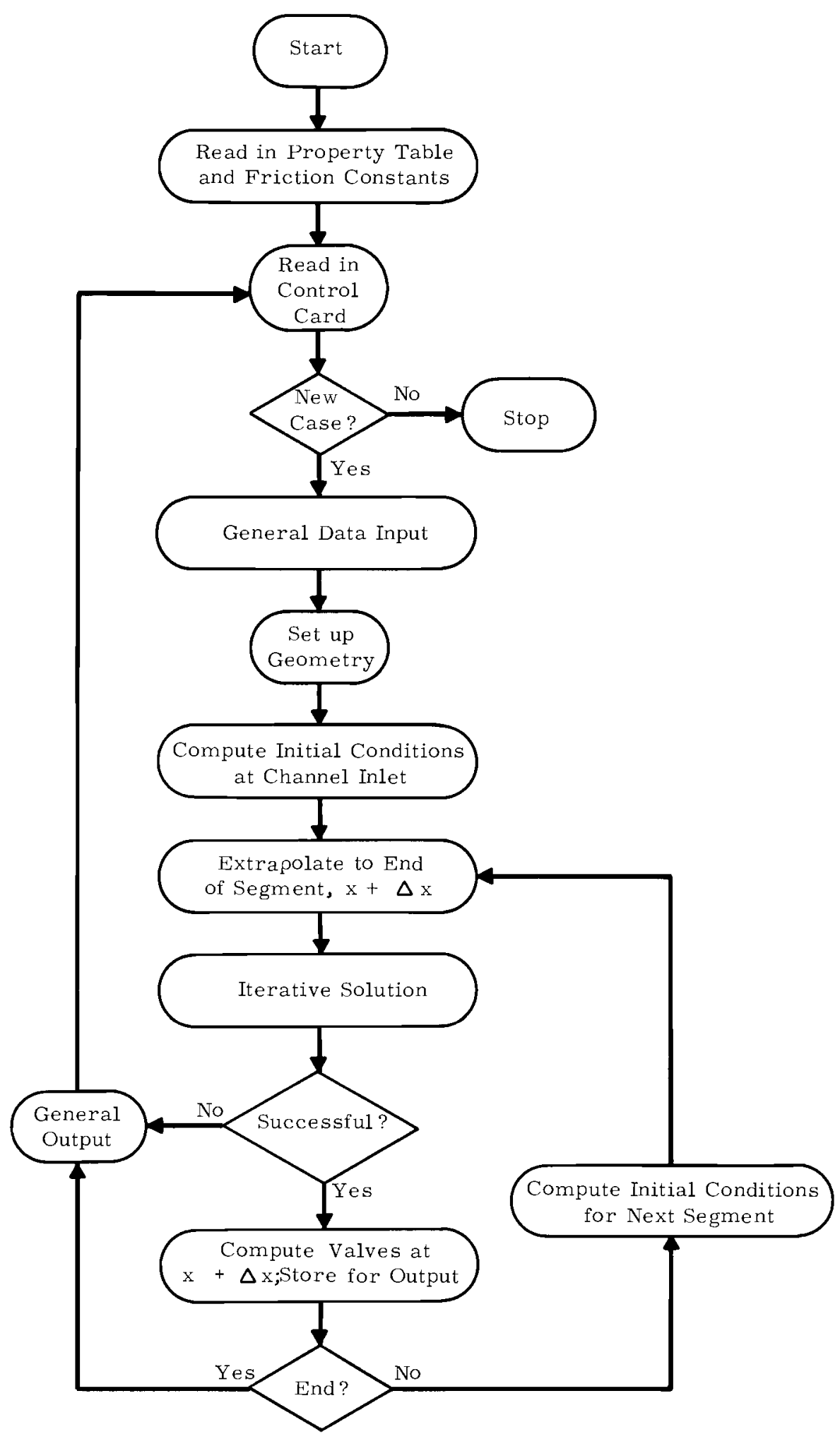

FIGURE 7. Simplified Flow Diagram for COBRA 
are not specified, the program distributes the total flow among the individual subchannels to give equal pressure gradients. One this has been established, the first derivatives of flow, enthalpy, and pressure are computed for initial conditions. Actual integration of the equations then begins by extrapolating to the end of the first increment. This extrapolation is updated and checked by successively solving for diversion cross-flow until convergence is achieved. If the iteration fails after a specified number of iterations, output data available to that point are written out, and the computation moves on to the next case. For a successful iteration, values at the end of the increment are computed and stored for output. These values provide the basis for new initial conditions at the start of the next increment where the entire procedure is repeated. When the end of the problem is reached, output data previously stored are written out, and the program moves on to the next case by reaching a new control card. A blank control card signals the program to stop.

Several checks are provided in COBRA to stop the calculation if trouble results. For all these stops, an error message and other potentially helpful data are written out. Also retained in the program is the option to write out intermediate data during the calculations.

COBRA was written in Fortran IV language for a UNIVAC 1107 computer. Except for memory storage, no problem should be encountered on other machines capable of compiling, assembling, and operating with a punched Fortran IV source deck and input cards. The UNIVAC 1107 at Hanford has two memory banks avai1able for program storage, and COBRA uses 6400 and 31077 , respectively, for a total storage requirement of 37477 . Other machines may use more, or less, storage depending upon the storage assignment during compilation. Although no auxiliary 
scratch tapes are used, their use could reduce the memory storage requirements. Input and output are on Tape Units 5 and 6 , respectively, but these can easily be changed by redefining the unit assignment variables $I 5$ and $I 6$ and recompiling the main program. Running time is difficult to estimate because it depends upon the size of the problem and how many times the simultaneous equations are solved. As an example of running time, the sample problem in Appendix $D$ is $17 \mathrm{sec}$ on the UNIVAC 1107.

\section{DIGITAL COMPUTER PROGRAM COMPARISONS}

Several computer programs $(13,17)$ have been written to analyze multidimensional two-phase flow in reactor channels and, in some cases, these programs have been used to predict $(18,19)$ local subchannel conditions in multirod fuel elements. Other programs $(7,8)$ have been written to analyze subchannel conditions but are limited to single-phase analyses only. Other work is also continuing on development of twophase subchannel analyses in the United States and in foreign countries; however, only limited information is available concerning the capabilities of these analyses. A general comparison of these digital computer programs is given in Table III.

THINC (17) has been developed by Westinghouse to predict flow and enthalpy in a semiopen or closed channel core during boiling. It is a general program for analyzing multirod bundles; however, as written, it has no provision for including turbulent thermal mixing. The analytical treatment in THINC is quite similar to this analysis but has a more simplified treatment of transverse momentum effects. An improved version of THINC, called THINC-II, has been written but is company proprietary. 
TABLE III. Comparisons of Features in Some Digital Computer Programs That Have Been Used for Rod Bundle Subchannel Analyses

Program Capabilities

\begin{tabular}{|c|c|c|c|c|c|c|c|c|c|}
\hline Computer Programs & 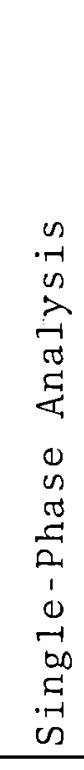 & 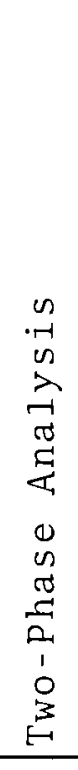 & 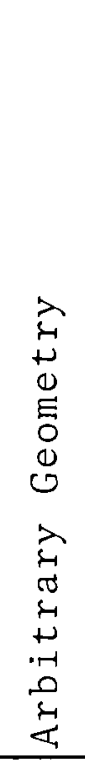 & 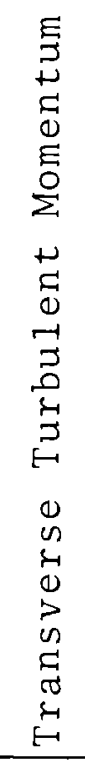 & 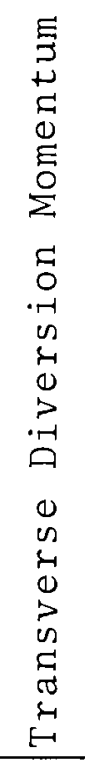 & 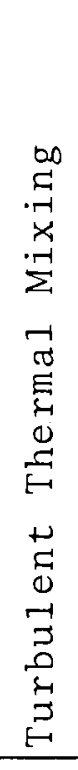 & 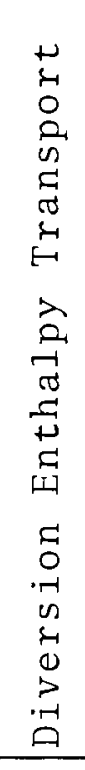 & 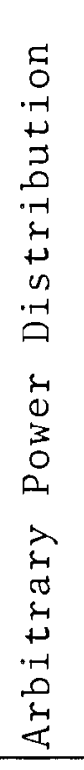 & 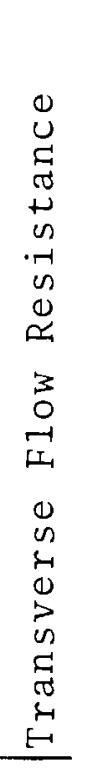 \\
\hline COBRA & $X$ & $\mathrm{X}$ & $\mathrm{X}$ & $x$ & $X$ & $x$ & $X$ & $x$ & $x$ \\
\hline THINC $(17)$ & $X$ & $\mathrm{X}$ & $\mathrm{X}$ & - & $\mathrm{X}$ & - & $\mathrm{X}$ & $\mathrm{X}$ & $X$ \\
\hline $\operatorname{HAMBO}(20)$ & (a) & (a) & (b) & (b) & (b) & (a) & (b) & (a) & (b) \\
\hline $\begin{array}{ll}\text { General } & \text { Electric } \\
\text { Company } & -\operatorname{APED}(21)\end{array}$ & $\mathrm{X}$ & $X$ & $X$ & (b) & (a) & $X$ & (a) & $\mathrm{X}$ & $\mathrm{a}$ \\
\hline HECT IC-I I ( 7) & $X$ & - & $X$ & $\mathrm{X}$ & - & $X$ & - & $\mathrm{X}$ & - \\
\hline$U-3^{(8)}$ & $\mathrm{X}$ & - & $\mathrm{X}$ & - & - & $\mathrm{X}$ & - & $\mathrm{X}$ & - \\
\hline Atomics International (15) & $\mathrm{X}$ & $\mathrm{X}$ & (c) & - & $\mathrm{X}$ & - & (c) & $\mathrm{X}$ & - \\
\hline $\operatorname{TITE}(13) \times \operatorname{XIE}$ & $\mathrm{X}$ & $X$ & (c) & - & $\mathrm{X}$ & - & $\mathrm{X}$ & $\mathrm{X}$ & - \\
\hline
\end{tabular}

(a) Apparentzy included, but no specific details are available (not published).

(b) No details are available (not published).

(c) Somewhat restrictive for rod bundle subchannel analysis. 
HAMBO is a program being developed by the British. Very little information is available but it is reported ${ }^{(20)}$ to be a rather complete program for multirod subchannel analysis.

General Electric Company, APED, (21) is developing a subchannel analysis program using a model similar to the one presented here. Specific details of the program are not yet available, but it will probably have many of the features of COBRA.

HECTIC-II (7) has been developed for the Army Gas-Cooled Reactor Systems Program. It is a rather complete analysis of heat transfer and fluid flow for gas-cooled reactor channels and is applicable to many other mixing problems involving a single-phase coolant. The model used is similar to that of COBRA but is limited to single-phase conditions.

U-3, (8) limited to single-phase coolants, is a modified version of a program originally written in Canada for heat transfer analysis of multirod elements. Modifications to the program have been made for heat transfer analyses of heavywater-moderated organic-cooled reactors.

Atomics International developed a program ${ }^{(15)}$ that has been used for two-phase rod bundle subchannel analysis. However, because it does not account for turbulent energy interchange between subchannels, this program is limited to problems where the coolant enthalpy is nearly uniform across the bundle. Enthalpy transport from diversion cross-flow is also limited because the flow diversion can only be in one direction, i.e., out from the center of the bundle.

TITE $^{(13)}$ and XITE ${ }^{(14)}$ are steady state and transient programs, respectively, that have limitations similar to those for the Atomics International program when applied to rod 
bundle subchannels. These programs, developed for two-phase flow in rectangular coolant channels, are set up to provide an adjacent subchannel on either side of a subchannel.

NUMERICAL METHODS USED TO DEVELOP COBRA

The equations of continuity, energy, and momentum are very complex nonlinear equations. Only for very simple cases, such as two parallel subchannels and single-phase flow, can a closed form analytical solution ${ }^{(2)}$ be obtained. Generally, a numerical solution is required.

The numerical solution is treated as an initial value problem* by integrating the equations in a stepwise manner starting at the inlet of the fuel bundle. Initial values of enthalpy, pressure, and flow rate are assumed to be known at the inlet to start the solution, and pressure drops are computed as positive values to give the proper direction of flow diversion.

Actual numerical solution of the equations proved to be a rather difficult task. The more simple integration techniques (Euler and Runge-Kutta) for solution of the differential equations were not satisfactory during the initial development of COBRA.

Modified Euler Method

The modified Euler method was the first technique attempted. This method computes the first derivative, based upon the initial conditions, and uses this first derivative to predict quantities at the end of the first increment. The calculation is repeated at the end of the first increment to get the average first derivative for the increment. Another prediction of the values at the end of the first increment is made and, if agreement with

\footnotetext{
* The physical problem is more truly a boundary value problem; however, because of the nearly equal pressures between rod bundle subchannels, treatment as an initial value problem is justified.
} 
the previous value is within an allowable tolerance, the calculation proceeds to the next increment. If agreement is not achieved, iteration continues until agreement is achieved.

The problem with the Euler method is that a small error in the predicted pressure at the end of the first increment can cause a large diversion cross-flow to occur [as computed from Equation (4)]. When this diversion cross-flow was used in the next calculation to predict pressure at the end of the increment, the difference in pressure between the channels was larger and opposite in direction than for the first calculation. This effect grew very rapidly with the next few iterations and led to a divergent solution. The source of the problem was traced to the momentum equations's last term which can be large with moderate values of flow diversion. Apparently, a method more accurately predicting the pressure at the end of the increment was needed.

Runge-Kutta Method

The Runge-Kutta formulas are generally considered stable and capable of predicting accurately ahead; therefore, the method of solution was shifted to those formulas. Difficulties similar to those found in the modified Euler technique were encountered but only for certain conditions. Stable solutions could be obtained if the increment were small and if the transverse resistance were large. For opposite conditions, unstable behavior was encountered except where continual flow diversions from boiling could be established.

This unstable behavior of the solution can be explained mathematically by looking at a partial derivative of Equation (4); in particular, the last term which is of the form $u_{i} w_{i j}$. If this is combined with Equation (4), we find the form 


$$
\frac{\partial}{\partial p_{i}}\left[u_{i} \sqrt{\frac{p_{i}-p_{j}}{C_{i j}}}\right]=\frac{u_{i}}{\sqrt{C_{i j}}}=\frac{1}{\sqrt{p_{i}-p_{j}}}
$$

A valid solution requires that such a partial derivative be bounded; however, it is not bounded if $p_{i}$ equals $p_{j}$ or if $C_{i j}$ equals zero.

These were the conditions that tended to give unstable solutions; i.e., $p_{i}$ close to $p_{j}$ and $C_{i j}$ small. If the flow diversion condition could be established causing $p_{i}$ to not equal $p_{j}$, of $C_{i j}$ taken large, then the partial derivative was finite and a solution was obtained. It was apparent from this difficulty that some other numerical technique was required. Iterative Solution

In the two previous methods, failure of the numerical integration had been caused by the inability to control the amount of diversion cross-flow as the solution moved forward. To correct this problem, a procedure, similar to the modified Euler method, has been developed that uses a special iterative scheme to control the diversion cross-flow. This procedure was designed to satisfy both the axial and transverse momentum equations.

The equations used are:

$$
\begin{aligned}
& m_{i, x+\Delta x}=m_{i, x}+\frac{\Delta x}{2}\left(\frac{d m_{i, x}}{d x}+\frac{d m_{i, x+\Delta x}}{d x}\right) \\
& h_{i, x+\Delta x}=h_{i, x}+\frac{\Delta x}{2}\left(\frac{d h_{i, x}}{d x}+\frac{d h_{i, x+\Delta x}}{d x}\right) \\
& p_{i, x+\Delta x}=p_{i, x}-\frac{\Delta x}{2}\left(\frac{d p_{i, x}}{d x}+\frac{d p_{i, x+\Delta x}}{d x}\right)
\end{aligned}
$$

The minus sign is used in Equation (14) to properly account for the direction of flow diversion as influenced by pressure differences between subchannels. 
The first derivatives in Equations (12), (13), and (14) are known from the initial conditions at the start of the solution and then at the beginning of every step as the integration proceeds. If the step size is small enough to give rather small changes in the flow, reasonable estimates of the first derivatives at $x+\Delta x$ in Equations (12) and (13) can be made. The same is not true in Equation (14) because the pressure gradient at $x+\Delta x$ is greatly influenced by the amount of diversion cross flow $\left(w_{i j}\right)$ which could be large and yet give a small change in axial flow for a small $\Delta x$. The pressure at $x+\Delta x$ can be determined by substituting Equation ( 3 ) into Equation (14) wherewe find that the pressure at $x+\Delta x$ is a linear function of the diversion cross-flows into or out of the subchannel. We can illustrate this effect and show how it is used to determine the cross-flow at $x+\Delta x$ by considering two subchannels. (Detailed in Appendix B.)

For the two-channel case, consider Subchannel 1 as boiling and diverting flow into Subchannel 2. If we plot the pressure at $x+\Delta x$ as a function of $w_{12}$, we get two linear curves (Figure 8 ). If we form the difference, $p_{1}-p_{2}$, as in Equation (B-12), we obtain another linear curve. We also have the transverse momentum Equation (B-15) which will intersect the linear curve of $p_{1}-p_{2}$ versus $w_{12}$. The point of intersection of Equation (B-12) represents the solution of Equation (B-15). In this simple case, it is the solution of a quadratic equation; for the general case, a nonlinear set of simultaneous equations results instead of the quadratic equation. The solution of this set of equations provides diversion cross-flows for a new evaluation of conditions at $x+\Delta x$ from which the entire procedure may be repeated. The iteration is stopped when the diversion cross-flows between successive iterations converge to an acceptable value. 


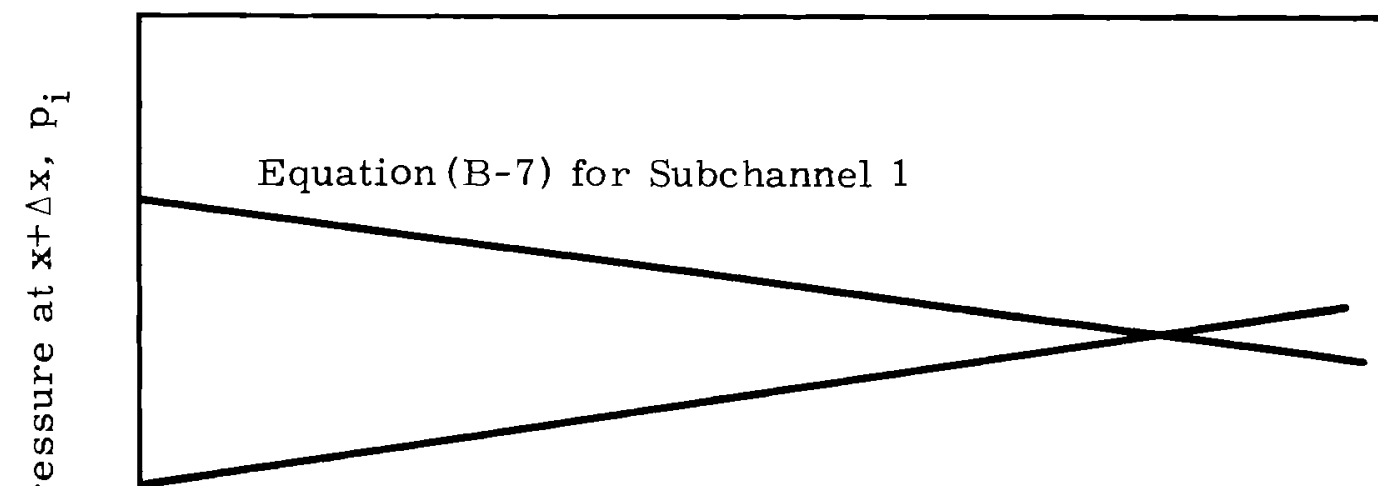

Equation (B-7) for Subchannel 2

Diversion Crossflow from Subchannel 1 to

Subchannel 2, $\mathrm{w}_{12}$

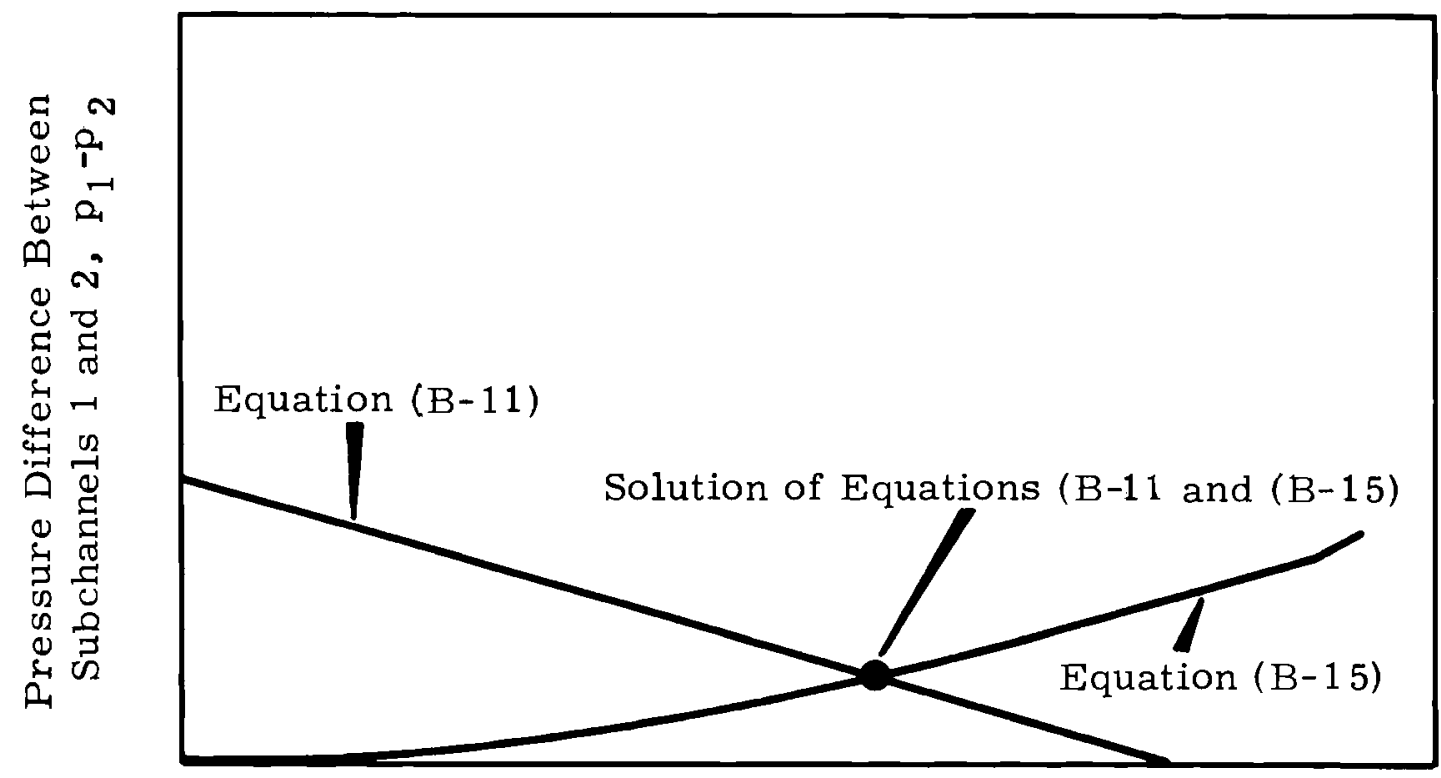

Diversion Crossflow from Subchannel 1 to Subchannel 2, $w_{12}$

FIGURE 8. IZZustration of Method Used to Solve for Diversion 


\section{FUTURE DEVELOPMENT}

The development of COBRA has relied primarily upon analytical considerations and has utilized several empirical correlations for its development. Future refinements to the model and program will be possible from some existing and future experimental data. Several areas of improvement, based upon experimental data, include:

- More accurate prediction of two-phase pressure drop, if needed.

- More accurate void correlation, if needed.

- Subcooled void fraction.

- Prediction of the local turbulent mixing parameter ( $\beta$ ) based on a correlation with local subchannel coolant conditions and mechanical design of the bundle. Additional turbulence, caused by rod spacer design (wire wraps, warts, grids, etc.), is expected to have a strong influence on $\beta$.

- Effect of rod spacer design for computing pressure drop.

- Correlation of the transverse diversion cross-flow resistance* to bundle geometry and coolant conditions.

- Correlation of the momemtum factors* $f_{T}$ and $f_{D}$ to bundle geometry and coolant conditons.

Possible future work to improve the general nature of the program includes:

- Variable channel area and gap spacing along length of channel to allow studies of rod bowing or misalignment within the bundle.

- "Forced"** cross-flow diversion resulting from mechanical devices such as wire wraps.

\footnotetext{
* These are weak parameters, but a more accurate determination of their values and what factors influence them would be useful.

** "Forced" diversion cross flow is not included in COBRA. The diversion cross-flows computed by COBRA could be considered "natural" because they result from pressures trying to equalize.
} 


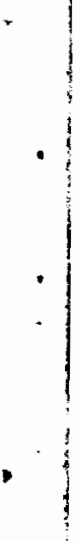


Dimensions are denoted by:

$\mathrm{L}=$ length, $\mathrm{T}=$ time, $\mathrm{M}=$ mass, $\theta=$ temperature,

$F=M L / T^{2}=$ force and $H=M L^{2} / T^{2}=$ energy.

$A=$ cross-sectional area, $\left(L^{2}\right)$

$\mathrm{C}=$ loss function for transverse momentum, Equation (4)

$\mathrm{C}_{\mathrm{p}}=$ specific heat $(\mathrm{H} / \mathrm{M} \theta)$

$\mathrm{D}=$ hydraulic diameter, (L)

$\mathrm{Dr}_{\mathrm{r}}=\operatorname{rod}$ diameter $(\mathrm{L})$

$F=$ force $\left(\mathrm{ML} / \mathrm{T}^{2}\right)$

$\mathrm{K}=$ number of connections between adjacent subchannels, (Dimensionless)

$\mathrm{L}=$ channel length, (L)

$\mathrm{N}=$ number of subchannels, (Dimensionless)

$\operatorname{Re}=$ Reynolds number, (Dimensionless)

$\mathrm{X}=$ quality, $\mathrm{m}_{\mathrm{g}} /\left(\mathrm{m}_{\mathrm{g}}+\mathrm{m}_{\mathrm{f}}\right)$, (Dimensionless)

$f=$ friction factor based on all-liquid flow, (Dimensionless)

$\mathrm{f}_{\mathrm{A}}=$ local to average axial power distribution (Dimensionless)

$f_{c}=$ fraction of rod power transferred to an adjacent subchannel, (Dimensionless)

$f 1=$ diversion cross-flow resistance parameter,

$\mathrm{f}_{\mathrm{R}}=$ relative rod power distribution, (Dimensionless)

$f_{T}, f_{D}=$ correction terms for turbulent and diversion momentum, respectively, (Dimensionless)

$\mathrm{g}_{\mathrm{C}}=$ gravitational constant, $\left(\mathrm{ML} / \mathrm{FT}^{2}\right)$

$h=$ enthalpy, $X h_{g}+(1-X) h_{f},(H / M)$

$h_{g}, h_{f}=$ saturated vapor and liquid enthalpy, (H/M)

$\ell=1$ ength $(\mathrm{L})$

$m=$ mass flow rate, $A_{f}\left[\rho_{g} \alpha \gamma+\rho_{f}(1-\alpha)\right],(M / T)$

$\mathrm{p}=$ pressure $\left(\mathrm{F} / \mathrm{L}^{2}\right)$

$q^{\prime}=$ heat addition per unit length, (H/L)

$\bar{q}^{\prime \prime}=$ average heat flux, $\left(\mathrm{H} / \mathrm{TL}^{2}\right)$ $\mathrm{s}=$ rod spacing, $(\mathrm{L})$

$u=$ channel effective momentum velocity, $\mathrm{mv} / \mathrm{A},(\mathrm{L} / \mathrm{T})$

$v=$ specific volume, $1 / \rho,\left(\mathrm{L}^{3} / \mathrm{M}\right)$

$v^{\prime}=$ effective specific volume for momentum considerations $(1-X)^{2} / \rho_{f}(1-\alpha)+X^{2} / \rho_{g} \alpha,\left(L^{3} / M\right)$

$\mathrm{w}=$ diversion cross $-\mathrm{flow}$ between adjacent subchannels, (M/TL)

$w^{\prime}=$ turbulent (fluctuating) cruss-flow between adjacent subchannels, (M/TL)

$x=$ space variable, $(L)$

$\alpha=$ void fraction, $A_{g} /\left(A_{g}+A_{f}\right)$, (Dimensionless)

$B=$ turbulent mixing parameter, (Dimensionless)

$\gamma=$ slip ratio, $u_{g} / u_{f}$, (Dimensionless)

$\varepsilon_{q}=$ eddy diffusivity, $\left(\mathrm{L}^{2} / \mathrm{T}\right)$

$\varepsilon_{t}^{q}=$ turbulent diffusivity for momentum, $\left(\mathrm{L}^{2} / \mathrm{T}\right)$

$\theta=$ orientation of channel with respect to vertical, (Radians)

$\rho=$ density, $\rho_{g}{ }^{\alpha}+\rho_{f}(1-\alpha),\left(M / L^{3}\right)$

$\rho_{g}, \rho_{f}=$ saturated vapor and liquid density, $\left(\mathrm{M} / \mathrm{L}^{3}\right)$

${ }_{t}{ }_{t}=$ turbulent shear stress, $\left(F / L_{1}^{2}\right)$

$\phi=$ two-phase friction multiplier, (Dimensionless)

Subscripts

$f, g$ = saturated conditions for liquid and vapor respectively

$i, j=$ channel identification number $i j, j i=\begin{aligned} & \text { double subscripts } i m p l y \\ & \text { respectively }\end{aligned}$

$k, l=$ number identifying each subchannel connection eack $k$ or $\ell$ implies a pair $i j$ or $j i$

$r=$ rod identification number

$\mathrm{ri}=$ refers to conditions from rod $\mathrm{r}$ to subchannel 



\section{REFERENCES}

1. J. G. Knudsen. The Effect of Mixing on Burnout in Multirod Bundles, $H W-8452$. Hanford Atomic Products operation, Richland, Washington, December, 1964.

2. R. O. Sandberg and A. A. Bishop. CVTR Thermal-Hydraulic Design for $65 \mathrm{MW}$ Gross Fission Power, CVNA-227. Westinghourse Electric Corporation, Atomic Power Department, Pittsburgh, Pennsylvania, February, 1965.

3. R. G. Deissler and M. F. Tayzor. Analysis of Axial Turbulent Flow and Heat Transfer Through Banks of Rods ox Tubes, TID-7529 (Pt 1) Book 2, 1956.

4. R. G. Deissler and M. F. Tayzor. Analysis of Turbuzent Flow and Heat Transfer in Noncireular Passages, NASA TR R-31. National Aeronautics and Space Administration, Washington D.C. 1955.

5. R. E. Grimble and W. H. Belz. An Analysis of Mixing in Parallel Flow Rod Bundles, WAPD-TH-178. Westinghouse Electric Corporation, Atomic Power Department, Pittsburgh, Pennsylvania, Undated.

6. C. B. Moyer. Coolant Mixing in Multirod Fuel Bundles, RISO-125. Danish Atomic Energy Commission, Research Establishment Risö, Raskilde, Denmark, July, 1966.

7. N. Kattchee and W. C. Reynolds. HECTIC-II-An IBM 7090 Fortran Computer Program for Heat Transfer Analysis of Gas or Liquid-Cooled Reactor Passages, IDO 28595 REV. Aerojet-General Nucleonics, San Ramon, California, December, 1962 .

8. J.P. Sanders. The Modified U-3 Code: A Thermal-Hydraulic Code for Axial Flow with Mixing in Fuel Bundles, ORNL-4016. Oak Ridge National Laboratory, Oak Ridge, Tennessee, November, 1966.

9. P. A. Nelson, A. A. Bishop, and L. S. Tong. Mixing in Elow Parallel to Rod Bundles Having a Square Lattice, WCAP-1607. Westinghouse Electric Corporation, Atomic Power Department, Pittsburgh, Pennsylvania, July, 1960.

10. E. D. Waters. Fluid Mixing Experiments with a WireWrapped 7-Rod Bundle Fuel Assembly, HW-70178 REV. Hanford Atomic Products operation, Richland, Washington, November, 1963 .

11. R. A. Dean. Coolant Mixing in Open Lattice Reactor Cores, WCAP-3735. Westinghouse Electric Corporation, Atomic Power Department, Pittsburgh, Pennsylvania, August, 1963. 


\section{REFERENCES (contd)}

12. T. T. Shimaz aki and $W$. J. Freede. Heat Transfer and Hydraulic Characteristics of the SRE Fuel Element, Reactor Heat Transfer Conference, Hotel Statier, New York, November 1 and $2,1956$.

13. R. I. Mizler and R. S. Pyze. TITE - A Digital Program for the Prediction of Two-Dimensional Two-Phase Hydrodynamics, WAPD-TM-240. Westinghouse Electric Corporation, Bettis Atomic Power Laboratory, Pittsburgh, Pennsylvania, 1962.

14. R. P. Rose and R. S. Pyle. XITE - A Digital Computer Program for the Analysis of Two-Dimensional Boiling Flow Transients with Fluid Expansion, WAPD-TM-302. Westinghouse Electric Corporation, Bettis Atomic Power Laboratory, Pittsburgh, Pennsylvania, Apriz, 1963.

15. D. E. Schramm and R. F. Berland. A Multichannel TwoDimensional, Two-Phase Flow Model and IBM 7090 Code, NAA-SR-MEMO 9444. Atomics International, Canoga Park, California, December 31, 1963.

16. L. R. Steele and R. F. Berland. A Transient Multichannel Two-Phase Hydraulic Code, NAA-SR-9425. Atomics International, Canoga Park, California, December 1, 1964.

17. W. Zernik, H. B. Currin, E. Flyash, and G. Previti. "THINC" A Thermal Hydrodynamic Interaction Code for a Semi-open or Closed Channel Core, WCAP-3704. Westinghouse Electric Corporation, Atomic Power Department, Pittsburgh, Pennsylvania, February, 1962 .

18. Report on Large Power Reactor (LPR) Program, WAPD-LPR-181. Westinghouse Electric Corporation, Bettis Atomic Power Laboratory, December, 1963.

19. Report on Large Power Reactor (LPR) Program, WAPD-LPR-256. Westinghouse Electric Corporation, Bettis Atomic Power Laboratory, Pittsburgh, Pennsyzvania, September, 1964.

20. G. A. Wikhammer. Unpublished Data, Atomic Energy of Canada Ltd., Chalk River, Ontario, October 1966, (Personal Communication).

21. J. Healzer. Unpublished Data, General EZectric Company, Atomic Products Division, San Jose, California, December, 1966, (Personal Communication).

22. J. E. Meyer. Conservation Laws in One-Dimensional Hydrodynamics, WAPD-BT-20, pP. 61-72. Westinghouse Electric Corporation, Bettis Atomic Power Laboratory, Pittsburgh, Pennsylvania, September, 1960. 
23. J. E. Meyer. "Hydrodynamic Models for the Treatment of Reactor Thermal Transients," Nuc. Sci. \& Engr., vol. 10, pp. 269-277, 1961 .

24. P. D. Crout. "A Short Method for Evaluating Determinants and Solving Systems of Linear Equations with Real or Complex Coefficients," AIEE Transactions, vol. 60, pp. $1235-1240,1941$.

25. J. P. Waggener. "Friction Factors for Pressure Drop Calculations," Nucleonics, vol. 19, p. 145, 1961.

26. A. A. Armand. "The Resistance During the Movement of a Two-Phase System in Horizontal Pipes," Translated by V. Beak, AERE Trans. 828. Izvestiya Vsesojuznogo Teplotekhnicheskogo Instituta (1), pp. 16-23, 1946.

27. W. A. Massena. Steam-Water Pressure Drop and Critical Discharge Flow - A Digital Computer Program, HW-65706. Hanford Atomic Products Operation, Richland, Washington, June 17, 1960 . 
APPENDIX A 


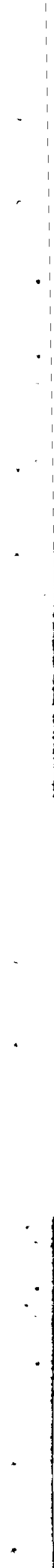




\section{APPENDIX A}

DERIVATION OF MIXING EOUATIONS

Consider a section of Flow Channel (i) with two types of adjacent subchannels. Adjacent subchannels of type (j) are diverting flow into (i), and adjacent subchannels of type (k) are receiving flow from (i). Assume that one-dimensional, separated, two-phase, slip flow exists in each subchannel. A further assumption is that, in addition to the diversion of flow between channels, a turbulent cross-flow simultaneously exists and causes no net flow imbalance when averaged over a short period of time. With these basic assumptions, we can now derive the basic equations of continuity, energy, and momentum along Flow Channel (i).

Continuity Equation

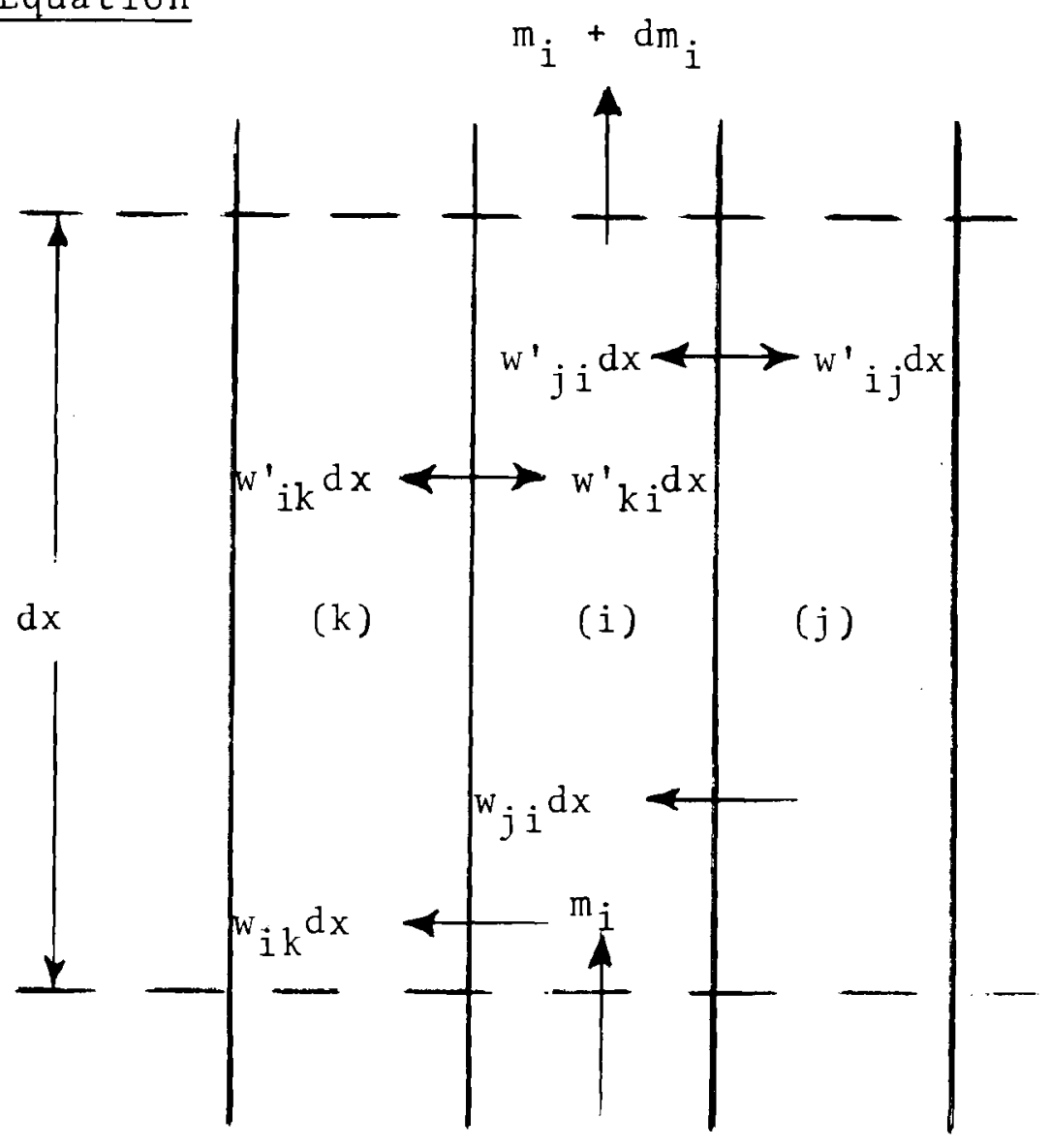


From a mass balance on Subchannel (i),

$$
\begin{aligned}
m_{i}+w_{j i} d x+w^{\prime} j i d x+d x+w^{\prime} k_{i} d x \\
=m_{i}+d m_{i}+w_{i k} d x+w^{\prime}{ }_{i k} d x+w^{\prime}{ }_{i j} d x .
\end{aligned}
$$

Our definition of the turbulent cross flow gives

$$
w^{\prime}{ }_{j i}=w^{\prime}{ }_{i j}
$$

and

$$
w^{\prime}{ }_{i j}=w^{\prime}{ }_{k i}
$$

therefore, the continuity equation reduces to

$$
\frac{d m_{i}}{d x}=w_{j i}-w_{i j}
$$

or, if we consider al1 possible Adjacent Subchannels (n) and take $w_{i k}$ as diversion cross-flow from (i) to (k) as positive, we find

$$
\frac{d m_{i}}{d x}=-\sum_{j=1}^{N} w_{i j} \quad i=1,2, \ldots N
$$

Energy Equation

An energy balance on Subchannel (i) gives

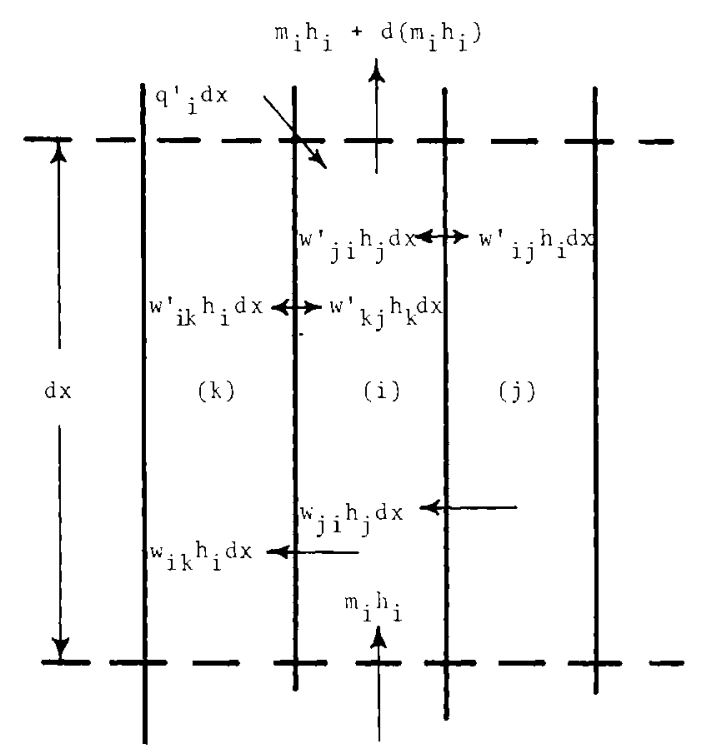




$$
\begin{aligned}
m_{i} h_{i}+w_{j i} h_{j} d x+w^{\prime}{ }_{j i} h_{j} d x+w^{\prime}{ }_{k i} h_{k} d x+q^{\prime}{ }_{i} d x \\
=w_{i k} h_{i} d x+w^{\prime}{ }_{i k} h_{i} d x+w^{\prime}{ }_{i j} h_{i} d x+m_{i} h_{i}+d\left(m_{i} h_{i}\right) .
\end{aligned}
$$

Inserting Equations $(A-1)$ and $(A-2)$ and combining with Equation (A-3) gives

$$
\frac{d h_{i}}{d x}=\frac{q^{\prime} i}{m_{i}}+\frac{w_{j i}}{m_{i}}\left(h_{j}-h_{i}\right)+w^{\prime}{ }_{i k}\left(h_{k}-h_{i}\right)
$$

There is not a term for $w_{i k}$ because, on an enthalpy basis, the system enthalpy change is dependent upon where fluid is coming from, not where it is going. If we adopt the same sign convention for diversion cross flow as in the continuity equation and and consider all possible Subchannels (N), we find

$$
\begin{aligned}
m_{i \frac{d}{d x}}=q^{\prime} h_{i} & +\sum_{j=1}^{N} w_{i j}\left(h_{j}-h_{i}\right) \\
& -\sum_{j=1}^{N}\left\{\begin{array}{c}
0 \\
w_{i j}\left(h_{j}-h_{i}\right) \quad ; i f w_{i j} \geq 0 \\
i j=0
\end{array}\right\} \\
i= & 1,2, \ldots N
\end{aligned}
$$

Axial Momentum Equation

Derivation of the momentum equation is a little more complex than the continuity and energy equations; however, the same technique applies. The primary difference is that an effective specific volume for momentum transport is used. The momentum in a two-phase flow stream is 


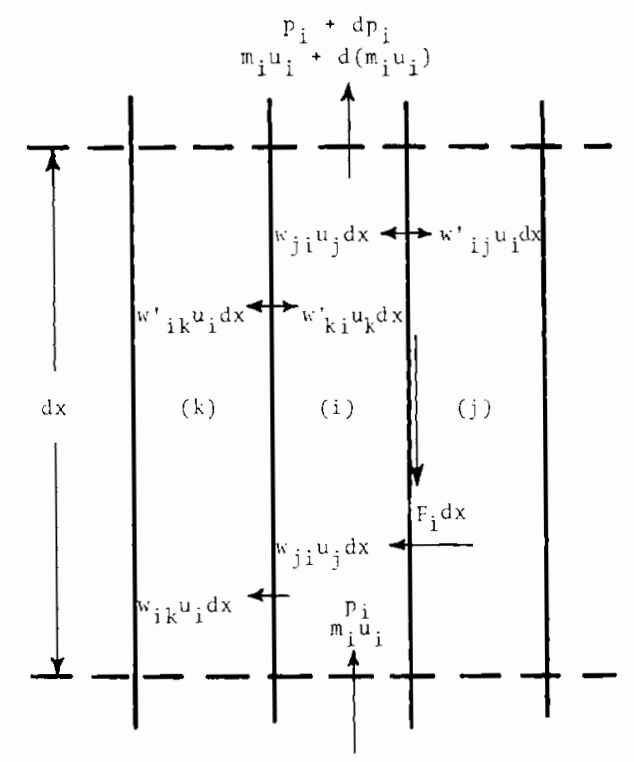

$$
\frac{A G^{2} v^{\prime}}{g_{C}}=\left(\frac{m}{A}\right)^{2} \quad \frac{A v^{\prime}}{g_{C}}=\frac{m u}{g_{C}}
$$

where we now have a momentum velocity,

$$
u=\frac{m v^{\prime}}{A}
$$

The effective specific volume term is that used by Meyer (23) in his development of two-phase flow equations.

Equating forces acting upon Subchannel (i) in the $x$ direction to the change in momentum, gives

$$
\begin{aligned}
& g_{C}\left(A_{i} p_{i}-F_{i} d x-A_{i} p_{i}-A_{i} d p_{i}-A_{i}^{\rho}{ }_{i} \cos \theta d x\right)= \\
& +\left[f D^{w}{ }_{i k} u_{i} d x+f_{T} w^{\prime}{ }_{i k} u_{i} d x+f_{T} w^{\prime}{ }_{i j} u_{i} d x+m_{i} u_{i}\right. \\
& \left.+d\left(m_{i} u_{i}\right)\right]-\left(m_{i} u_{i}+f_{D} w_{j i} u_{j} d x+f_{T}{ }^{\prime}{ }_{k i} u_{k} d x\right. \\
& \left.+f_{T} w^{\prime}{ }_{j i} u_{j} d x\right)
\end{aligned}
$$


where the terms $f_{T}$ and $f_{D}$ are arbitrarily included to help account for nonuniform velocity and phase distributions in each subchannel for the turbulent and diversion momentum terms, respectively. These are used because the momentum intercharge from the cross-flows occur primarily near the gap where reduced velocities exist and phase distribution is unknown.

If Equations (A-1), (A-2), and (A-3) are combined with the above equation, we find

$$
\begin{aligned}
-\frac{d_{p}}{d x}= & \frac{F_{i}}{A_{i}}+\rho_{i} \cos \theta+\frac{f_{T^{W^{\prime}}}{ }^{\prime} k}{g_{C} A_{i}}\left(u_{i}-u_{k}\right)+\frac{f_{T^{W^{\prime}} i j}}{g_{C} A_{i}}\left(u_{i}-u_{j}\right) \\
& +\frac{w_{j i}}{g_{C} A_{i}}\left(2 u_{i}-f_{D^{\prime}} u_{j}\right)+\frac{w_{i k}}{g_{C} A_{i}} u_{i}\left(f_{D}-2\right) \\
& +\frac{1}{g_{C}}\left(\frac{m_{i}}{A_{i}}\right)^{2} \frac{d v^{\prime}{ }_{i}}{d x} .
\end{aligned}
$$

The frictional force along the subchannel wall is evaluated by using

$$
\frac{F_{i}}{A_{i}}=\frac{f_{i} \phi_{i}}{2 g_{C^{\rho} f^{D} D_{i}}}\left(\frac{m_{i}}{A_{i}}\right)^{2}, \theta_{i}
$$

where $\phi_{i}$ is a two-phase friction multiplier based on all-1iquid flow. The pressure drop component, due to density change, is evaluated from the equation of state that relates void fraction to enthalpy and pressure

$$
\alpha=\alpha(h, p) .
$$

With $v^{\prime}$ evaluated as

$$
v^{\prime}=\frac{(1-x)^{2}}{(1-\alpha) \rho_{f}}+\frac{x^{2}}{\alpha \rho_{g}},
$$


we may write

$$
\frac{d v_{i}}{d x}=\frac{\partial v^{\prime} i}{\partial p} \frac{d p_{i}}{d x}+\frac{\partial v^{\prime}{ }_{i}}{\partial h} \frac{d h_{i}}{d x} .
$$

By inserting Equations $(A-9)$ and $(A-12)$ into Equation (A-8) gives

$$
\begin{aligned}
& -\left[1+\frac{1}{g_{c}}\left(\frac{m_{i}}{A_{i}}\right)^{2}\left(\frac{\partial v^{\prime} i}{\partial p}\right)\right] \frac{d p_{i}}{d x}=\frac{f_{i}{ }^{\phi}}{2 g_{c}{ }^{\rho} f^{D}}\left(\frac{m_{i}}{A_{i}}\right)^{2}+\rho_{i} \cos \theta \\
& +\frac{1}{g_{c}}\left(\frac{m_{i}}{A_{i}}\right)^{2}\left(\frac{\partial v^{\prime} i}{\partial h}\right) \frac{d h_{i}}{d x}+\frac{f_{T^{h^{\prime}} i k}}{g_{c} A_{i}}\left(u_{i}-u_{k}\right) \\
& +\frac{f_{T}{ }^{\prime}{ }^{\prime} j}{g_{c} A_{i}}\left(u_{i}-u_{j}\right)+\frac{w_{j i}}{g_{c} A_{i}}\left(2 u_{i}-f_{D} u_{j}\right) \\
& +\frac{w_{i k}}{g_{C} A_{i}} u_{i}\left(f_{D}-2\right) \text {. }
\end{aligned}
$$

If we consider all possible subchannels connected to (i) and use the same sign convention for cross-flow as in the continuity and momentum equations, Equation $(A-13)$ reduces to

$$
\begin{gathered}
-\left[1+\frac{1}{g_{c}}\left(\frac{m_{i}}{A_{i}}\right)^{2} \frac{\partial v_{j}^{\prime}}{\partial p}\right] \frac{d p_{i}}{d x}=\frac{1}{g_{c}}\left(\frac{m_{i}}{A_{i}}\right)^{2}\left[\frac{f \phi_{i}}{2 \rho_{f} D_{i}}+\frac{\partial v_{i}}{\partial h} \frac{d h_{i}}{d x}\right] \\
+\rho_{i} \cos \theta+\frac{1}{g_{c}^{A}} \sum_{j=1}^{N} f_{T} w^{\prime}{ }_{i j}\left(u_{i}-u_{j}\right) \\
+\frac{1}{g_{c}{ }^{A}} \sum_{j=1}^{N}\left[w_{i j} w_{i j}\left(f_{D}-2\right) ; \text { if } w_{i j} \geq 0\right] \\
(A-14)
\end{gathered}
$$


Transverse Momentum

If we assume that significant cross-flow velocity only occurs in the gap between adjacent subchannels and that any cross-flow occurring in a subchannel has a small velocity compared to the axial velocity, then a transverse momentum equation may be written as

$$
p_{i}-p_{j}=C_{i j} w_{i j}\left|w_{i j}\right| \quad .
$$

The factor $C_{i j}$ is a loss function, which accounts for the transverse resistance to flow plus any other unrecoverable losses occurring. 
.

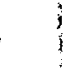

$\cdot$

$\cdot$

. 
APPENDIX B 


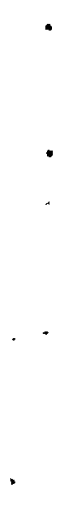


APPENDIX B

NUMERICAL SOLUTION TO MIXING EQUATIONS

Consider the continuity, energy, and momentum equations where $\Delta x$ is sufficiently small validate the approximations: Continuity

From Equation (12) write

$$
m_{i, x+\Delta x}=m_{i, x+\Delta x / 2}+\frac{\Delta x}{2} \frac{d m_{i, x+\Delta x}}{d x}
$$

where we have from initial conditions at $x$

$$
m_{i, x+\Delta x / 2}=m_{i, x}+\frac{\Delta x}{2} \frac{d m i, x}{d x} .
$$

The last term of Equation (B-1) is evaluated as updated values are obtained during iteration.

\section{$\underline{\text { Energy }}$}

From Equation (13) write

$$
h_{i, x+\Delta x}=h_{i, x+\Delta x / 2} * \frac{\Delta x}{2} \frac{d h_{i, x+\Delta x}}{d x}
$$

where we have from initial conditions at $x$,

$$
h_{i, x}+\Delta x / 2=h_{i, x}+\frac{\Delta x}{2} \frac{d h_{i, x}}{d x} .
$$

The last term in Equation (B-3) is evaluated by using updated values of $m_{i, x+\Delta x}$ as they are obtained during iteration. Momentum

From Equation (14) write

$$
p_{i, x+\Delta x}=p_{i, x+\Delta x / 2}-\frac{\Delta x}{2} \frac{d p_{i, x+\Delta x}}{d x}
$$




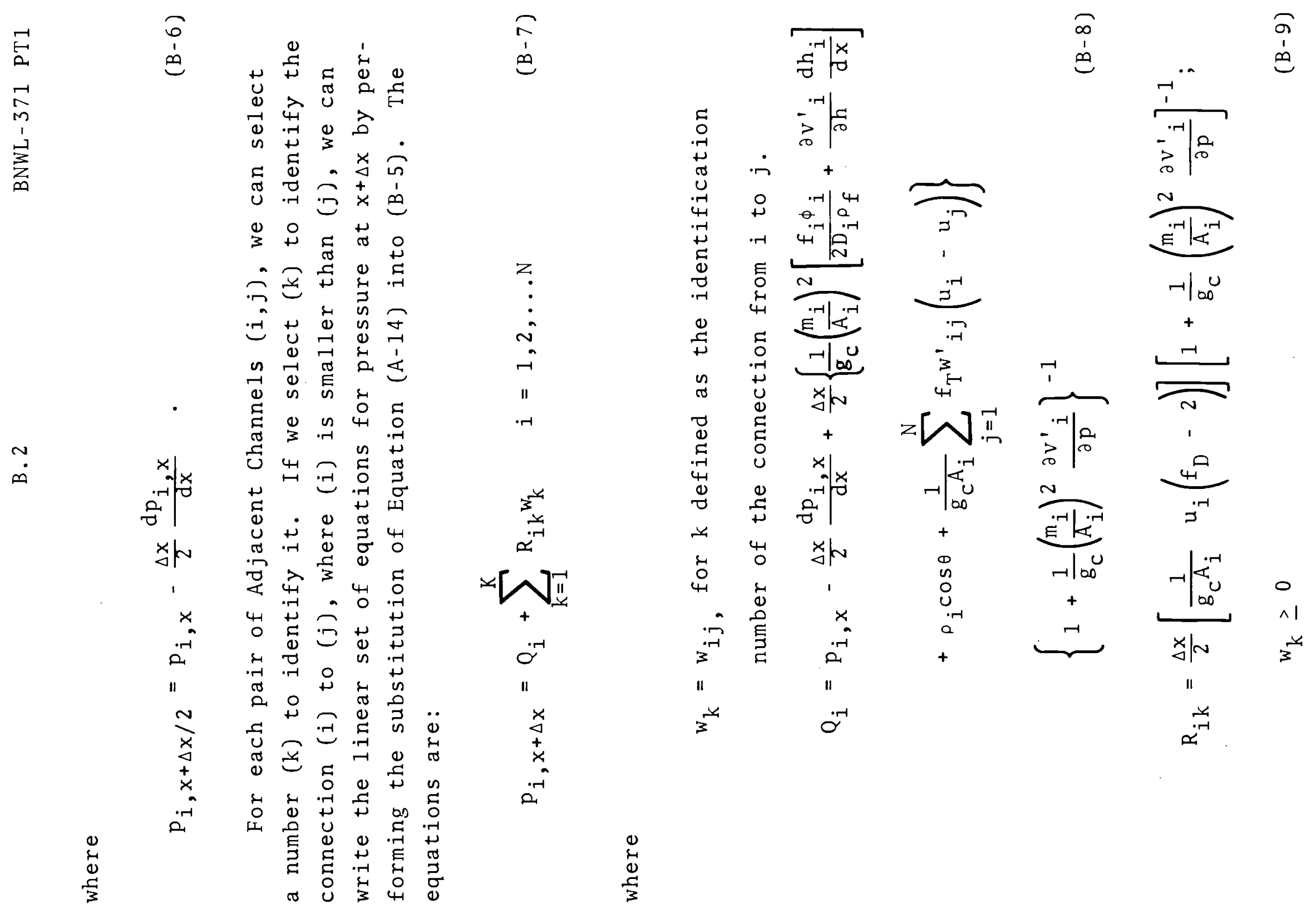


or

$R_{i k}=\frac{\Delta x}{2}\left[\frac{1}{g_{c} A_{i}}\left(f_{D} u_{j}-2 u_{i}\right)\right]\left[1+\frac{1}{g_{c}}\left(\frac{m_{i}}{A_{i}}\right)^{2} \frac{\partial v^{\prime} i}{\partial p}\right]^{-1} ;$ if $w_{k}<0(B-10)$

In the above equations for $Q_{i}$ and $R_{i k}$, the quantities are evaluated at $x+\Delta x$ as updated values become available after each iteration.

By selecting a Subchannel (i) and another Subchannel in the manner chosen to define $(\mathrm{k})$, we now can generate a new set of equations by subtraction,

$\left(p_{i}-p_{j}\right)_{x+\Delta x}=Q_{\ell}+\sum_{k=1}^{K} R_{\ell k} w_{k} \quad \ell=1,2, \ldots K$

where

$$
\begin{aligned}
Q_{\ell} & =Q_{i}-Q_{j} \\
R_{\ell k} & =R_{i k}-R_{i j},
\end{aligned}
$$

and ( $l$ ) is the subchannel connection number with the same definition as (k). From Equation (4), we may also write

$$
\left(P_{i}-P_{j}\right)_{x+\Delta x}=C_{\ell} W_{\ell}\left|W_{\ell}\right| . \quad \ell=1,2, \ldots K
$$

Combining Equations $(B-11)$ and (B-14) for each value of ( $($ ) gives

$$
\sum_{\mathrm{k}=1}^{\mathrm{K}} \mathrm{R}_{\ell \mathrm{k}^{\mathrm{w}} \mathrm{k}}-\left.\mathrm{C}_{\ell} \mathrm{w}_{\ell}\right|^{\mathrm{W}} \mid+\mathrm{Q}_{\ell}=0 . \ell=1,2, \ldots \mathrm{K}
$$

This is a nonlinear set of simultaneous equations with (K) equations and ( $K$ ) unknowns-the diversion cross-flows. An 
iterative solution to these equations is made by solving a set of linear equations with the method of Crout. (24) The linear set consists of

$\sum_{k=1}^{\ell-1} R_{\ell k} w_{k}+\left(R_{\ell \ell}-C_{\ell}\left|w_{\ell}\right|\right) w_{\ell}+\sum_{k=\ell+1}^{K} R_{\ell k} w_{k}+Q_{\ell}=0 . \ell=1,2, \ldots K(B-16)$

The term $C_{\ell}\left|w_{\ell}\right|$ is evaluated by using the presently known value of $w_{\ell}$. Solution of the set of Equations (B-16) gives an updated value for $w_{\ell}$ which is used in the next iteration to correct a previous estimate of $\mathrm{C}_{\ell}\left|\mathrm{w}_{\ell}\right|$. Iteration is continued until all the new and old values of $w_{\ell}$ have converged to suitable values.

Solutions to the set of equations (B-16) were found to be very sensitive to the coefficients. Matrix inversion was initially used to solve the equations but was found unsuitable because of large errors. The Crout (24) method was found to be satisfactory if the number of significant figures required to balance the set of Equations (B-16) was not excessive. Accuracy to a few figures (presently 4) was found to be sufficient since additional significant figures did not cause significant improvement in the accuracy of the solution.

The problem with the solution of the Equations (B-16) is that they are "ill-conditional" for certain types of problems. For example, in a square rod array with zero cross-flow resistance $\left(C_{\ell}=0\right)$ and all subchannel conditions equal, the equations are homogeneous and any value of division cross-flow satisfies them. This produces uncontrolled transverse flow loops around fuel rods. Including cross-flow resistance helps considerably by modifying the time $\left(R_{\ell \ell}-C_{\ell}\left|w_{\ell}\right|\right)$ in Equation (B-16) and thus reducing the "ill-condition." This permits realistic solutions that do not allow transverse flow loops. 
Initial calculations were carried out by using the new value of diversion cross-flow for the updating quantities for the next iteration. This gave a slowly converging oscillating solution for the cross flows. To improve the convergence, a reduced value of the updated cross-flow was used.

$$
\mathrm{w}_{\mathrm{k}}=0.6\left(\mathrm{w}_{\mathrm{k}}\right)_{\mathrm{New}}+0.4\left(\mathrm{w}_{\mathrm{k}}\right)_{\mathrm{old}} .
$$

Equation (B-17) reduces the new cross flow if it changes very much from the old value. 
$\cdot$ 
APPENDIX C 


\section{APPENDIX C \\ DIGITAL COMPUTER PROGRAM CORRELATIONS}

To carry out a solution, several correlations have been assumed in the computer program. Although others could have been used, these appear to be satisfactory for the present time.

\section{Friction Factor}

The friction factor correlation is based upon that of Koos $(25)$ and is of the form

$$
f_{i}=a\left(R_{e_{i}}\right)^{b}+c
$$

where $a, b$, and $c$ are specified constants.

Two-Phase Friction Multiplier

Increases in the friction pressure gradient from twophase flow are accounted for by using the Armand ${ }^{(26)}$ friction multiplier ( $\phi)$ which is the ratio of the pressure gradient for two-phase flow to that for all-liquid flow.

$$
\begin{array}{ll}
\phi=1.0 & \mathrm{~h} \leq \mathrm{h}_{\mathrm{f}} \\
\phi=\frac{(1-x)^{2}}{(1-\alpha)^{1.42}} & 0.39<(1-\alpha) \leq 1.0 \\
\phi=0.478 \frac{(1-x)^{2}}{(1-\alpha)^{2.2}} & 0.1<(1-\alpha) \leq 0.39 \\
\phi=1.730 \frac{(1-x)^{2}}{(1-\alpha)^{1.64}} & 0 .<(1-\alpha) \leq 0.1
\end{array}
$$

Void Fraction

The relationship between void fraction and enthalpy and pressure represents the equation state. The program uses the Armand ${ }^{(26)}$ void correlation as modified by Massena. 

$\alpha=1.0$
$\mathrm{h} \leq \mathrm{h}_{\mathrm{f}}$
$\alpha=\frac{(0.833+0.167 X) X v_{g}}{(1-X) v_{f}+X v_{g}}$
$\mathrm{h}>\mathrm{h}_{\mathrm{f}}$

Turbulent Cross-Flow

The turbulent cross-flow for two-phase flow is assumed to have a form similar to that for single-phase flow; i.e., the turbulent cross-flow per unit area is some fraction of the axial flow rate per unit area. Since an adjacent channel may be flowing at a different mass velocity, the average is assumed to be the turbulent cross-flow between the two channels.

$$
w^{\prime}{ }_{i j}=\frac{1}{2} B S_{i j}\left(\frac{m_{i}}{A_{i}}+\frac{m_{j}}{A_{j}}\right) \text {. }
$$

\section{Loss Function for Transverse Momentum}

For purposes of obtaining an estimate on the transverse flow resistance, a simple friction model is used. If we assume the gap is a slot of spacing $S$ and $\ell$ wide, the loss function is

$$
C_{i j}=\frac{f \ell}{4 g_{c} s^{3} j^{\rho} i}
$$

The product $f \ell$ is an arbitrary friction constant that is input to the problem. The density $\rho_{i}$ is taken in lieu of a two-phase friction multiplier for the transverse two-phase flow.

Power Distribution

The heat input per unit length of channel is the sum of al1 such inputs from fuel rods adjacent to the subchanne1. The Heat Transfer ( $q^{\prime}{ }_{r}$ ) from a Rod ( $r$ ) to a Subchannel (i) is given by 


$$
q^{\prime}{ }_{r i}=\bar{q}^{\prime \prime} \pi D_{r} f_{C} f_{R} f_{A}(x / L)
$$

where

$$
\int_{0}^{1} f_{A}(x / L) d(x / L) \equiv 1
$$

The sum of the heat inputs from rods adjacent to Subchannel is the total heat input per unit length $\left(q_{i}\right)$.

Fluid Properties

Fluid properties are obtained from a linear interpolation of the table of input properties. The terms $\partial v^{\prime}{ }_{i} / \partial p$ and $\partial v^{\prime}{ }_{i} / \partial h$ are evaluated

as

$$
\frac{\partial v^{\prime}{ }_{i}}{\partial p}=\left(\frac{v^{\prime} i, p+\Delta p-v^{\prime}{ }_{i, p}}{\Delta p}\right)_{h},
$$

and

$$
\frac{\partial v^{\prime}{ }_{i}}{\partial h}=\left(\frac{v^{\prime}{ }_{i, h+\Delta h}-v^{\prime}{ }_{i, h}}{\Delta h}\right)_{p}
$$

where

$$
v^{\prime}{ }_{i} \text { is evaluated from equation }(A-11) .
$$


. 
APPENDIX D 


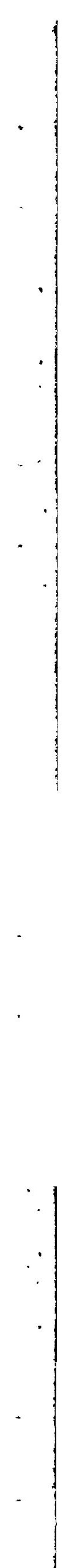




\section{APPENDIX D}

DIGITAL COMPUTER PROGRAM SAMPLE PROBLEM

A section of symmetry from a 19 rod bunde will be used for a sample problem to illustrate how it is set up and input to the computer program. The section of symmetry from a 19 rod bundle consisting of three fuel rods and five subchannels will be used for the problem (Figure 2). Dimensions and power distribution are shown in the tabulations. For the calculations, we will assume that the quantities $f_{T}$ and $f_{D}$ are equal to 1.0 . The cross-flow resistance constant is assumed to be 0.001 , and the mixing parameter $\beta$ is assumed to be 0.04 .

$$
\begin{aligned}
\text { Operating Conditions for the sample problem are: } & \\
\text { Average heat flux } & =0.4 \times 10^{6} \mathrm{Btu} / \mathrm{hr}-\mathrm{ft}^{2} \\
\text { Average mass velocity } & =1.0 \times 10^{6} \mathrm{~b} / \mathrm{hr}-\mathrm{ft}^{2} \\
\text { System pressure } & =1000 \mathrm{psia} \\
\text { Inlet enthalpy } & =400 \mathrm{Btu} / 1 \mathrm{~b} \\
\text { Channel length } & =60 \mathrm{in} .
\end{aligned}
$$

\section{Channel Geometry (a)}

$\begin{array}{cccc}\text { Channe1 } & \begin{array}{c}\text { Area } \\ \text { in.2 }\end{array} & \begin{array}{c}\text { Wetted } \\ \text { Perimeter, } \\ \text { in. }\end{array} & \begin{array}{c}\text { Heated } \\ \text { Perimeter, } \\ \text { in. }\end{array} \\ 2 & 0.027 & 0.442 & 0.442 \\ 3 & 0.083 & 0.884 & 0.884 \\ 4 & 0.027 & 0.442 & 0.442 \\ 5 & 0.064 & 0.935 & 0.516 \\ & 0.064 & 0.935 & 0.516\end{array}$

\footnotetext{
(a) Rod diameter $\quad=0.563$ in.; Rod spacing $\quad=0.080 \mathrm{in}$. ; Rod-to-Wall spacing $=0.080 \mathrm{in}$.
} 
Rod Flux Distribution (b)

\begin{tabular}{|c|c|c|c|c|c|c|}
\hline \multirow[b]{2}{*}{ Rod } & \multirow{2}{*}{$\begin{array}{l}\text { Relative } \\
\text { Power } \\
\end{array}$} & \multicolumn{3}{|c|}{ Fraction of } & \multicolumn{2}{|c|}{ Channels } \\
\hline & & 1 & 2 & 3 & 4 & 5 \\
\hline 1 & 1.0 & 0.0833 & - & - & - & - \\
\hline 2 & 1.0 & 0.1667 & 0.2500 & 0.0833 & - & - \\
\hline 3 & 1.0 & - & 0.2500 & 0.1667 & 0.2916 & 0.2916 \\
\hline
\end{tabular}

(b) Uniform axial flux distribution.

INPUT LISTING FOR SAMPLE PROBLEM

30

\begin{tabular}{|c|c|c|}
\hline 50 & 281.01 & .0173 \\
\hline 100. & 327.81 & .0177 \\
\hline 150. & $358 \cdot 42$ & .0181 \\
\hline 200. & 381.79 & . $\cup 184$ \\
\hline 250 & $400 \cdot 95$ & .0187 \\
\hline 300. & 417.33 & .0189 \\
\hline $\begin{array}{l}350 . \\
400\end{array}$ & $\begin{array}{l}431.72 \\
444.59\end{array}$ & .0191 \\
\hline 440 & 454.02 & .0195 \\
\hline 480 & 462.82 & .0157 \\
\hline 520. & 471.07 & . ט \\
\hline 560. & 478.85 & .0200 \\
\hline 600. & $486 \cdot 21$ & .0201 \\
\hline 640. & 483.21 & $.0<03$ \\
\hline 680 & 499.88 & .0204 \\
\hline 720 & $5 \cup 6.25$ & $.0<06$ \\
\hline 760. & $512 \cdot 36$ & .0207 \\
\hline 800 & 518.23 & .0209 \\
\hline 840. & 523.88 & .0210 \\
\hline 880. & 529.33 & - $\cup \angle 12$ \\
\hline 920. & $534 \cdot 2 y$ & - $U<13$ \\
\hline 960. & 539.68 & .0214 \\
\hline 1000 & 544.61 & $.0<10$ \\
\hline $1 \cup 5 \cup$ & $5 b c .57$ & - $0<16$ \\
\hline 1100 & $256 \cdot 31$ & $.0 \angle 20$ \\
\hline 1150. & 501.80 & $.0 \angle \angle 1$ \\
\hline 1200 & 507.22 & .0223 \\
\hline 1250 & $572 \cdot 42$ & $.0 \angle \angle b$ \\
\hline 1300 & $577 \cdot 46$ & .0227 \\
\hline 1350. & $582 \cdot 32$ & .0229 \\
\hline
\end{tabular}
4.4320

3.0150

2.2880

1.8438

1.5433

1.3260

1.1613

1.0556

.$\$ 670$

.8915

.8265

.7698

.7198

.6757

.0362

.6007

.5687

.5390

.2130

.4886

.4663

.4450

$.4 \angle 10$

.4001

.3802

- 3015

.3450

. 3293

. 3148

11111111 SAMPLE PROBLEM

\begin{tabular}{|c|c|c|}
\hline $250 \cdot 1$ & 1174.1 & .491 \\
\hline 298.4 & 1187.2 & .410 \\
\hline 330.5 & 1194.1 & .369 \\
\hline $\begin{array}{l}355.4 \\
376.0 \\
393.8\end{array}$ & $\begin{array}{l}1198.4 \\
1201.1 \\
1202.8\end{array}$ & $\begin{array}{r}.345 \\
.326 \\
.313\end{array}$ \\
\hline $\begin{array}{l}409.7 \\
424.0\end{array}$ & $\begin{array}{l}1203.9 \\
1204 \cdot 5\end{array}$ & $\begin{array}{l}.301 \\
.290\end{array}$ \\
\hline 434.6 & 1204.6 & .283 \\
\hline $444 \cdot 6$ & 1204.5 & .278 \\
\hline $454 \cdot 1$ & $1204 \cdot 2$ & .273 \\
\hline 463.0 & 1203.8 & .269 \\
\hline $471 \cdot 6$ & 1203.6 & .264 \\
\hline 479.6 & $1<02 \cdot 5$ & .260 \\
\hline 487.7 & 1201.7 & .255 \\
\hline $495 \cdot 3$ & $1<00.7$ & .252 \\
\hline $302 \cdot 6$ & 1199.7 & .248 \\
\hline $509 \cdot 7$ & 1198.6 & .245 \\
\hline$=16 \cdot 6$ & 1197.4 & - $\angle 42$ \\
\hline 523.3 & 1196.1 & .240 \\
\hline 229.8 & 1154.7 &.$<37$ \\
\hline $536 \cdot 2$ & 1193.3 & .234 \\
\hline $542 \cdot 4$ & I1S1.8 & .232 \\
\hline 200.0 & $116 \vartheta \cdot 9$ & .229 \\
\hline 557.4 & 1107.8 & .226 \\
\hline 264.6 & 1105.6 & .223 \\
\hline 271.7 & 1183.4 & .221 \\
\hline 578.6 & 118.1 .0 & .219 \\
\hline 280.4 & 2178.6 & .217 \\
\hline$b y z \cdot 1$ & 1176.1 & .215 \\
\hline
\end{tabular}

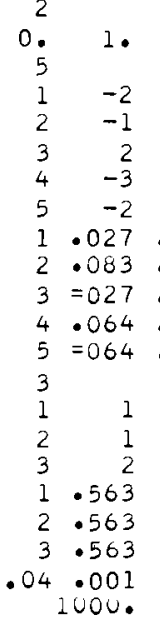

$$
\begin{array}{rrr}
1 . & 1 . & \\
& & \\
0 & 0 & 0 \\
3 & -5 & 0 \\
-4 & 0 & 0 \\
5 & 0 & 0 \\
4 & 0 & 0 \\
442 & .442 & .08 \\
834 & .084 & .08 \\
442 & .442 & .08 \\
935 & .516 & .08
\end{array}
$$

.08
.08 .08

.08
.08

.08 .08

.08
.08

0
.08
0
0
0

0
0
0
0
0

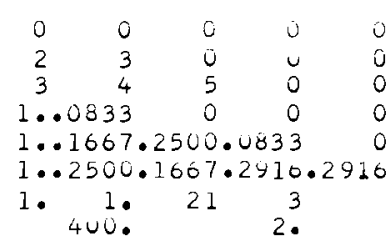

0

$\begin{array}{ll}0 & 0 \\ 0 & 0 \\ 0 & 0\end{array}$

.4

60. 
FLUID PROPERTY TALLE

\begin{tabular}{|c|c|c|c|c|c|c|}
\hline$P$ & $\mathbf{T}$ & VF & VG & HF & $H E$ & VISC \\
\hline 50.0 & 281.01 & .0173 & 8.5150 & 250.1 & 1174.1 & .4910 \\
\hline 100.0 & 327.81 & .0177 & 4.4320 & 298.4 & 1187.2 & .4100 \\
\hline 150.0 & 358.42 & .0181 & 3.0150 & 330.5 & 1194.1 & .3690 \\
\hline 200.0 & 381.79 & .0184 & 2.2880 & $3\llcorner 5.4$ & 1198.4 & .3450 \\
\hline 250.0 & 400.95 & .0187 & 1.8438 & 376.0 & 1201.1 & .3260 \\
\hline 300.0 & 417.33 & .0189 & 1.5433 & 393.8 & 1202.8 & .3130 \\
\hline 350.0 & 431.72 & .0191 & 1.3260 & 409.7 & 1203.9 & .3010 \\
\hline 400.0 & 444.59 & .0193 & 1.1613 & 424.0 & 1204.5 & .2900 \\
\hline 440.0 & 454.02 & .0195 & 1.0556 & 434.6 & 1204.6 & .2830 \\
\hline 480.0 & 462.82 & .0197 & .9670 & $444 \cdot 6$ & $1204 \cdot 5$ & .278 \\
\hline 520.0 & 471.07 & .0198 & .8915 & 454.1 & 1204.2 & .273 \\
\hline $500 \cdot 0$ & 478.85 & .0200 & .8265 & 463.0 & 1203.8 & .269 \\
\hline $600 \cdot 0$ & 486.21 & .0201 & .7698 & 471.6 & 1203.6 & .264 \\
\hline $640 \cdot 0$ & 493.21 & .0203 & .7198 & 479.8 & 1202.5 & .260 \\
\hline 680.0 & 499.88 & .0204 & .6757 & 407.7 & 1201.7 & .255 \\
\hline 720.0 & 506.25 & .0206 & .6362 & 495.3 & 1200.7 & .252 \\
\hline 700.0 & 512.36 & .0207 & .6007 & 502.6 & 1199.7 & .248 \\
\hline 300.0 & 518.23 & $.0<09$ & .5687 & 509.7 & 1198.6 & .245 \\
\hline 040.0 & 523.88 & .0210 & .5396 & 516.6 & 1197.4 & .242 \\
\hline 880.0 & 529.33 & .0212 & .5130 & 523.3 & 1196.1 & .240 \\
\hline 920.0 & 534.59 & .0213 & .4886 & 529.8 & 1194.7 & .237 \\
\hline 960.0 & 539.68 & .0214 & .4663 & 536.2 & 1193.3 & .234 \\
\hline 1000.0 & 544.61 & .0216 & .4456 & 542.4 & 1191.8 & .232 \\
\hline 1ubo.0 & 550.57 & .0218 & .4218 & 550.0 & 1189.9 & .229 \\
\hline $1200 \cdot 0$ & 556.31 & .0220 & .4001 & 557.4 & 1187.8 & .226 \\
\hline 1150.0 & 561.86 & .0221 & .3802 & 564.6 & 1185.6 & .223 \\
\hline $1<00 \cdot 0$ & 567.22 & .0223 & .3619 & 571.7 & 1183.4 & .221 \\
\hline 1250.6 & 572.42 & .0225 & .3450 & 578.6 & 1181.0 & .219 \\
\hline 1340.0 & 577.46 & .0227 & .3293 & 585.4 & 1178.6 & .217 \\
\hline 1350.0 & $58<.35$ & .0229 & .3148 & 592.1 & 1176.1 & .215 \\
\hline & & & & & & \\
\hline
\end{tabular}


울
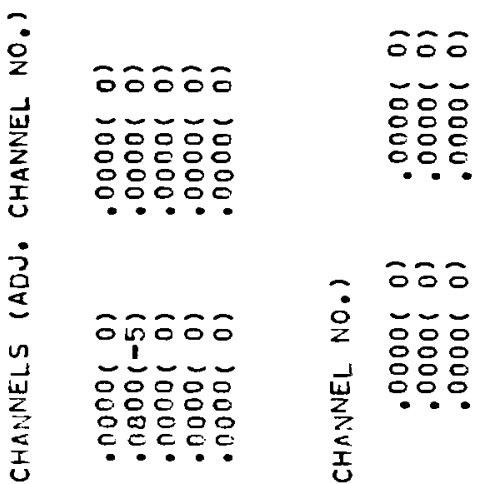

苫 jên

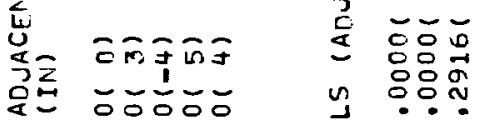

岁

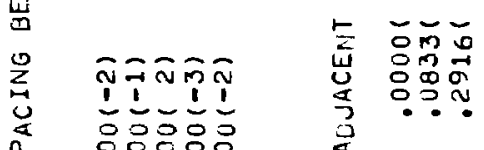

出

웅

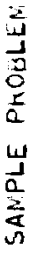

บ :

○ลักิ

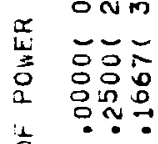

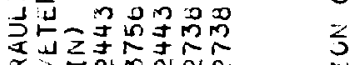

西要

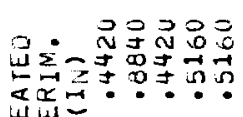

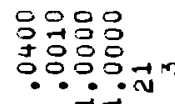

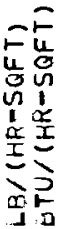

㟧㟧

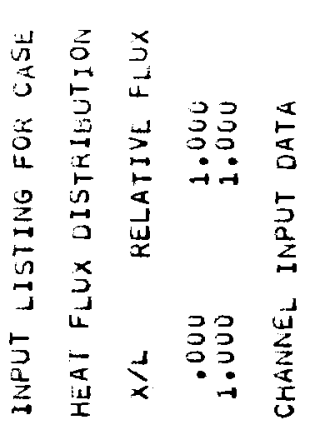

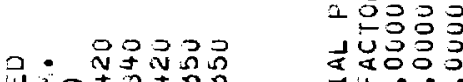

๓ก̃

0.0

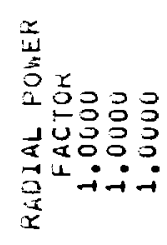

$-x_{0}=0.0 \%$

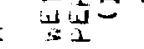

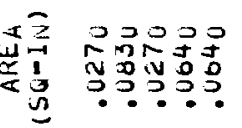
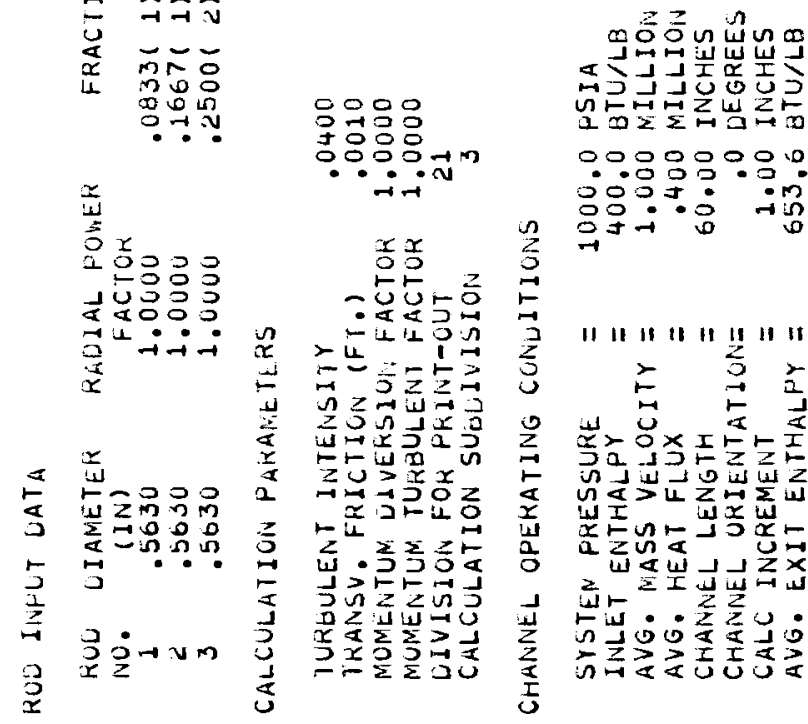

0009000.

영ำ

3

| 11 | " | | || |

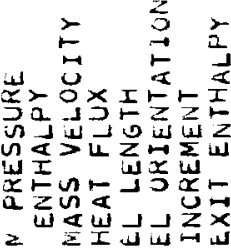

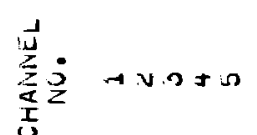

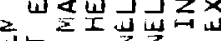

出

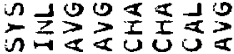




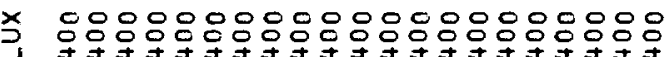

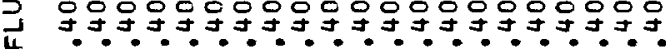

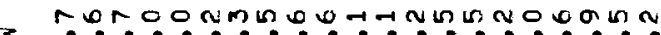
- An

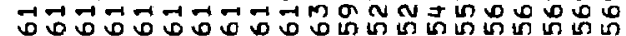

ดี-

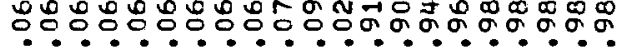
w

山

岳

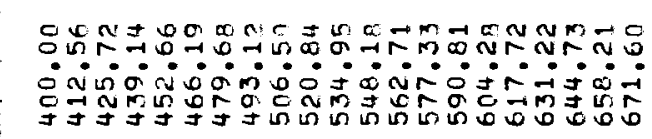

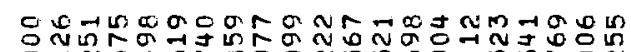

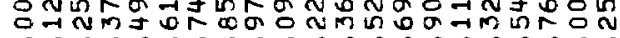
$\frac{x}{\alpha}$

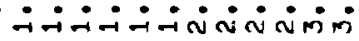

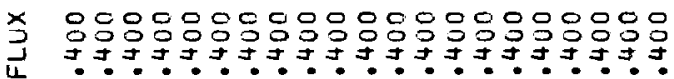

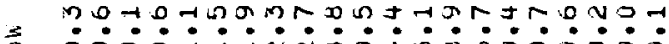

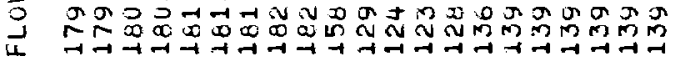

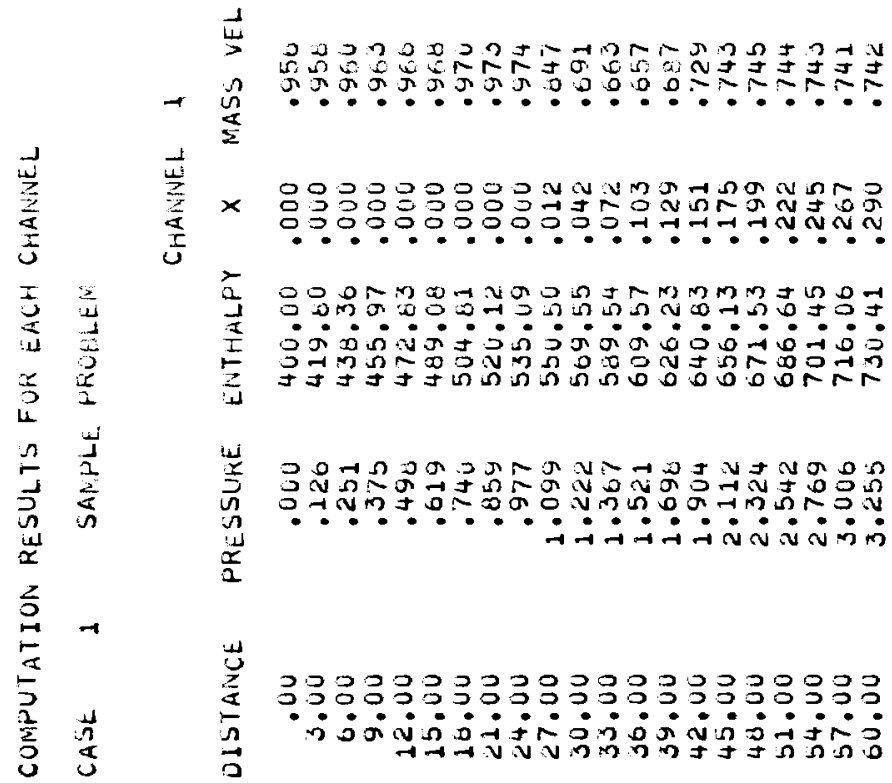




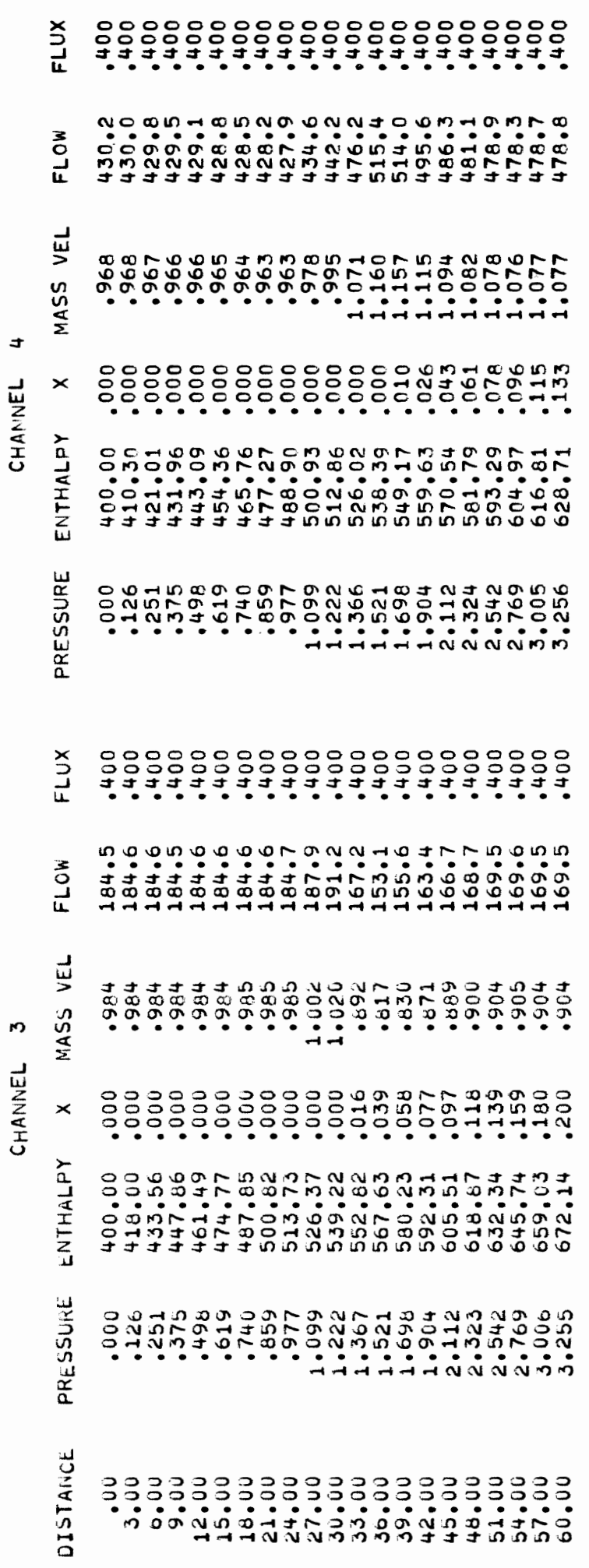




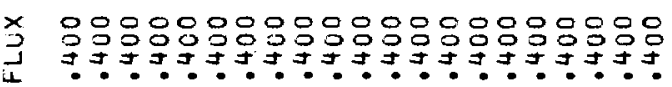

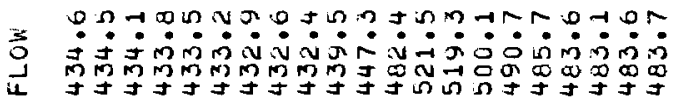

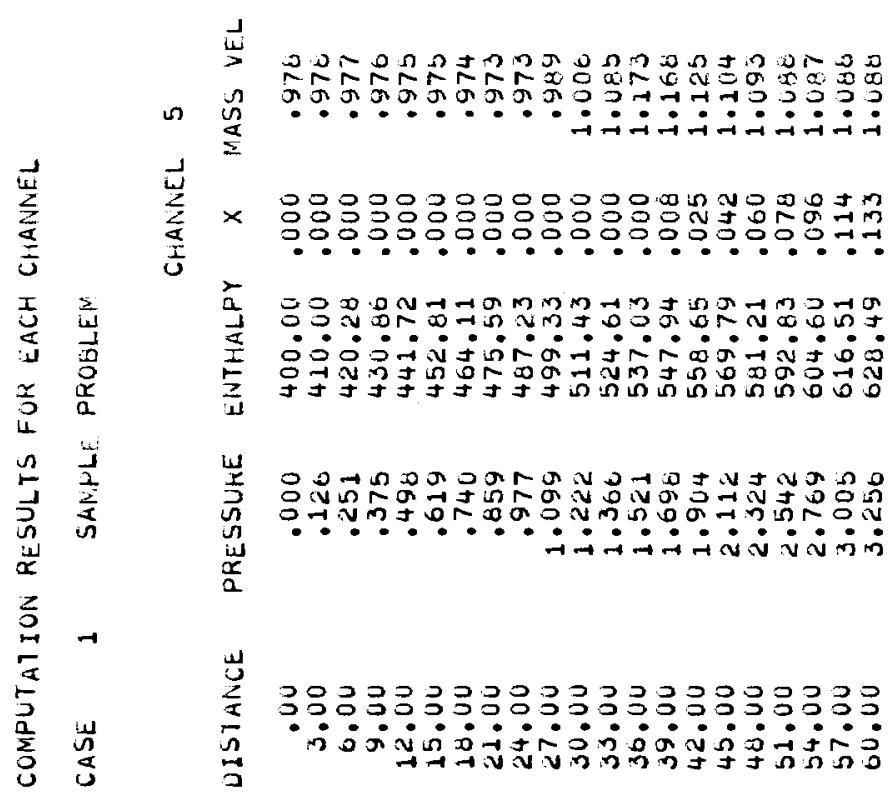



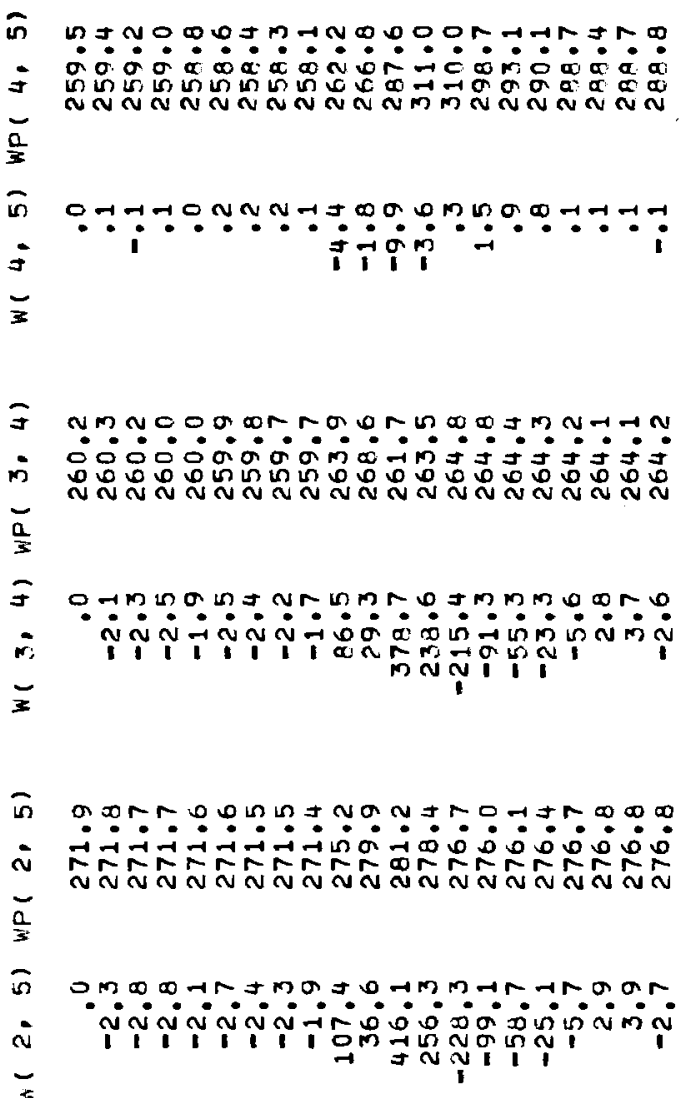

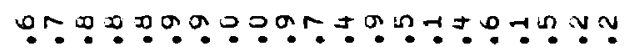
ivivising

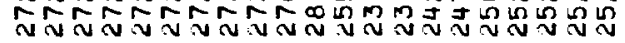
范

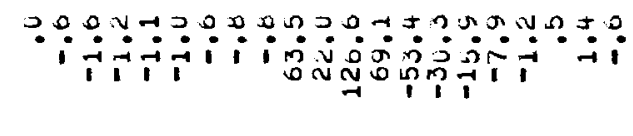

onoomnotomadn

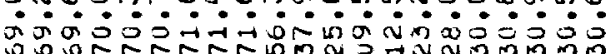

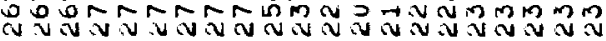

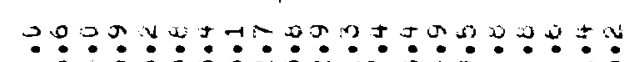

की

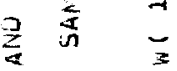




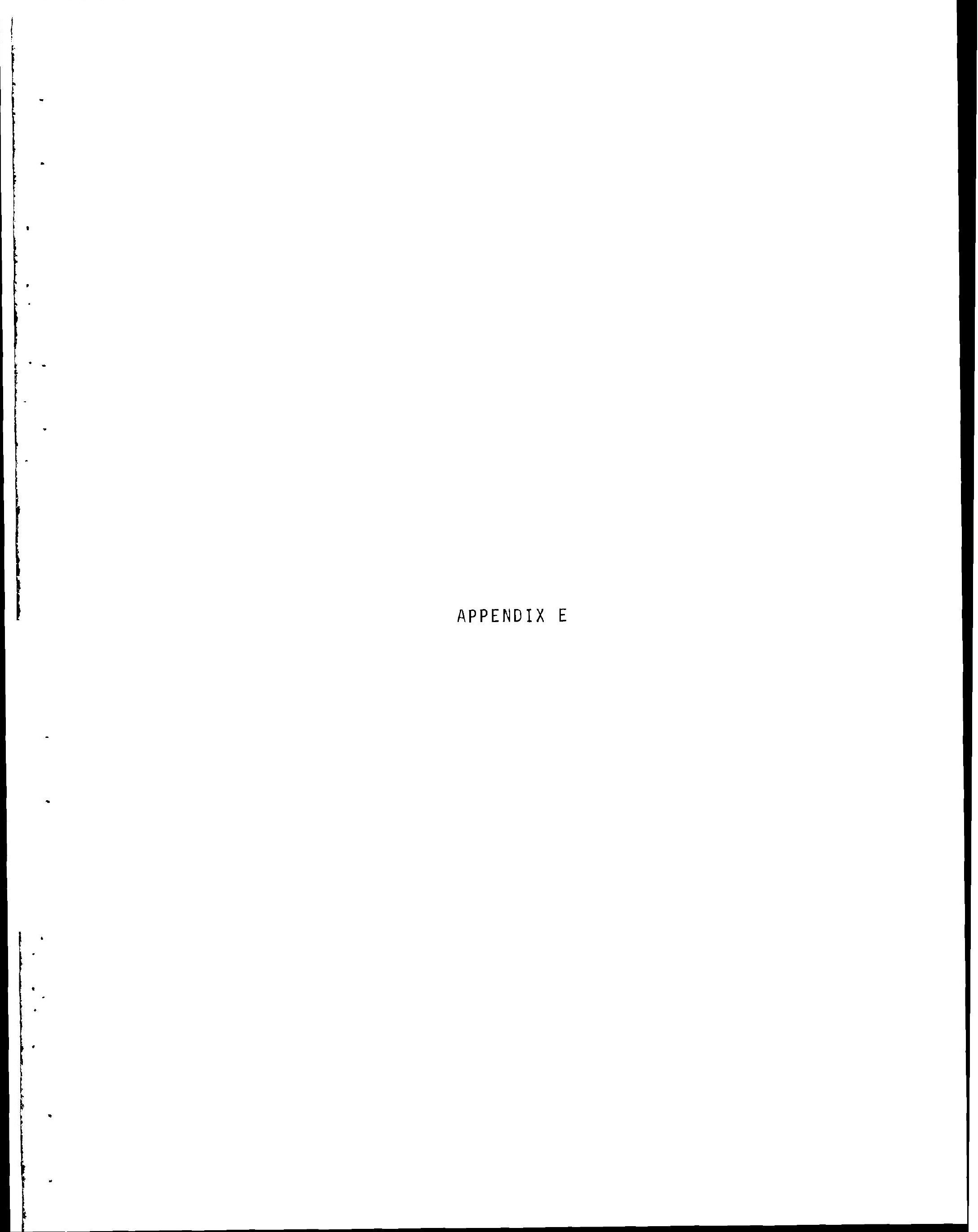




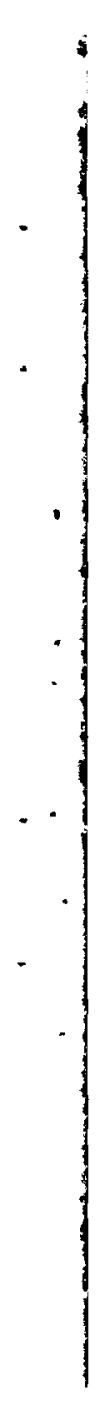

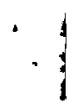

1
.1

$\cdot$

-

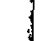


APPENDIX E

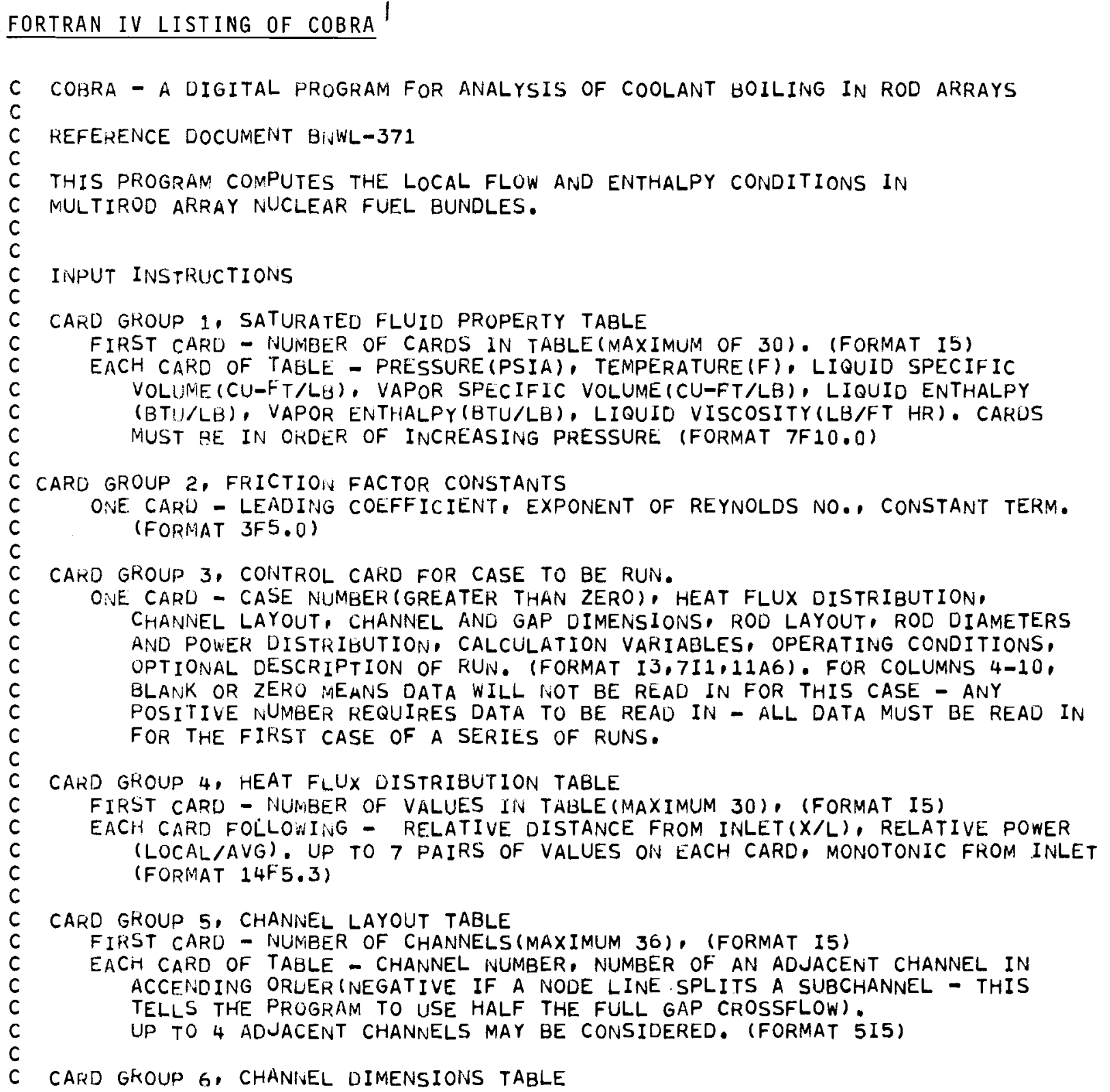




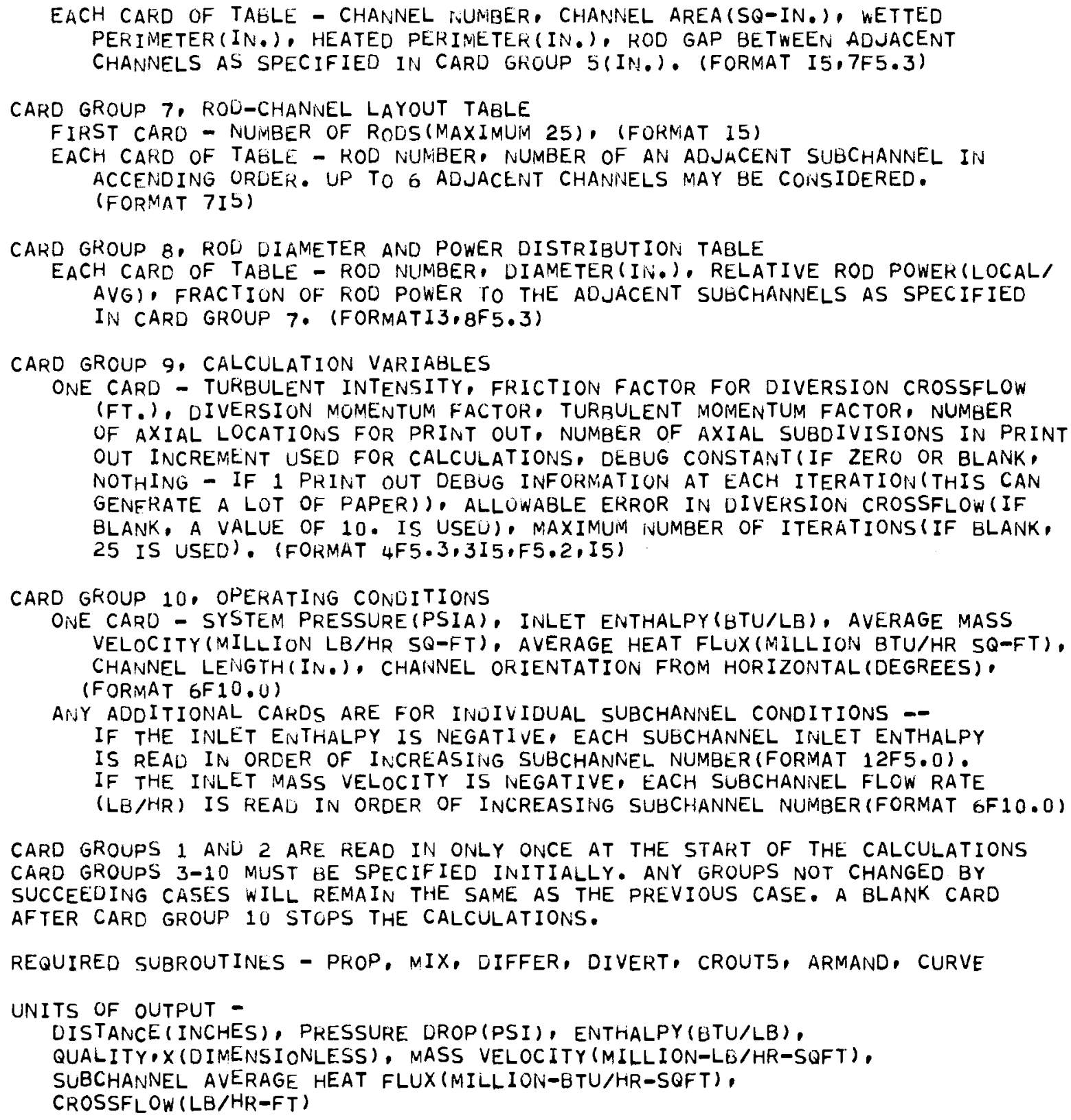


DIMENSION TEXT(11), DHYUE $(36)$, KKOD $(36,25), \operatorname{LC}(36,4), L R(25,6)$, IS $(36,4)$, PHI $(25,0)$, PWRF (36, 25), RADIAL (25), D (25), PERIM(36), IHPERIM (36), AC (36), PVi $(36), \mathrm{PH}(36)$, DR $(25), D C(36)$, WOLL $(60)$

DIMEINSION PV $(30,31)$, HV $(36,31), F V(36,31), Q V(36,31), X V(31)$, ¿FLOW $(36,31)$, QUALTY $(36,31)$, HEAD $(4,60)$, WV $(60,31)$, WPV $(60,31)$ COMVION /BTEL/ PP(30),TT (30), VVF (30), VVG $(30)$, HHF (30), HHG $(30)$, 1 UUF (30), HH (26), OVPDPP(25),NPROP.LPROP

COMMON /BPROP/ RHHU(36), V(36), VP(36), DVPLP (36), DVPLH(36), VISC (36), 1 PREF, QUAL (36), ALPHA (36), VF, VG,T(36)

COMMON /BEQN/ AAA $(60.01)$.W $(60)$

COMINON / RMIX/ WP( 60$), U(36), P(36,2), H(36,2), F(36,2), A(36), G A P(60)$, $1 X(2), B E T A, X M I X, F D I V, F M I X, C(60), D F(36), D H(36), D P(36), D X, D H Y O(36)$, 1QPRIM(36), AFLUX,Z, KCHAN $(36,36)$, AXIAL $(30), Y(30), A Q P R I M(36), A A$, $1 B B, C C, T H E T A, N A X, F A C T O K(60)$, IK $(60), J K(60), P I, G$ COMNON/RCOM/ I 3 , NCHANL, NK, IERROR, KDEBUG,N DATA $\left(H E_{A O}(I, I), I=1,60\right) / 60 * 6 \mathrm{Hi} \quad w\left(/,\left(H E_{A D}(2, I), I=1,60\right) / 60 * 1 \mathrm{H}, /\right.$, C $I(H E A D(3, I), I=I, 60) / 60 * 5 H)$ WP $(/,(H E A D(4, I), I=1,60) / 60 * 1 H)$ /

1 FORMAT (I5/(7F10.5))

2 FORIVAT (I3,7I1,1IAG)

3 FORMAT ( 3 HIINPUT LISTING FOR CASE I6.5X 11A6)

5 FORMAT (I5/(14F5.3))

6 FORMAT (23HOHEAT FLUX DISTRIBUTION //23H X/L RELATIVE.FLUX// $1(F 7 \cdot 3 \cdot F \perp 2.3))$

7 FORMAT (I5) (7IS))

3 FORMAT ( I5 / (5I5))

9 FORIMAT $(6 F 10.0)$

10 FORMAT $(12 F 5.0)$

11 FORIAT $($ I $5,7 F 5,3)$

12 FURMATI I 9 HOCHANIAEL IMPUT DATA // 11 OSHI CHANNINEL AREA WETTED HEATED HYORAULIC ROD SPACIN IG BETWEEN AOJACENT CHANNELS (ADU. CHANNEL NO.)
$176 \pi$ NO. (SU-IN) PERIM. PERIM. OLAMETER $176 \pi$ NO. (IN) $1 / 46 H$
IF $14.4 .1 H(I 2,1 H) F 10.4 .1 H(I 2,1 H) F 10.4,1$

13 FORMAT (22HIFLUID PROPERTY TAGLE // $168 H$ P V $P$ VF $V$ HF HG

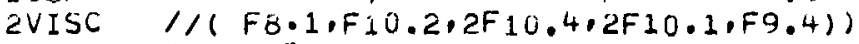

14 FORMAT (I5,8F5.3)

15 FORIIAT(15HOROD INPUT LATA // 96H KOD DIAMETER RAOIAL POWER 1 FRACTION OF POWER TO ADUACE HT CHANHELS (ALJ. CHANNEL IVO.) I $30 \mathrm{H} N \mathrm{NO}$ (IN) FACTOR/(IS,F9.4,F13.4,F11.4.1H(I2,

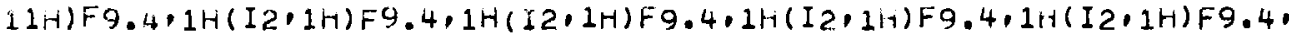
11 in(12,1H)))

17 FORIAT ( 4F5.3,3IS.F5.2,I5)

18 FORMAT (23HOCALCULAIION PARAMETERS //

$128 \mathrm{H}$ TURBULENT INTENSITY FB.4 /

$228 \mathrm{H}$ TRANSV. FRICTION (FT.) FB.4, 


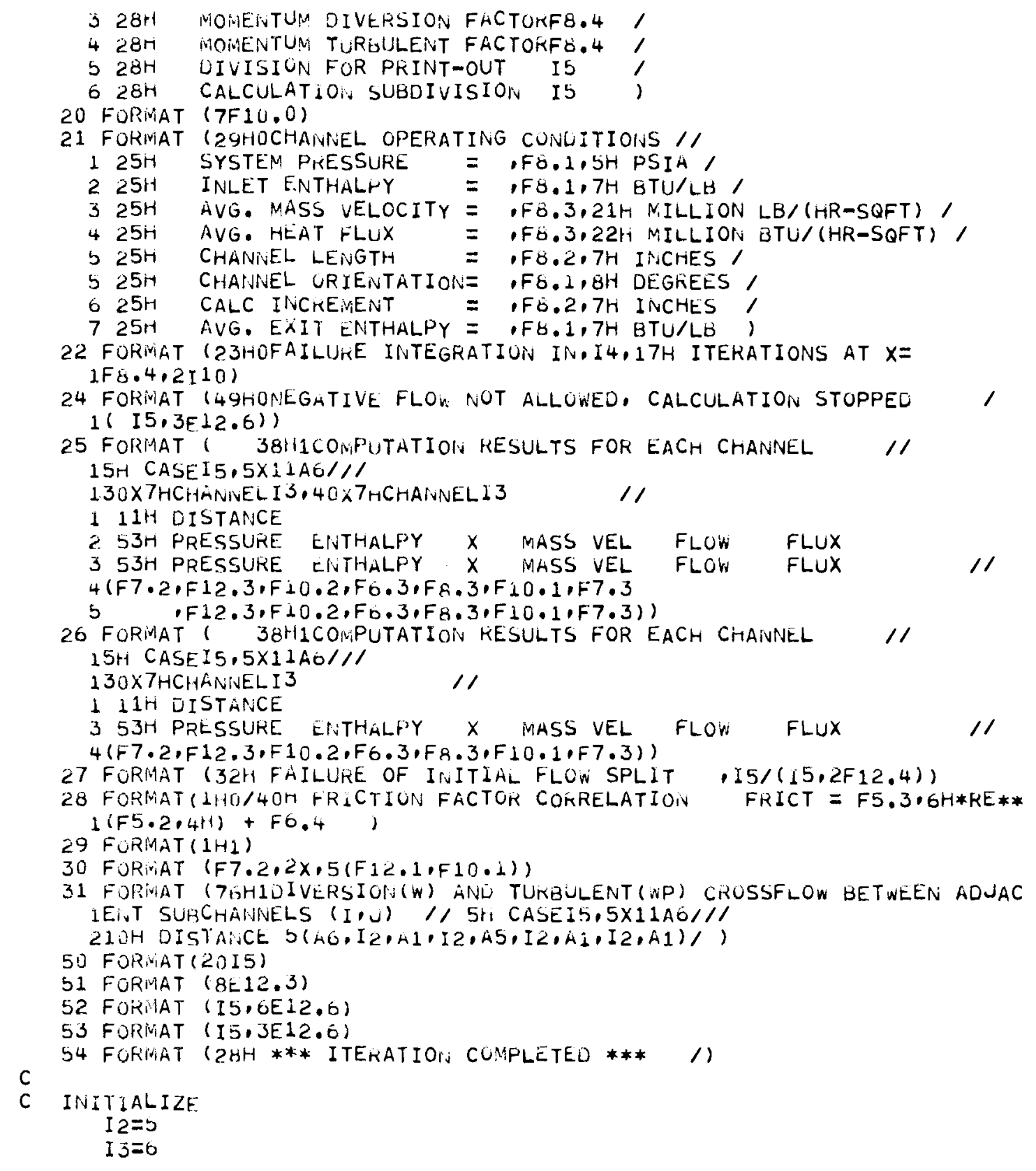




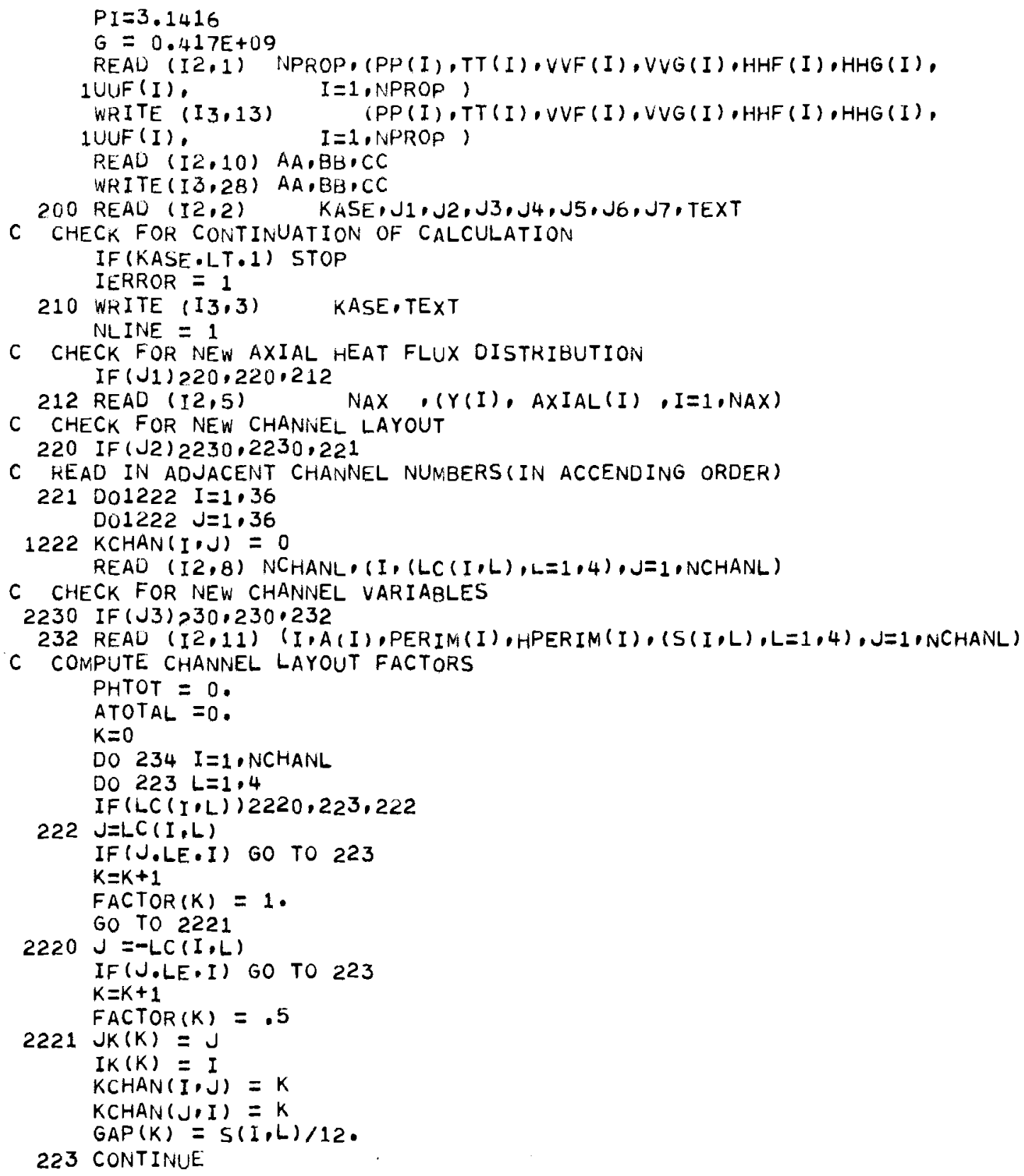


$\operatorname{PW}(I)=\operatorname{PERIM}(I)$

PERIM(I) $=$ PERIM(I) 12 .

$\operatorname{Pri}(I)=\operatorname{HPERIM}(I)$

HPERIM(I) =HPERIM(I)/12.

$A C(I)=A(I)$

$A(I)=A(I) / 144$.

DHYD (I) $=4 . * A(I) / P E R I M(I)$

$D C(I)=D H Y D(I) * 12$.

PHTOT $=$ PHTOT + HPERIM(I)

234 ATOTAL = ATOTAL + A(I)

NK $=K$

230 IF $(J 4) \geqslant 35,235,224$

224 D01225 $I=1,36$

DO1225 $j=1,25$

$\operatorname{PWRF}(I, U)=0$.

$1225 \operatorname{KROD}(I, J)=0$

REAU $(I 2,7)$ NROU, (NR, (LR (NR,L),L=1,6), J=1,NROD)

235 IF (U5) 250.250 .236

$236 \operatorname{READ}(I 2,14)(I, U(I), \operatorname{RADI} A L(I), \quad(P H I(I, L), L=1,6), J=1, N R O D)$

C COMPUTE ROD LAYOUT FACTORS

DO 238 NRE $=1$ NKOU

DO $226 L=1,6$

IF (LR $(N R, L)) 226,226,225$

$225 K=L R(N R, L)$

$\operatorname{KROD}(K, N R)=1$

PWRF $(K, N R)=\operatorname{PHI}(N R, L)$

226 CONT INUE

$D R(N R)=O(N R)$

$238 D(N R)=D(N R) / 12$.

C CHECK FOR NEW CALCULATION TOLERANCES, ETC.

250 IF (J6) 260.260.252

252 READ (I2,17) BETA, XMIX,FDIV,FMIX,NPRINT,NX,KDEBUG,WERROR, ITERAT IF (NXX.LT.1) NX=1

IF (WERROR LLT.1.QE-10) WERROR $=10$.

IF ( $I T E R A T \cdot L T .1$ ) ITERAT $=25$

C CHECK FOR NEW OPERATING CONOITIONS

260 IF ( J7) $\geqslant 90.290 .262$

262 READ $(I 2.20)$ POUT,HIN,GIN.AFLUX,Z, THETA

IF (HIN) $254,254,255$

254 READ $(12.10)(H(J, 1), J=1$. NCHANL $)$

255 IF(GIN) 256.256 .257

$256 \operatorname{READ}(12.9)$ (F $(J .1), J=1$, NCHANL)

257 PREF $=$ POUT

$Z Z=Z$

$z=z / 12$

290 OX $=Z / F L O A T((N P R I N T-1) * N X)$

$D X X=D X * 12$.

HOUT $=$ HIN + AFLUX*PHTOT $* Z /$ (GIN*ATOTAL)

PIN $=0$. 


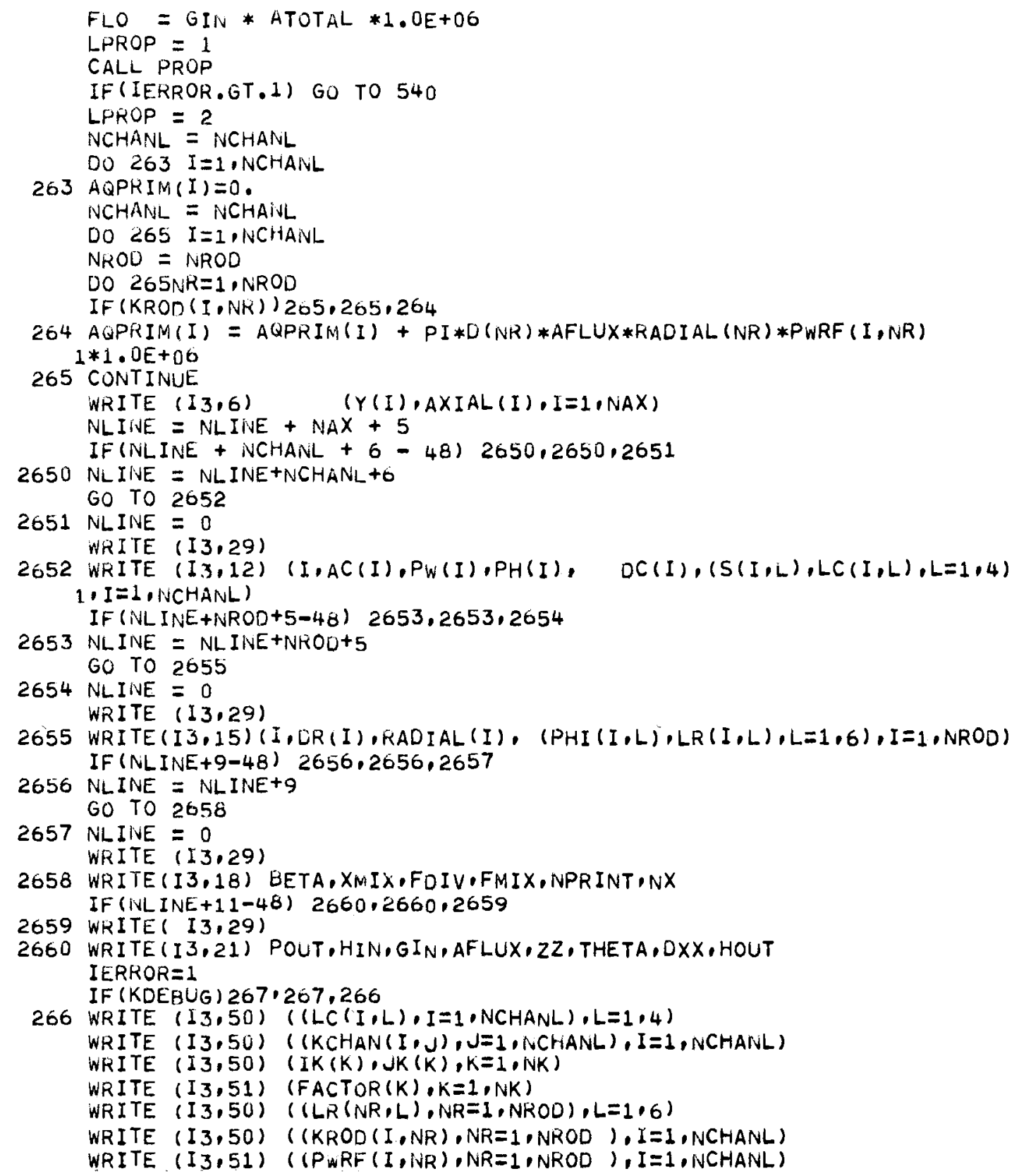


WRITE (I.3.51) (O(NR),NR=1,NROU), (RADIAL (NR),NR=1,NROD)

WRITE (I3.51) (AQPRIM(I), I =1, NNCHANL), (HPERIM(I), I = , NCHANL)

267 NCHANL $=$ NCHANL

DO $291 I=1$. NCHANL

291 DHYDE (I) $=$ DHYD (I) $* * 0.3$

DO $302 J=1$, NCHAINL

DEN $=0$.

DO 301 I = I NCHANL

301 DEN $=D E N+A(I) * D H Y D E(I) /(A(J) * D H Y D E(J))$

$P(J, 1)=P I N$

IF (HIN) $3011,3011,3010$

$3010 H(J \cdot 1)=H I N$

3011 IF(GIN) $302,302,3012$

$3012 F(J, 1)=F L O / D E N$

$F(J, 2)=F(J, 1)$

302 CONTINUE

$N=1$

CALL PROP

C FLOW SPLITTING ROUTINE

$E=.005$

DO $3030 \mathrm{~K}=1$, NK

$3030 W(K)=0$.

IF (GIN) $311,311,303$

303 DO $309 L=1,200$

ISPLIT $=1$

CALL MIX

CALL DIFFER (1)

IF (IERROR.GT.1) GO TO 3090

IF (KDERUG.LT.1) GO TO 304

WRITE $(I 3,52)$ (I,DP (I),OHi(I),OF (I),

$1 P(I, N), H(I, N), F(I, N), I=1, N C H A N L)$

304 FTOT $=0$.

PAVG $=0$.

DO $305 \quad 1=1$, NCHANL

IF (DP (I ) ) 3090,3090,305

305 PAVG $=$ PAVG + DP(I)*A(I)

PAVG = PAVG/ATOTAL

DO $306 \quad I=1$, NCHANL

CORR $=($ PAVG/DP (I) $) * *(0.4-0.3 * F M I X)$

IF (CORR -LT.1.05.AND.CORR.GT..95) GO TO 3050

IF (CORR.GT .1.04) CORR $=1.05$

IF (CORR.LT..96) CURR $=.95$

$3050 F(I, 1)=F(I, 1) * C O R R$

IF ( (PAVG/DP(I)) .GT •1.-E.AND. (PAVG/DP(I)).LT.1.+E) GO TO 306 ISPLIT $=2$

306 FTOT $=$ FTOT $+F(I, 1)$

FTOT $=$ FLO /FTOT

DO 307 I $=1$.NCHANL

$F(I, 1)=F(I, 1) * F$ TOT 


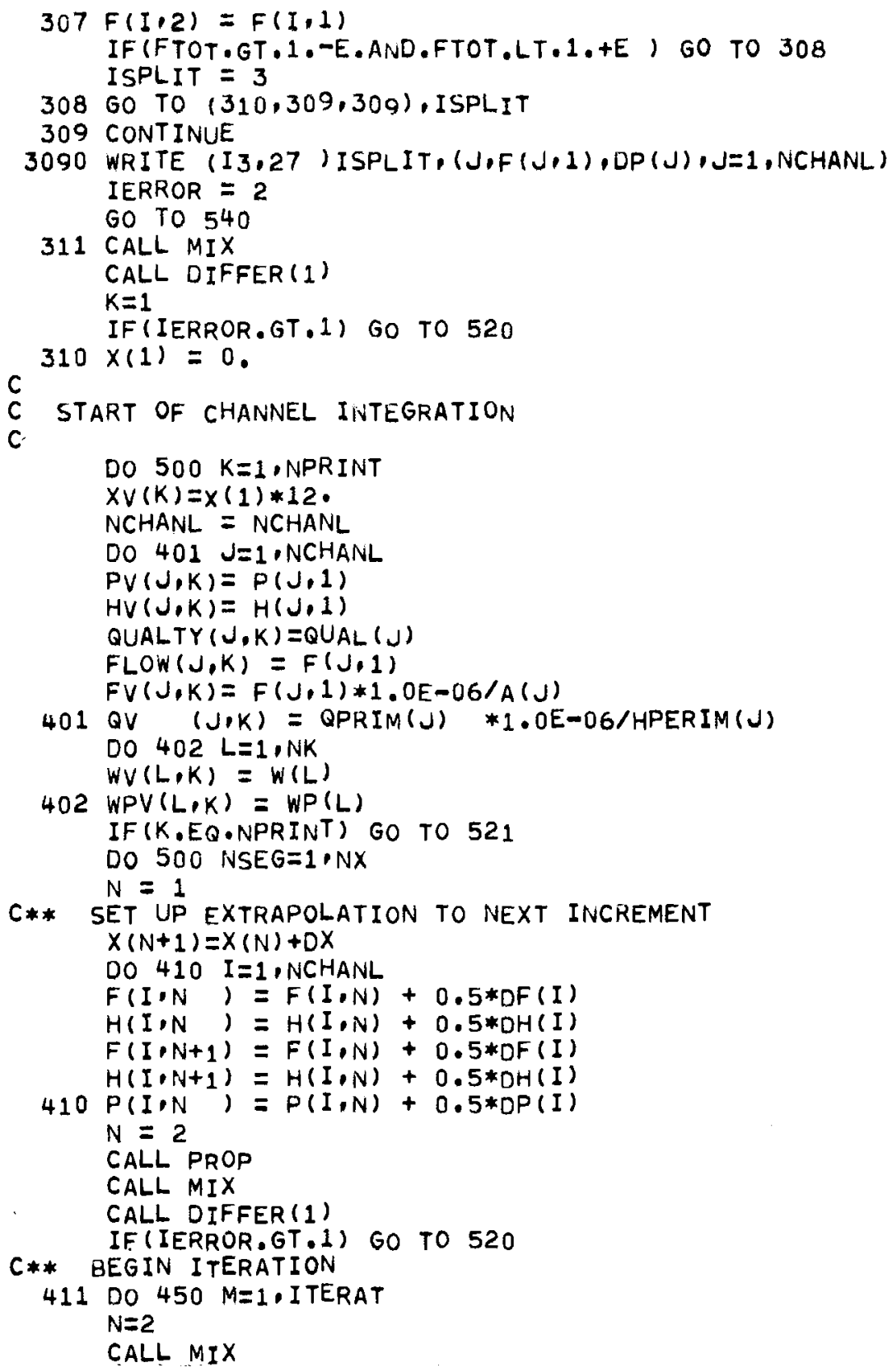


CALL DIFFER (IPART)

C** PRESSURE AT X+DX WITHOUT NATURAL DIVERSION CROSSFLOW DO 420 I=I.NCHANL

$420 P(I, 2)=P(I, 1)+0.5 * D P(I)$

C** COMPUTE NATURAL DIVERSION CROSSFLOW AT $X+D X$

CALL DIVERT

IF(IERROR.GT.1) GO TO 520

IPART $=2$

DO $430 L=1, N K$

IF (ABS (W(L)-WOLD(L)) . GT . WERROR) IPART $=1$

$I F(C(L), G T, 1, E-30) W(L)=.6 * W(L)+.4 * W O L D(L)$

430 WOLD $(L)=W(L)$

C** COMPUTE VALUES FOR NEXT ITERATION OR NEXT INCREMENT

CALL DIFFER (IPART)

IF(IERROR.GT.1) GO TO 520

$N=1$

DO $440 I=1$, NCHANL

$F(I, N+1)=F(I, N)+0.5 * D F(I)$

$H(I, N+1)=H(I, N)+0.5 * D H(I)$

$440 P(I, N+1)=P(I$, N $)+0.5 * D P(I)$

IF (KDEBUG.LT.1) GO TO 425

WRITE(I3.52) (I,DP(I),DH(I),DF(I),P(I,N+1),H(I,N+1),F(I,N+1), $1 \mathrm{I}=1, \mathrm{NCHANL}$ )

425 GO TO $(450,480)$, IPART

450 CONTINUE

WRITE $(I 3,22)$ ITERAT, $X(N+1), K$,NSEG

GO TO 520

480 IF (KDEBUG) $482,482,481$

481 WRITE (I 3.54)

482 DO $445 I=1$,NCHANL.

$P(I, N)=P(I, N+1)$

$F(I, N)=F(I, N+1)$

$445 H(I \cap N)=H(I, N+1)$

$X(N)=X(N+1)$

DO $500 \mathrm{~J}=1$.NCHANL

IF (F (U.1).LT.O.) GO TO 505

500 CONTINUE

GO TO 521

505 WRITE $(I 3,24)(U, P(J, 1), H(J, 1), F(U, 1), J=1, N C H A N L)$

IERROR $=2$

$520 \quad N=1$

WRITE $(I 3,53)(I, D P(I), D H(I), D F(I), I=1, N C H A N L)$

WRITE $(I 3,52) \quad(I, P(I, N+1), H(I, N+I), F(I, N+1), P(I, N), H(I, N), F(I, N)$,

1 I $=1$, NCHANL)

WRITE (I3.53) (I,RHO (I), U(I), QUAL (I),I =1, NCHANL)

WRITE $(13,53) \quad(L, W(L), W O L D(L), W P(L), L=1, N K)$

521 ND $=K$

DO 535 M $=1$.NCHANLL, 2

$M M=M+1$ 
IF (INCHANL.GE.MM) GO TO 531

IF (INCHANL.GE, MM-1) GO TO 532

GO TO 535

531 WRITE $(I 3,25)$ KASE,TEXT, (J,JEM,MM), (XV (N), (PV (J,N),HV(J,N), $1 Q U A L T Y(J, N), F V(U, N), \quad F L O W(J, N), Q V(J, N), J=M, M M), N=1, N D)$ GO TO 535

$532 M M=M M-1$

WRITE $(I 3,26)$ KASE, TEXT, $(J, J=M, M M),(X V(N),(P V(J, N), H V(J, N)$, IQUALTY $(J, N), F V(U, N), \quad F L O W(N, N), Q V(J, N), J=M, M M), N=1, N D)$

535 CONTINUE

DO $539 \mathrm{M}=1, \mathrm{NK} \cdot 5$

$M M=M+4$

IF (NK.LE.MM) MMENK

WRITE $(13,31)$ KASE, TEXT, (HEAD $(1, K), I K(K), H E A D(2, K), J K(K)$,

$\operatorname{IHEAD}(3, K), I K(K), \operatorname{HEAD}(2, K), J K(K), \operatorname{HEAD}(4, K), K=M, M M)$

DO $536 \mathrm{~N}=1, \mathrm{ND}$

536 WRITE $(I 3,30) \quad X V(N),(W V(K, N), W P V(K, N), K=M, M M)$

539 CONTINUE

540 GO TO 200

END 


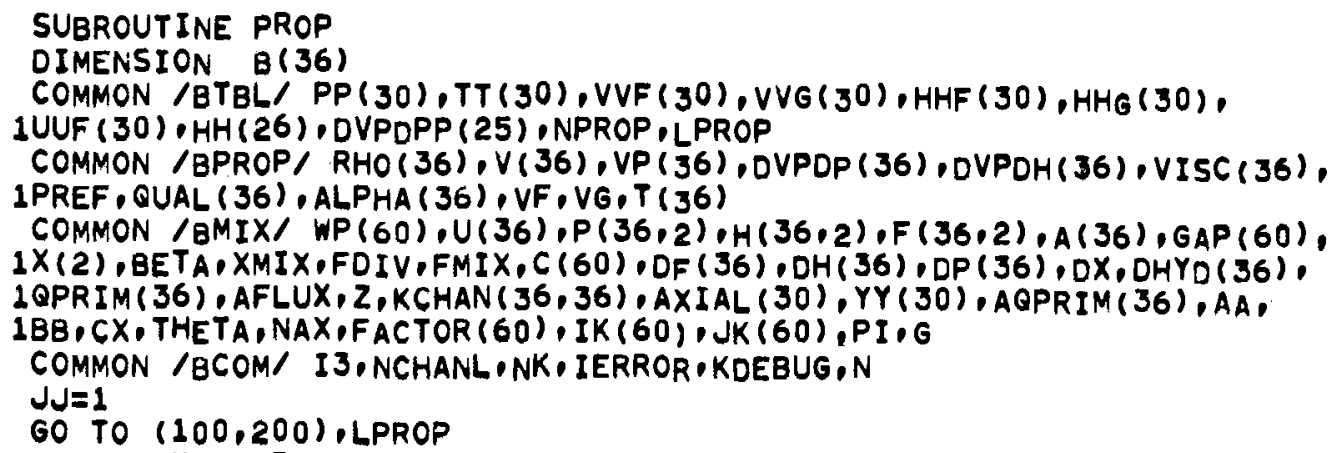

$140 C C=(P R E F-P P(I-1)),(P P(I)-P P(I-1))$

$H F=H H F(I-I)+C C *(H H F(I)-H H F(I-I))$

$H G=H H G(I-1)+C C *(H H G(I)-H H G(I-1))$

$\operatorname{VF}=\operatorname{VVF}(I-1)+C C *(\operatorname{VVF}(I)-\operatorname{VVF}(I-1))$

$V G=\operatorname{VVG}(I-1)+C C *(V V G(I)-V V G(I-1))$

$\operatorname{UF}=\operatorname{UUF}(I-1)+C C *(\operatorname{UUF}(I)-\operatorname{UUF}(I-1))$

$T F=T T(I-1)+C C *(T T(I)-T T(I-I))$

$H F G=H G-H F$

RHOF $=1 . / V F$

RHOG $=1 . / V O$

C COMPUTE TABLE OF DVPDP VS $H$ $C C=(P R E F+10,-P P(I-1)),(P P(I)-P P(I-1))$

$\operatorname{VFP}=\operatorname{VVF}(I-1)+C C *(\operatorname{VVF}(I)-\operatorname{VVF}(I-1))$

$V G P=\operatorname{VVG}(I-1)+C C *(V V G(I)-V V G(I-1))$

$\operatorname{HFP}=\operatorname{HHF}(I-1)+C C *(\operatorname{HHF}(I)-H H F(I-1))$

$H G P=H H G(I-1)+C C *(H H G(I)-H H G(I-1))$

$\mathrm{OH}=\mathrm{HFG} * 0.04$

HFGP = HGP-HFP

$H H(1)=H F$

$H H(2)=H F+D H$

$\operatorname{DVPOPP}(1)=0$. 


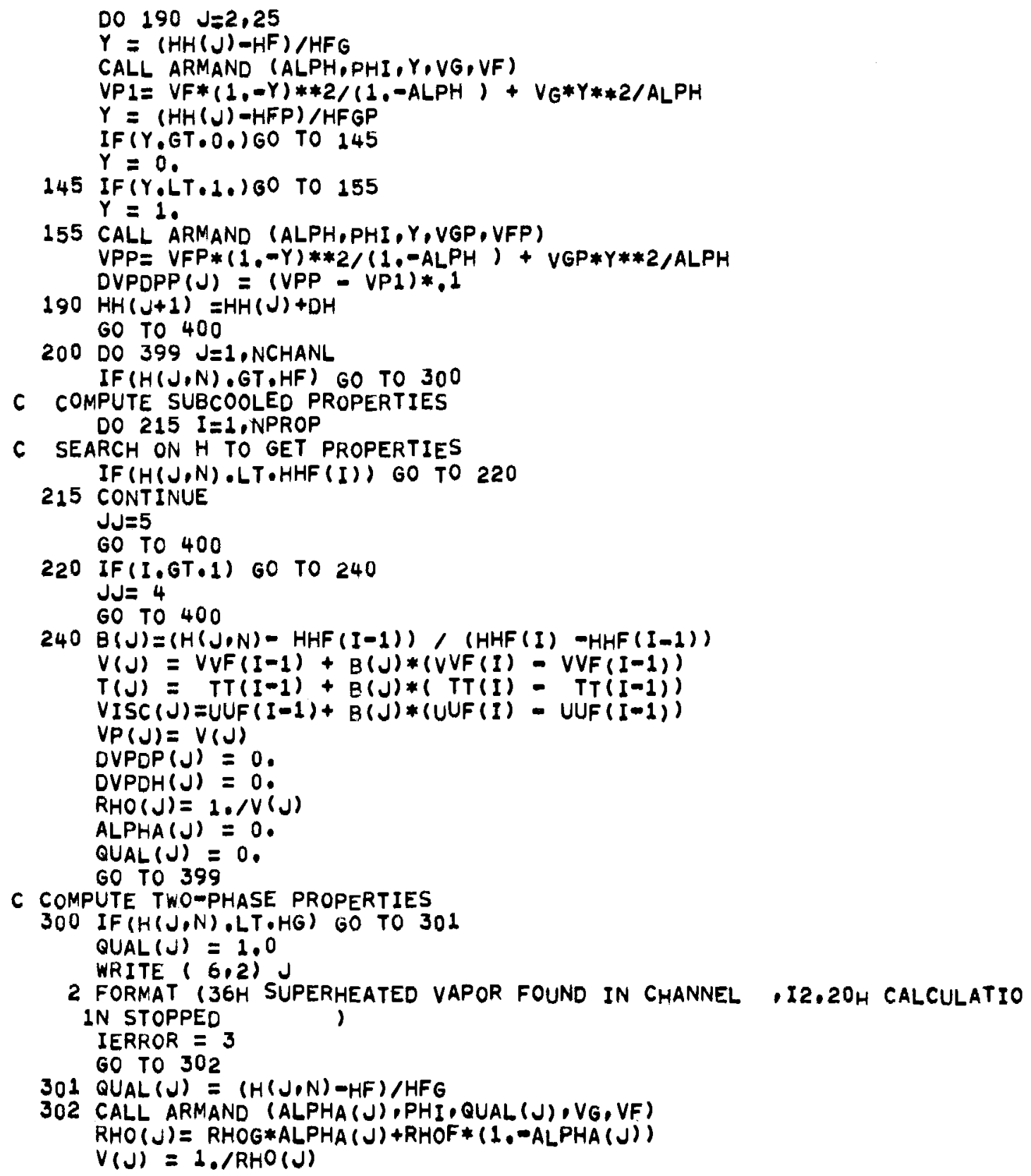


$\operatorname{VP}(J)=\operatorname{VF} *(1,-Q U A L(J)) * * 2 /(1,-A L P H A(J))+\operatorname{VG} * Q U A L(J) * * 2 / A L P H A(J)$ CALL CURVE (DVPDP $(J), H(J, N), D V P D P P, H H, 25, K)$

$X P=$ QUAL $(J)+10 . / H F G$

IF (XP.LT.1.) GO TO 305

$X P=1$.

305 CALL ARMAND (ALPHAP,PHI,XP,VG,VF)

$V P P=V F *(1,-X P) * * 2 /(1,-A L P H A P)+V G * X P * * 2 / A L P H A P$

$\operatorname{DVPDH}(J)=(\mathrm{VPP}-\mathrm{VP}(\mathrm{J})) * \cdot 1$

$V I S C(J)=U F$

399 CONTINUE

400 IF (JJ.EQ.1)GO TO 500

WRITE $(I 3,1)$ JJ

1 FORMAT (6OH FAILURE OF PROPERTY SUBROUTINE, CALCULATION STOPPED,

$1 \mathrm{JJ}=$ I5 )

IERROR $=2$

500 RETURN

END 


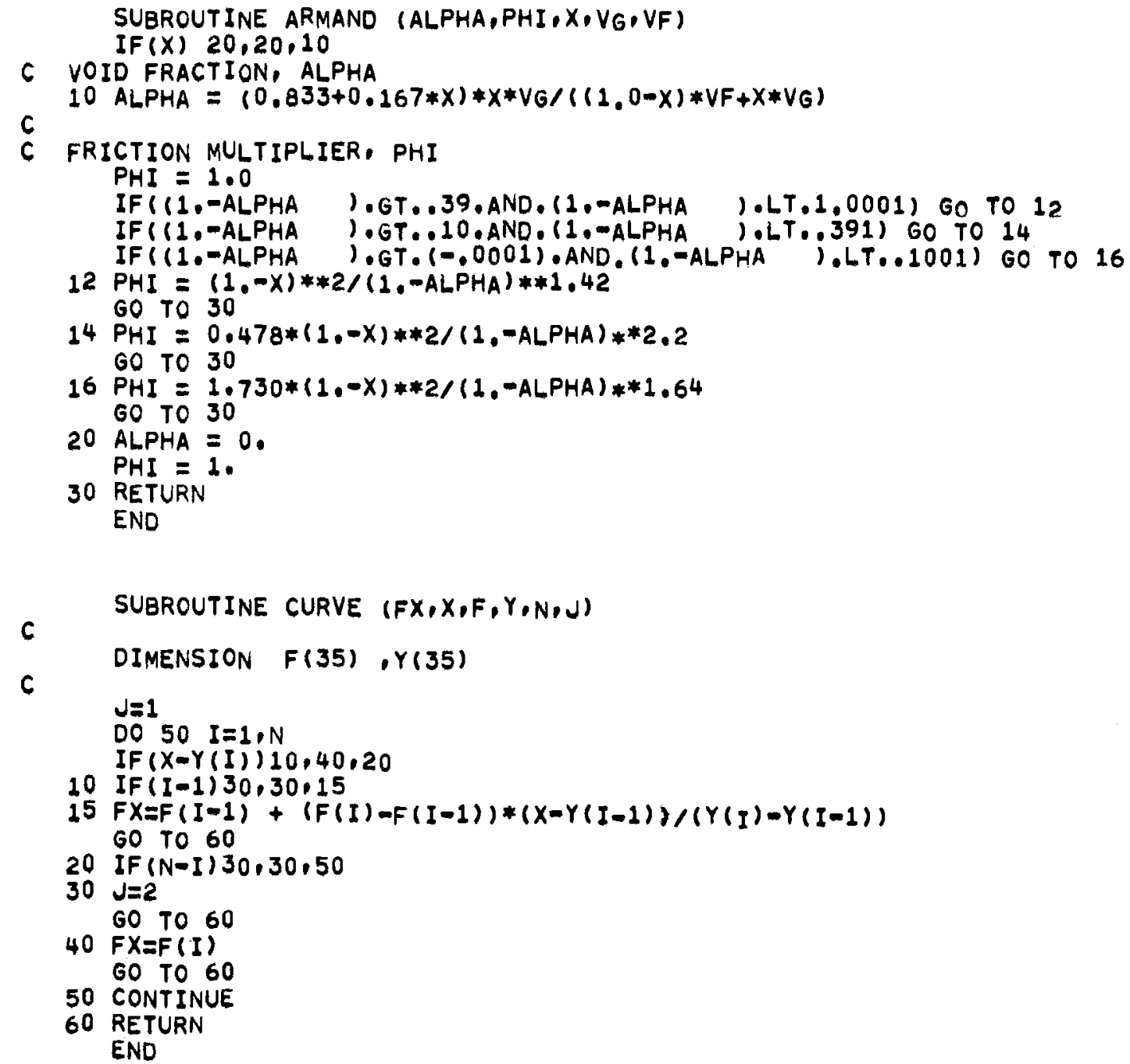




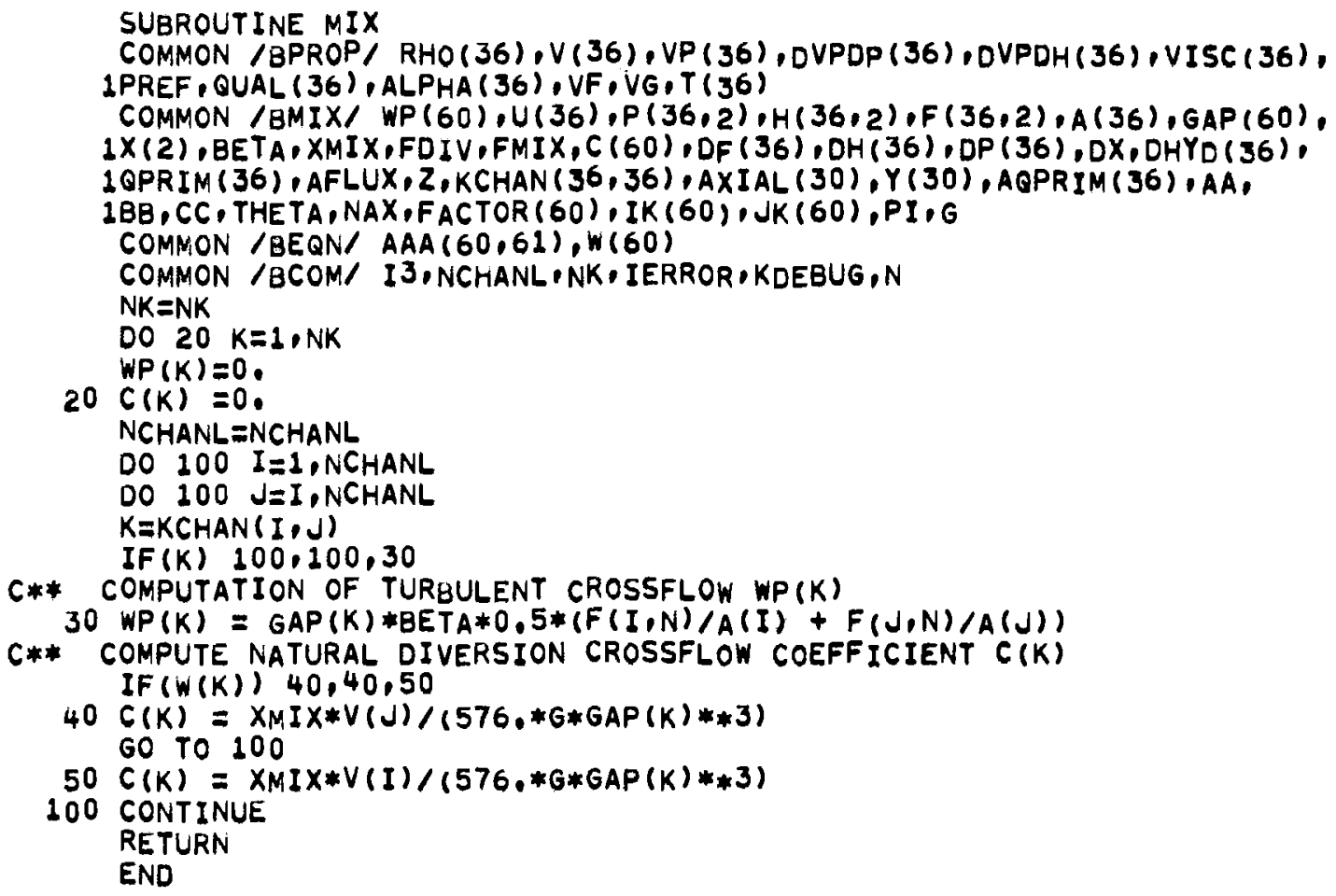


SUBROUTINE DIFFER (IPART)

COMMON /BPROP/ RHO (36),V (36), VP (36), DVPDP (36) , DVPDH (36) ,VISC (36), 1PREF, GUAL (36), ALPHA (36), VF, VG,T (36)

COMMON /BEQN/ AAA $(60,61), W(60)$

COMMON /BMIX/ WP(60),U(36),P(36,2),H(36,2), F $(36,2), A(36), G A P(60)$, IX(2),BETA,XMIX,FDIV,FMIX, C (60),DF (36),DH(36),DP (36),DX,DHYD(36), 1QPRIM(36), AFLUX,Z,KCHAN $(36,36)$, AXIAL $(30), Y(30), A Q P R I M(36), A A$, 1BB,CC, THETA, NAX, FACTOR $(60)$, IK $(60), J K(60), P I, G$ COMMON /BCOM/ I 3 , NCHANL, NK, IERROR, KDEBUG, N

C COMPUTE AXIAL FLUX FACTOR

CALL CURYE (QAX,X(N)/Z,AXIAL,Y,NAX,JA)

NCHANL = NCHANL

DO $10 \quad I=1$, NCHANL

$10 U(I)=F(I, N) * V P(I) / A(I)$

NCHANL=NCHANL

DO 90 I=I, NCHANL

C COMPUTE INITIAL VALUES BEFORE ANY MIXING

$D F(I)=0$.

CALL ARMAND (ALPHA(I),PHI, QUAL (I), VG,VF)

RE = $F(I, N) / A(I) \quad * D H Y D(I) / V I S C(I)$

IF (KDEBUG) $16,16,15$

15 WRITE (I3,101) I,F (I,N),DHYD(I),VISC (I), QUAL(I), ALPHA (I),PHI, $10 V P D H(I), O V P D P(I), R H O(I), D H(I), U(I)$

101 FORMAT $(I 5,11 E 10.3)$

$16 \mathrm{FSP}=A A * R E * * B B+C C$

$D P(I)=(F(I, N) / A(I)) * 2 / G *(0,5 * F S P * V F * P H I / D H Y D(I)+D V P D H(I)$

$1 * D H(I) / D X)+R H O(I) * \operatorname{COS}(0.017453 *$ THETA

QPRIM(I) $=$ AQPRIM(I)*QAX

$D H(I)=\operatorname{QPRIM}(I)$

DO $70 \mathrm{~J}=1$. NCHANL

$K=K C H A N(I, J)$

IF $(K) 70,70,20$

$20 D H(I)=D H(I)+W P(K) *(H(J, N)-H(I, N)) * F A C T O R(K)$

$D P(I)=D P(I)+W P(K) *(U(I)-U(J)) * F M I X * F A C T O R(K) / G / A(I)$

IF $(I-J) 21,21,40$

$21 D F(I)=D F(I)-W(K) * F A C T O R(K)$

$\operatorname{IF}(W(K)) 22,30,30$

$22 D H(I)=D H(I)-W(K) *(H(J, N)-H(I, N)) * F A C T O R(K)$

IF (IPART,EQ,2)

$1 D P(I)=D P(I)+W(K) * U(I) *(F D I V * U(J) / U(I)-2) * F A C T O R,(K) / G / A(I)$ GO TO 70

30 IF (IPART,EQ.2)

$1 D P(I)=D P(I)+W(K) * U(I) *(F D I V-2 \cdot) * F A C T O R(K) / G / A(I)$

GO TO 70 


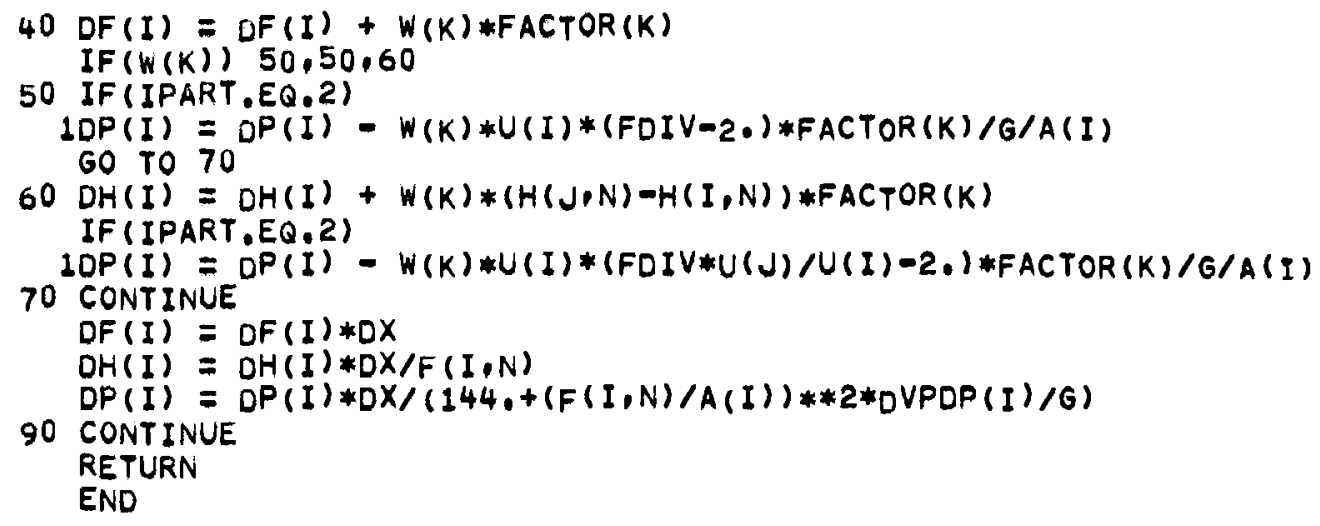




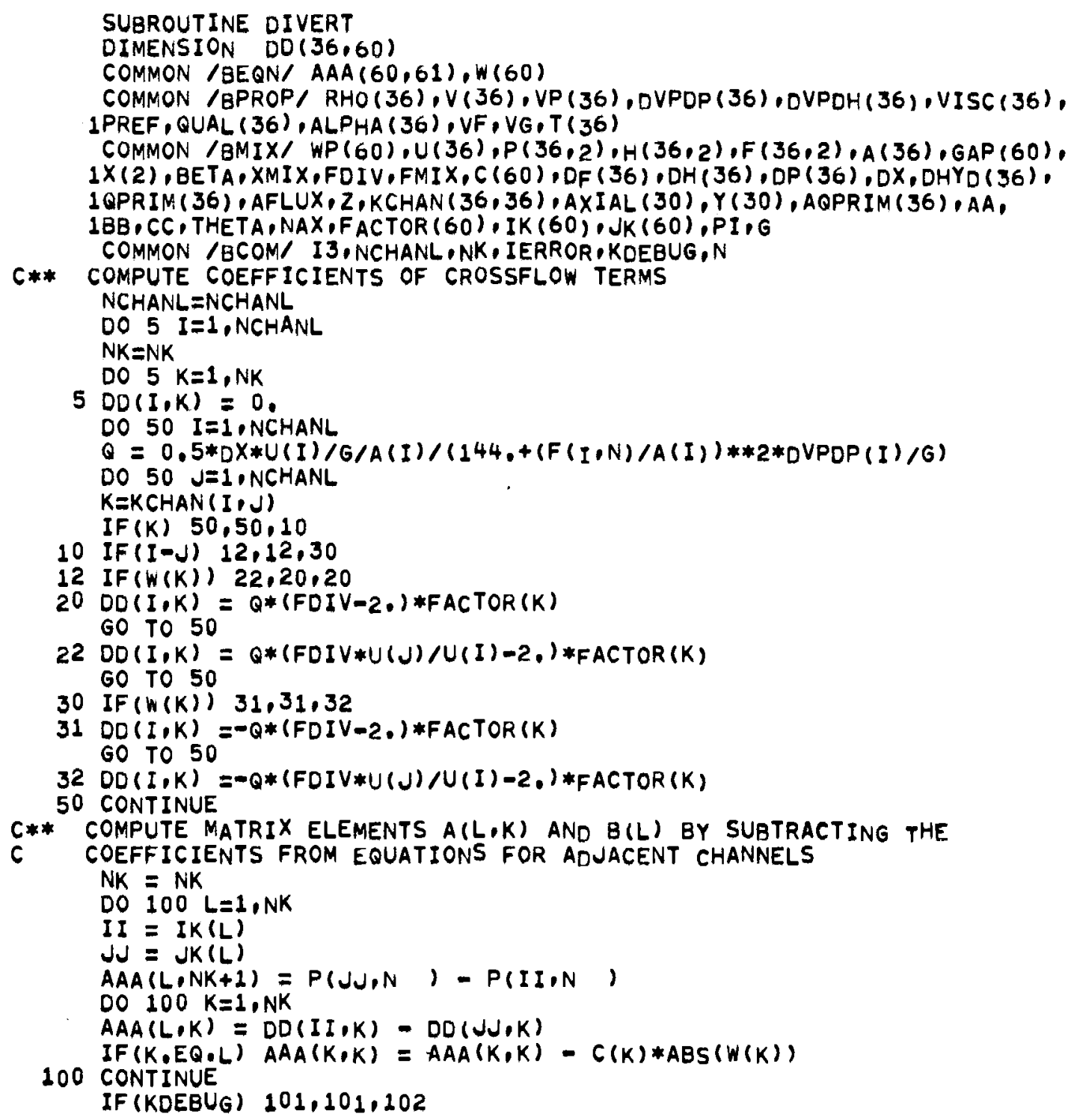




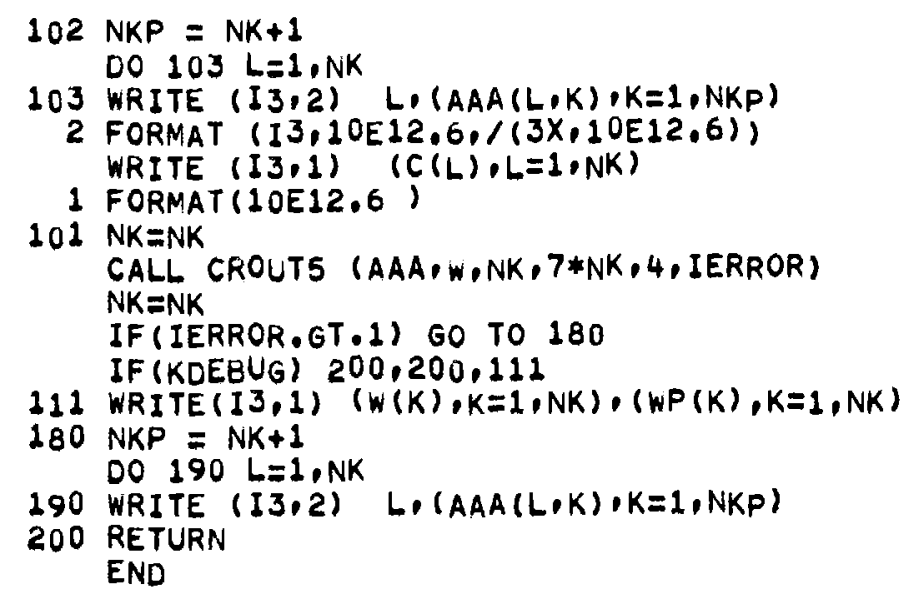


SUBROUTINE CROUT5 ( $A A, C$, INPUTN, NC, NF, IERROR)

C SOLVES A SYSTEM OF $N$ LINEAR ALGEBRAIC EQUATIONS IN N UNKNOWNS BY

C THE CROUT METHOD

C REF- AIEE TRANS 1941 VOL 60 P1235-1240

C A IS N,N+1 MATRIX OF INPUT COEFFICIENTS

C C IS N.1 COLUMN MATRIX OF UNKNOWNS AS OUTPUT

C NC IS MAX NUMBER OF ITERATIONS TO BE PERMITTED

c NF IS NUMBER OF SIGNIFICANT FIGURES OF ACCURACY REQUIRED IN

C

C

C

C BALANCE OF TWO SIDES OF EACH EQUATION (NOT TO EXCEED 6)

(REVISION FOR SPECIFIC APPLICATIONS - A CHANGE IN THE DIMENSION STATEMENT DOES NOT REQUIRE ANY ADDITIONAL PROGRAM CHANGES)

DIMENSION $A(60,61), B(60,61), 0(60), A L(61)$ COMMON /BEQN/ AA $(60,61), C(60)$

100 FORMAT (B4HOACCURACY OF SIMULTANEOUS EQUATION SOLUTION HAS NOT REA LCHED THE REQUIRED VALUE AFTERI3, $13 \mathrm{H}$ CORRECTIONS./59H MAXIMUM ERROR 2 IN BALANCE OF TWO SIDES OF EACH EQUATION IS 1 PE $10,3,8 \mathrm{H}$ IN THE I1, 322HTH SIGNIFICANT FIGURE,)

101 FORMAT (119HOSUBROUTINE CROUT5 REQUIRES THAT AT LEAST ONE INPUT EQ IUATION HAVE A NON-ZERO FIRST COEFFICIENT. NO SOLUTION IS POSSIBLE)

102 FORMAT (119HOSUBROUTINE CROUTS IS UNABLE TO FORM AN AUXILIARY MATR 1IX WITHOUT A ZERO ON THE DIAGONAL. NO VALID SOLUTION IS POSSIBLE.)

204 FORMAT (101HONO SOLUTION IS POSSIBLE FROM CROUT5 BECAUSE OF AN INS 1UFFICIENT NUMBER OF EQUATIONS IN THE INPUT SET.14H ROW I3,28H IS A 2N EXACT MULTIPLE OF ROW I3, $1 \mathrm{H}_{0}$ )

105 FORMAT (7HOCOLUMN I5,21H IS IDENTICALLY ZERO.)

206 FORMAT (7HO ROW I5,21H IS IDENTICALLY ZERO,)

107 FORMAT (7HOCOLUMNI5,31H IS AN EXACT MULTIPLE OF COMUMNI5, 1H.) $13=6$

$N=I N P U T N$

$Z F A C=10 \cdot * *(N F-1)$

KOUNT $=0$

NIL $=1$

$\mathrm{NP}=\mathrm{N}+1$

$N M=N-1$

$00201 I=1, N$

DO $201 \mathrm{~J}=1, \mathrm{NP}$

c

$201 A(I, J)=A A(I, J)$

TESTS FOR INVALID INPUT DATA

DO $401 \mathrm{~J}=1, \mathrm{~N}$ 
IF (FACTOR) $311,1211,311$

$1211 P=A B S(A(I, J))$ $Q=A B S(A(I, K))$

IF $(B O O L(A N D(O R(P, Q), O R(C O M P L(P), C O M P L(Q))))) 511,211,511$

211 CONTINUE 60 TO 511

311 IF (KKI-N) $1311,1311,511$

1311 DO 411 I=KKIIN

IF (ABS $((F A C T O R-A(I, J) / A(I, K)) / F A C T O R)=.5 E-7) \quad 411,411,511$

411 CONTINUE

60 TO 85

C

511 CONTINUE

CONSTRUCTION OF INTERMEDIATE MATRIX

12 DO $13 \quad I=1, N$

$D(I)=0.0$

$A L(I)=A(I, N P)$

$13 B(I, 1)=A(I, 1)$

14 DO $15 I=1, N$

$15 B(1, I+1)=A(1, I+1) / A(1,1)$

DO $17 L=2, N$

DO $17 I=L, N$

$S M=0$.

$S P=0$.

$T M=0$.

$T P=0$.

DO $16 \mathrm{~J}=2 \cdot \mathrm{L}$

$S=B(I, J-1) * B(J-1, L)$

$T=B(L, J-1) * B(J-1, I+1)$

IF (S) $215,415,315$

$215 S M=S M+5$

GO TO 415

$315 S P=S P+S$

415 IF (T) $515,16,615$

$515 \quad T M=T M+T$

GO TO 16

$615 T P=T P+T$

16 CONTINUE

$S=S P+S M$

$T=T P+T M$

$B(I, L)=A(I, L)-S$

$17 B(L, I+I)=(A(L, I+1)-T) / B(L, L)$

C TEST FOR ZERO DIAGONAL IN AUXILIARY MATRIX DO $23 I=1, N$

IF $(B(I, I)) 23,202,23$

23 CONTINUE

c

CALCULATION OF MATRIX OF VARIABLES

31 KOUNT $=K O U N T+1$

$C(N)=B(N, N P)$

DO $33 I=2, N$

(BACK SUBSTITUTION) 


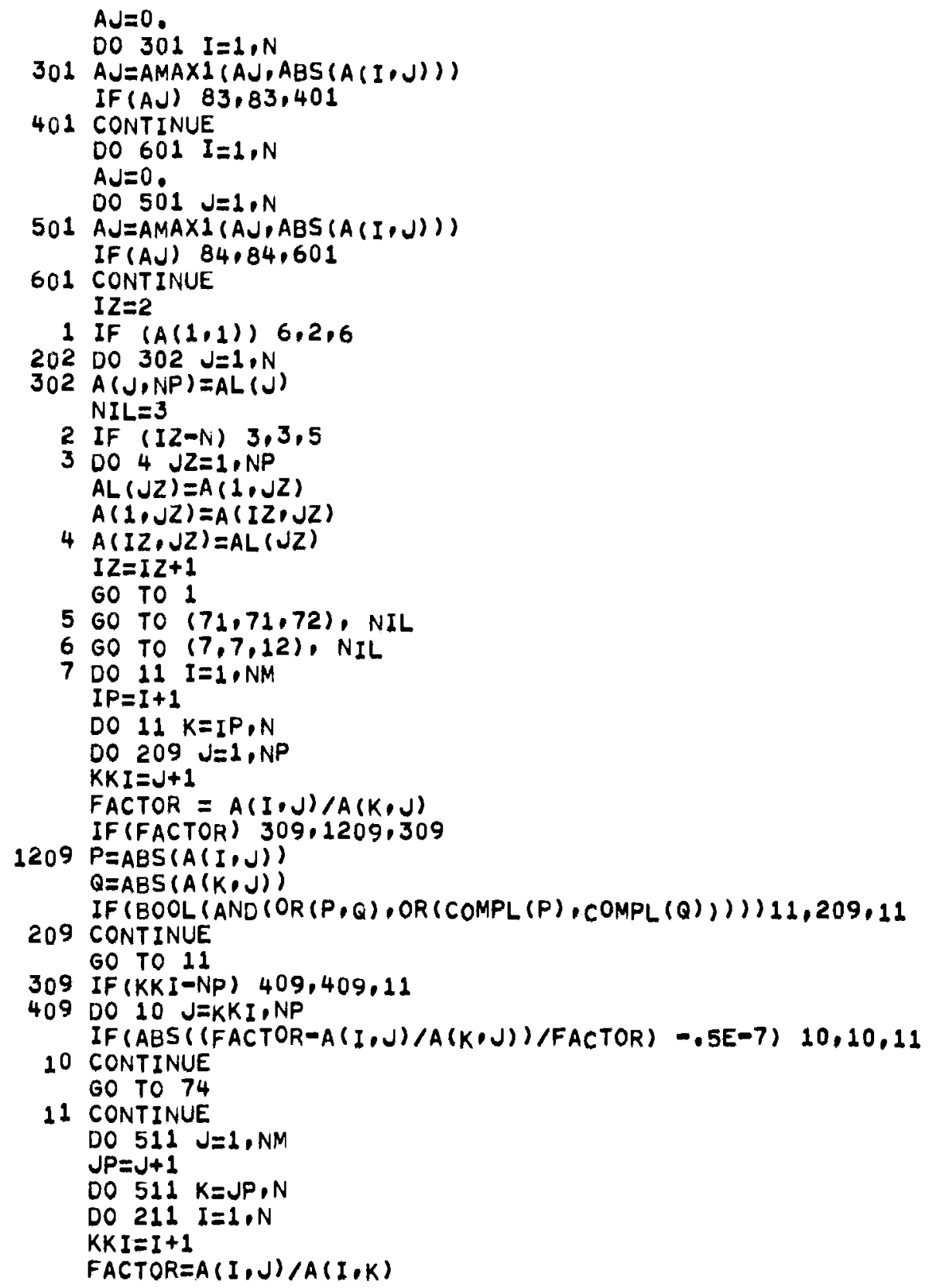




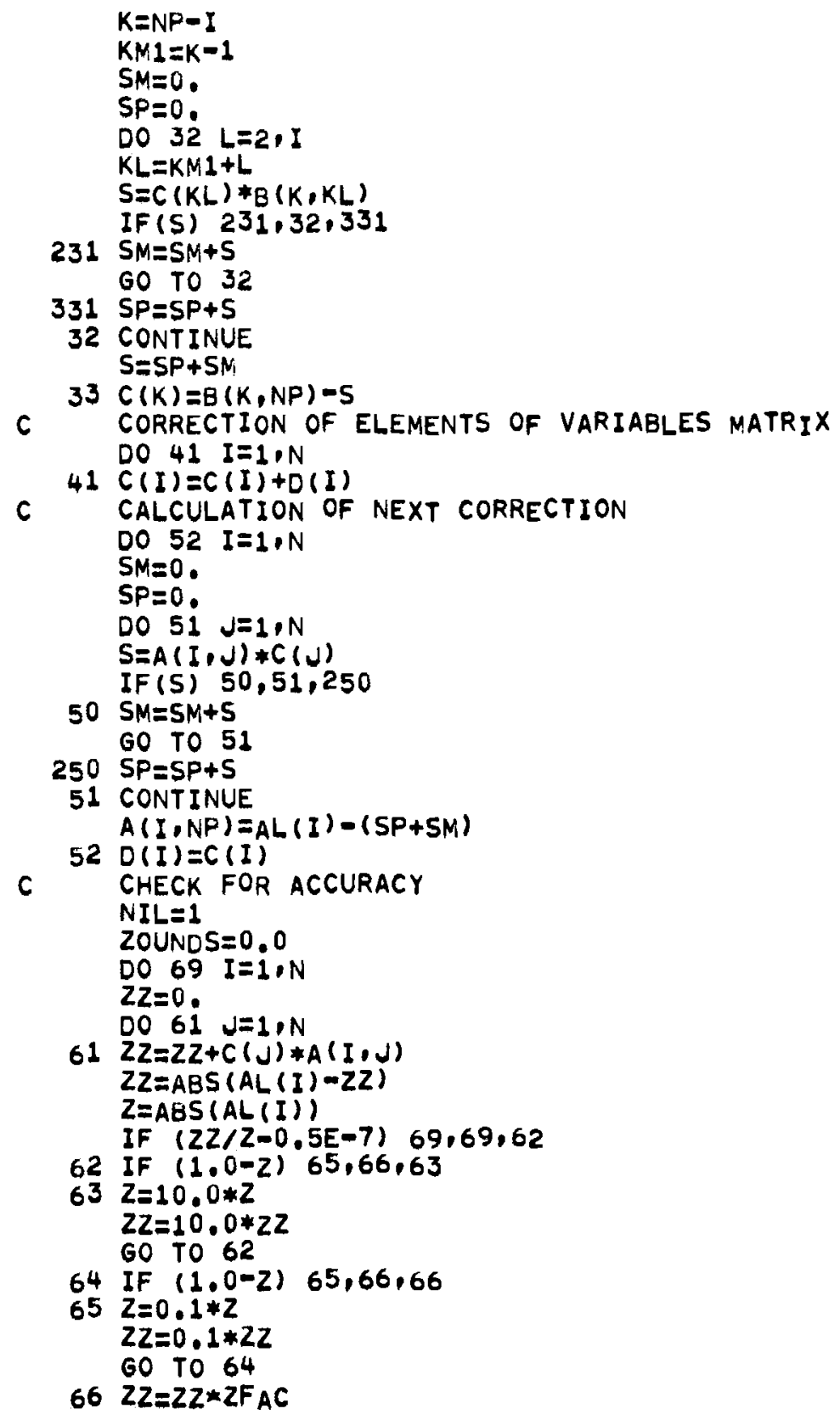




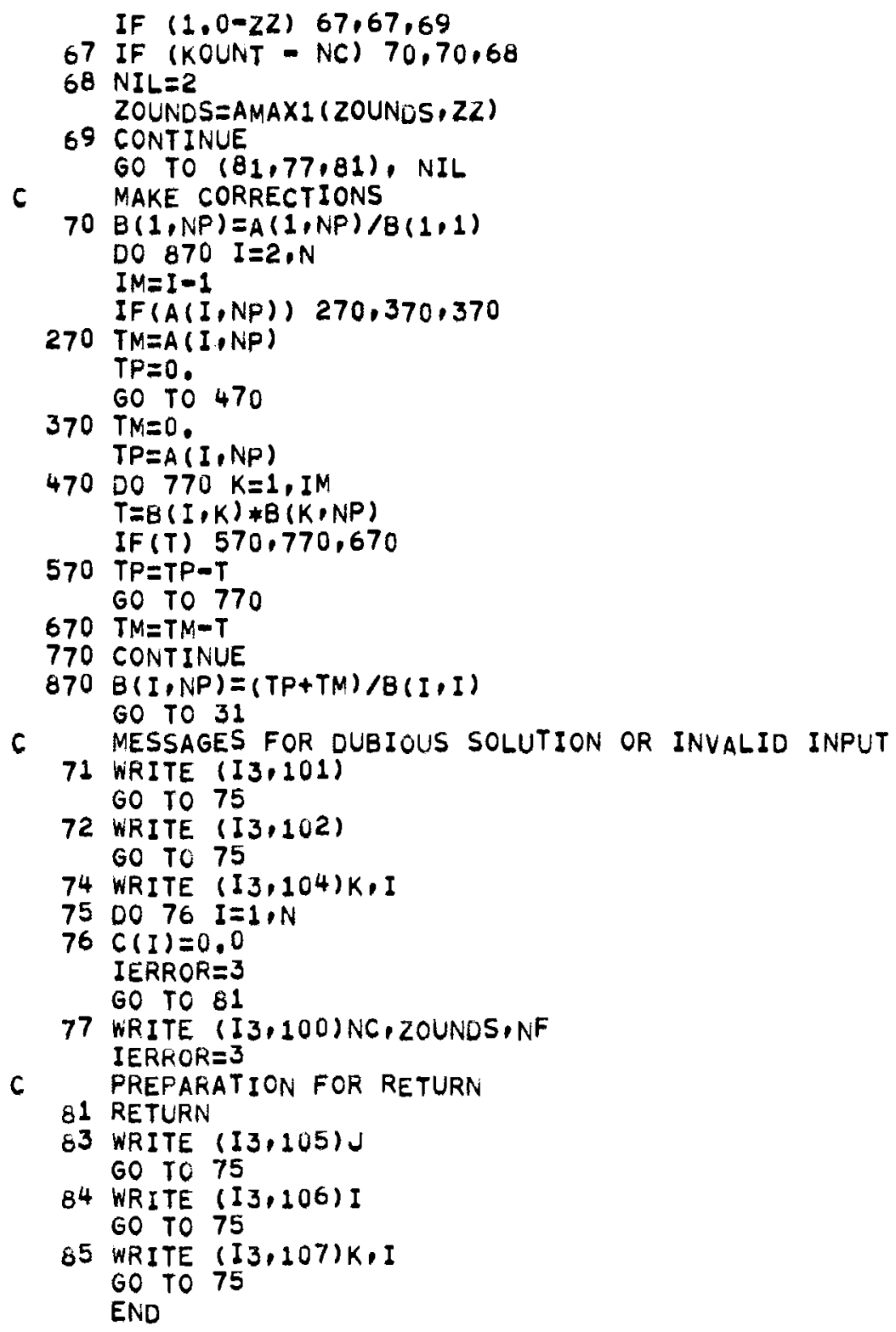


.

" 


\section{DISTRIBUTION}

No. of

Copies

Aerojet-General Nucleonics

H. Jaffee

Allis-Chalmers Manufacturing Company

Atomic Energy Division

6933 Arlington Road

P.O. Box 5976

Bethesda, Maryland 20014

W. S. Farmer

Argonne National Laboratory

Dr. Paul Lottes

Dr。M. Petrick

R. P. Stein

Leonard J. Koch

M. Novick

Robert E. Macherey

Dr。T. R. Bump

Atomic Energy Commission

Brussels office

U. S. Mission to the European Communities

APO, New York, N. Y. 09667

Atomics International

P.O. Box 591, Canoga Park, California 91305

Senior Site Rep., AI-CE

Acting Senior Site Rep., AI

12

Atomic Energy of Canada Limited

Chalk River, Ontario, Canada

A. Pearson

G. A. Wikhammer

Scientific Representative

Division of International Affairs (10)

Atomic Energy Commission, Washington, D. C.

Division of Reactor Development \& Technology

Chief, HWOCR Branch

Assistant Director, Plant Eng.

Chief, Inst. \& Cont. Br. 
Chief, Systems Eng. Br.

Chief, Core Design Br.

Chief, Fuel Fab. Br.

Chief, Control Mech. Br.

Asst. Dir., Reactor Tech.

Chief, Fuels \& Mat. Br.

Chief, Reactor Phy. Br.

Chief, Special Tech. Br.

Asst. Dir., Nuclear Safety

Asst. Dir., Program Analys is

Water Projects Branch

Research and Development Branch

R. Feit

R. M. Scroggins

S. Strauch

N. E. Todreas

A. Van Echo

Division of Safety Standards

R. Impara

Office of Assistant General Manager for Reactors Dr. R. C. Dalzell

Office of Assistant General Counsel for Patents

R. A. Anderson

RDT Site Offices

Atomic Energy Commission, Richland, Washington

Senior Site Representative, PNL

P. G. Holsted

Atomic Energy Establishment

Winfrith, Heath

Eng 1 and

W. S. Eastwood

2

Atomic Energy Research Establishment Harwe11, Berkshire

Eng 1 and

G. F. Hewitt

J. G. Collier (Nr. Didcot Berkshire)

Atomics International

Director, HWOCR Program Office (6)

R. C. Noyes

David C. Fulton (2)

Donald T. Eggan 
Atomic Power Development Associates, Inc. Alton P. Donnell

Babcock \& Wilcox Co. Barberton, Ohio

P. B. Probert

Babcock and Wilcox Company

HWOCR Project Manager

Donald F, Judd

Baldwin-Lima-Hamilton Corporation Industrial Equipment Division

Eddyston, Pennsylvania

Philip Otten

Brookhaven National Laboratory

Dr。O.E. Dwyer

Dr. David Gurinsky

Canadian Westinghouse Co. Ltd. $\mathrm{P}$.0. Box 510

Hamilton, Ontario

Canada

$$
\text { F。 Stern }
$$

Chicago Operations office

G. H. Lee

Richard J。Gariboldi

Columbia University

Department of Chemical Engineering

Combustion Engineering, Inc.

HPO, Windsor Representative

F. Bevilacqua

Senior Site Representative

3 Douglas United Nuclear, Inc.

T. W. Ambrose

P.A. Carlson

$H=R$. Kosmata 
$1 \quad$ Duke Power Company

P.O. Box 2178

Charlotte, North Carolina 28201

E. C. Fiss

4 Du Pont Company, Aiken

G. Dessauar

Supervisor, Technical Information Service (2)

Site Representative, SR

2 Du Pont Company, Wilmington

Director, Reactor Engineering Section

J. S. Neill

1 Dynatech Corporation

17 Tudor Street

Cambridge, Massachusetts 02139

A. Bergles

\section{European Contractors}

1 AEG-Kernenergieversuchsanlage

8752 Grobwelzheim (Unterfranken)

Germany

Dr. Kirchenmayer

$1 \quad$ Alshthom

38 avenue Kleber

Paris $16 \mathrm{e}$

France

M. P. Domenjoud

1 ANSALDO

Direzione Generale

Piazza Carignano 2

Genova

Italy

10 CEN Saclay

Boite Postale 2

Gif-Sur-Yvette ( $S$ et $O)$, France

G. Vendryes

1 Centre d'Etudes Nucleaires

Chemin des Martyrs

Grenoble (Isere)

France

M. Mondin 
1 Centre d'Etudes Nucléaires de Saclay

$$
\text { Gif-sur-Yvette ( } S \text { and } 0 \text { ) }
$$

France

$$
\text { M. J. Horowitz }
$$

$1 \quad$ CISE

$$
\text { Casella Postale } 3986
$$

Milano (Segrate)

I taly

$$
\text { Prof。M. Silvestri }
$$

$1 \quad$ CNEN

$$
\begin{aligned}
& \text { Rome } \\
& \text { Via Belisario, } 15 \text { Italy }
\end{aligned}
$$

M. Bianchi

$1 \quad$ CNEN

Via Mazzini 2

Bologna, Italy

Dott, Ing. F. Pierantoni

$1 \quad$ EURATOM

Casella Postale 1

Ispra (Varese)

Italy

M. R. Morin

12 EURATOM

Direction Générale $R$ and $E$

51, rue Belliard

Bruxelles

Belgium

Dr。P. Kruys (2)

A. De Stordeur (10)

1 FIAT

Sezione Energia Nucleare

Via Settembrini 235

Torino

Italy

M. G. Cesoni

10 Kernforschungszentrum Karlsruhe

7500 Karlsruhe, Germany

Professor W. Haefele 
$1 \quad$ MAN

Abholfach

Nürnberg 2

Germany

Dr. Mayinger

1 Reactor Centrum Nederland

112 Scheveningseweg

's Gravenhage

Netherlands

Prof. Dr. M. Bogaardt

1 SNECMA

Division Atomique

22, Quai Gallineni

Suresnes (Seine)

France

M. Fouré

1 Technische Hogeschool Eindhoven

$\mathrm{P} . \mathrm{O}$. Box 313

Eindhoven

Netherlands

Prof。D. M. Bogaardt 
General Atomics

P.0. Box 608

San Diego 12, California

Division of General Dynamics Corp.

Dr. Peter Fortescue

Genera1 Electric Company, N-Reactor Department

R. H. Shoemaker

1

General Electric Company, San Jose, (Trumbu11)

Advanced Engineering

Karl P. Cohen

General Electric Company, San Jose

Dr. S. Levy (2)

Ear1 Janssen (1)

$1 \quad$ M。W. Kellogg Company

711 3rd Avenue

New York 17, New York

B. W. Jesser

1

Knol1s Atomic Power Laboratory

Genera1 Electric Company

Schenectady, New York

G. H。 Halsey

Los Alamos Scientific Laboratory

Dr. David B. Hall

Massachusetts Institute of Technology

Dr. W. Rohsenow

Dr. P. Griffith

MSA Research Corporation

Callery, Pennsylvania 14024

Marketing Division

C. H. Staub

6

NASA Lewis Research Center

Librarian (3)

R. Weltmann (SEPO)

$\mathrm{J}$. M. Savino 
New York Operations Office Jules Wise

1

North Carolina State University

Dr. J. K。 Ferrell

1 Nuclear Materials \& Equipment Corp. Zalman M. Shapiro

1 Oregon State University

J。G. Knudsen

1 Power Reactor Development Company

1911 First Street Detroit, Michigan 48226

Arthur S. Griswold

1 Purdue University

Mechanical Engineering Department

R. J.Grosh

Richland Operations Office

C. L. Robinson

R. K. Sharp

Technical Information Library

1 Rutgers, University

R. L。 Peskin

1 Southwest Atomic Energy Associates

Post Office Box 1106

Shreveport, Louisiana 71102

$\mathrm{J}$ 。 Robert Welsh

1 Stanford University

Dr。G. Leppert

1 TWR Space Technology Laboratories

TRW Systems Group

S. M。Zivi

Union Carbide Corporation (ORNL)

Dr。Floyd L. Culler (2) 


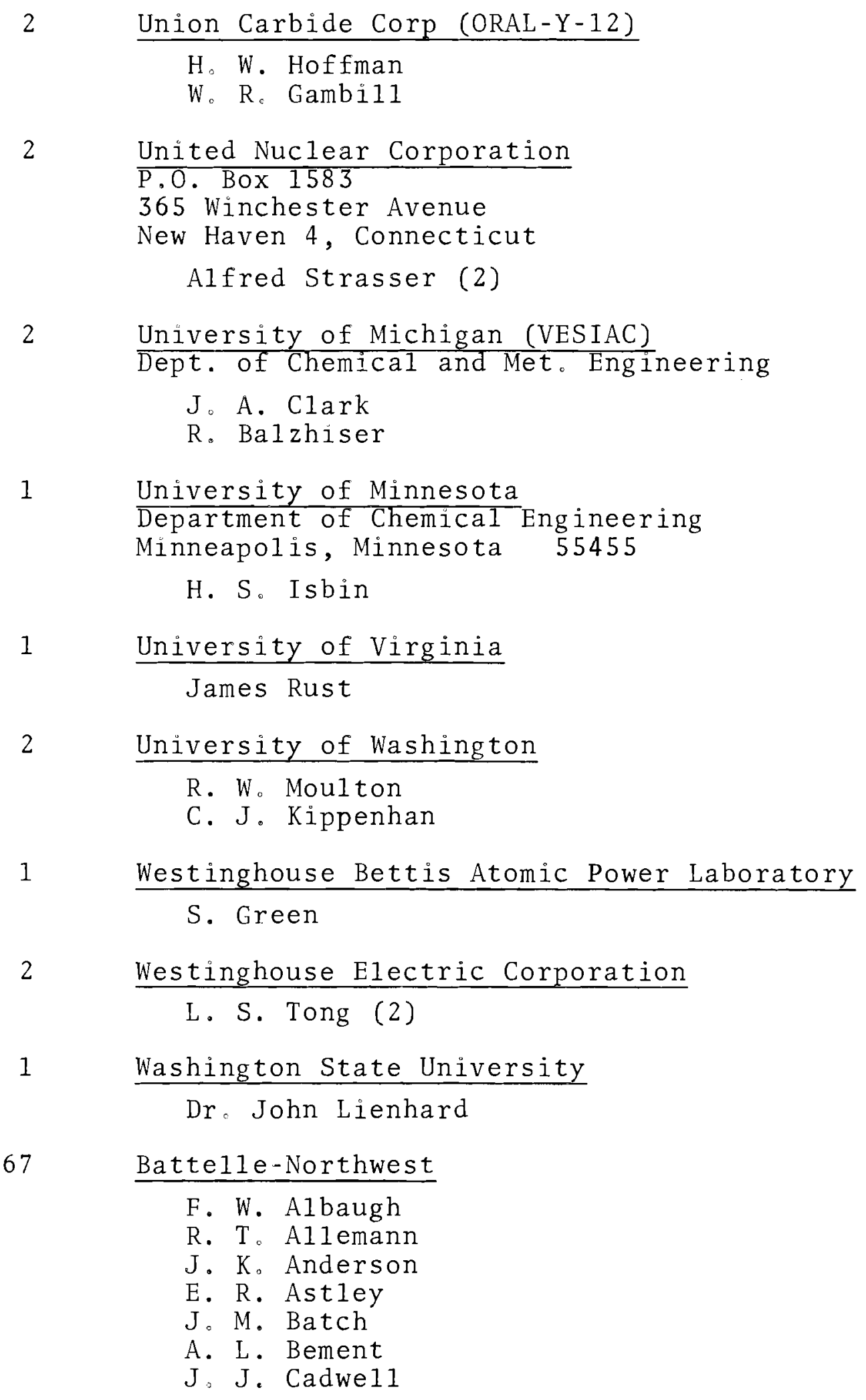

University of Washington

R. W. Moulton

C. J. Kippenhan

Westinghouse Bettis Atomic Power Laboratory

S. Green

Westinghouse Electric Corporation

$$
\text { L. S. Tong (2) }
$$

1 Washington State University

$$
\text { Dr. John Lienhard }
$$

Batte11e-Northwest
F. W. Albaugh
R. T. Allemann
$\mathrm{J}$. K. Anderson
E. R. Astley
J.M. Batch
A. L. Bement
J. J . Cadwe11

67 
P. D. Cohn

D. L. Condotta

R. F。Corlett

R. L。 Dillon

E. A. Eschbach

W. R. Fishbaugher

D. E. Fitzsimmons

J. C. Fox

M. D。Fresh1ey

H. E. Hanthorn

H. Harty

R.A. Harvey

G. M. Hesson

B. M. Johnson/G. Jansen

R。 L。 Junkins

C. E。 Leach

W. R. Lewis

M。K. Mi11hollen

L. T. Pederson

R. E. Peterson

R. H. Purcell

W. D. Richmond

W. E. Roake

G。 J. Rogers

D. S. Rowe (20)

R。E. Skavdah1

R。 I Smith

W. L. Thorne

P.C. Walkup

R。G. Wheeler

N. G. Wittenbrock

J. M。 Yatabe

F. R. Zaloudek

Technical Information Files

Technical Publications (2) 